\title{
Meta-aprendizagem aplicada à classificação de dados de expressão gênica
}





\title{
Meta-aprendizagem aplicada à classificação de dados de expressão gênica
}

\author{
Bruno Feres de Souza \\ Orientador: Prof. Dr. André C. P. L. F. Carvalho \\ Co-orientador: Prof. Dr. Carlos Manoel M. de Oliveira Pinto Soares
}

Tese apresentada ao Instituto de Ciências Matemáticas e de Computação - ICMC-USP, como parte dos requisitos para obtenção do título de Doutor em Ciências - Ciências de Computação e Matemática Computacional. 



\section{Agradecimentos}

Agradeço, primeiramente, a Deus por tudo e, em especial, pelas oportunidades que me tem concedido e pelas pessoas que tem posto em meu caminho.

Sou muito grato a meus pais e irmãos por serem meu porto seguro. O amor, o companheirismo, a amizade e a dedicação incondicionais que eles me têm são recíprocos e espero sempre poder demonstrá-los com a mesma intensidade com que os recebi. Mãe, obrigado pelas palavras de conforto e fé ao telefone. Pai, obrigado pela confiança e pelos assuntos cotidianos que me acalmavam. Mana, obrigado por ter sempre a palavra certa nas horas em que eu mais precisei. Ivo Jr., obrigado pelo apoio e por ter nos dado de presente Giovanna.

Agradeço ao professor André por sempre ter estado comigo para comemorar os bons resultados. Mas especialmente, eu sou grato por também estar presente quando dos resultados, aparentemente, desfavoráveis. Nessas horas, aprendi muito com ele sobre o que trata a pesquisa e também que, nesse ramo que escolhemos, reveses podem ser tão valiosos quanto sucessos. Eu sou muito afortunado por ter meu caminho ligado ao dele durante os anos de mestrado e doutorado. Ele é uma pessoa pela qual eu tenho profunda admiração em diversos aspectos, tanto profissional quanto pessoalmente e, devido a seus ensinamentos e exemplos, eu me considero hoje alguém melhor.

Agradeço imensamente ao Carlos por ter aceitado ser meu co-orientador. Graças aos seus vastos conhecimentos sobre meta-aprendizagem, esse projeto pôde ser concluído. Eu tenho muito orgulho do trabalho que desenvolvemos juntos e considero que as oportunidades surgidas dessa colaboração vão sempre figurar entre os pontos altos do meu currículo acadêmico e de minha vida pessoal.

O meu doutorado foi uma jornada. Por vezes, considerei-a longa demais. Nessas horas, a amizade, as brincadeiras, a parceria e a presença de pessoas como o Calvo, Thiago, Pablo, Rosane, Paulo, Mariá, André, Chris, Lucas, Luiz, Murilão, Cerri, Ricardinho, Danilo, Jonathan, Renatinho, Márcio, Marcelinho, Rodrigão, Marcelão, Mônica, Erika, Mello, Balans, Elaine, Leo, Arnaldo, Robertox, Edmilson, QRU, Camillão, Chico, Glória, Nilson e Tanaka me mostraram que na verdade ela foi curta. Muito curta. Este trabalho não teria sido possivel sem a inestimável ajuda desses amigos. Também de fundamental importância foram os amigos que tive a honra de 
fazer no BIOCOMP, no LABIC e nos demais laboratórios do ICMC e da USP durante esses anos. O convívio com eles foi bastante enriquecedor e não será esquecido. Em especial, sou grato ao Japa, à Debora e ao Vinícius. Conheço o Japa desde o mestrado. Ele sempre foi meu amigo. Durante os meses finais do doutorado, mostrou-se um verdadeiro irmão. Sem sua ajuda e conselhos nos momentos mais críticos do trabalho, eu, definitivamente, não teria conseguido terminar. Com a Debora partilhei diversas situações. Seu entendimento, simpatia, generosidade e presença nas horas difíceis me deram a força necessária pra seguir adiante. A parceria do Vinícius foi importante. Quando a quantidade de trabalho parecia excessiva, ele prontamente se dispôs a me ajudar. Assim, muitíssimo obrigado, pessoal! Considero essa tese uma obra conjunta e tenho enorme satisfação em ter vocês todos como co-autores!

Agradeço a todos os professores e funcionários do ICMC, por tudo que eu aprendi e por estarem sempre dispostos a ajudar.

Agradeço à FAPESP, pelo suporte financeiro essencial a este trabalho. 


\section{Resumo}

Dentre as aplicações mais comuns envolvendo microarrays, pode-se destacar a classificação de amostras de tecido, essencial para a identificação correta da ocorrência de câncer. Essa classificação é realizada com a ajuda de algoritmos de Aprendizagem de Máquina. A escolha do algoritmo mais adequado para um dado problema não é trivial. Nesta tese de doutorado, estudou-se a utilização de meta-aprendizagem como uma solução viável. Os resultados experimentais atestaram o sucesso da aplicação utilizando um arcabouço padrão para caracterização dos dados e para a construção da recomendação. A partir de então, buscou-se realizar melhorias nesses dois aspectos. Inicialmente, foi proposto um novo conjunto de meta-atributos baseado em índices de validação de agrupamentos. Em seguida, estendeu-se o método de construção de rankings $k \mathrm{NN}$ para ponderar a influência dos vizinhos mais próximos. No contexto de meta-regressão, introduziu-se o uso de SVMs para estimar o desempenho de algoritmos de classificação. Árvores de decisão também foram empregadas para a construção da recomendação de algoritmos. Ante seu desempenho inferior, empregou-se um esquema de comitês de árvores, que melhorou sobremaneira a qualidade dos resultados.

Palavras-chave: Classificação de dados de expressão gênica. Aprendizado de Máquina. Meta-aprendizagem. 


\section{Abstract}

Among the most common applications involving microarray, one can highlight the classification of tissue samples, which is essential for the correct identification of the occurrence of cancer and its type. This classification takes place with the aid of machine learning algorithms. Choosing the best algorithm for a given problem is not trivial. In this thesis, we studied the use of meta-learning as a viable solution. The experimental results confirmed the success of the application using a standard framework for characterizing data and constructing the recommendation. Thereafter, some improvements were made in these two aspects. Initially, a new set of meta-attributes was proposed, which are based on cluster validation indices. Then the $k \mathrm{NN}$ method for ranking construction was extended to weight the influence of nearest neighbors. In the context of meta-regression, the use of SVMs was introduced to estimate the performance of ranking algorithms. Decision trees were also employed for recommending algorithms. Due to their low performance, a ensemble of trees was employed, which greatly improved the quality of results.

Keywords: Gene expression data classification. Machine Learning. Meta-learning 


\section{Lista de Figuras}

2.1 Exemplos de células genéricas. Imagens adaptadas de (Lodish et al., 2007) . . . . . . . . . . . . . . . . . . . 9

2.2 Representação de molécula de DNA. Imagem extraída de (Filho, 2003). . . . . . . . . . . . . . . . . . 10

2.3 Processo de expressão gênica. Adaptado de (Casley, 1992). . . . . 12

2.4 Microarray de DNA complementar. Imagens adaptadas de (Harrington et al., 2000) . . . . . . . . . . . . . . . . . . 14

2.5 Microarray de oligonucleotídeos. Imagens adaptadas de (Harrington et al., 2000) $\ldots \ldots \ldots \ldots$

4.1 Processo de recomendação de algoritmos utilizando meta-aprendizagem. Adaptado de (Brazdil et al., 2009) . . . . . . 41

5.1 Desempenho dos métodos 1NN, LR e PCT com caracterização de dados utilizando o conjunto VALIDITY após redução . . . . . . . 67

5.2 Desempenho dos métodos 1NN, LR e PCT com caracterização de dados utilizando o conjunto STATLOG após redução . . . . . . . . 69

5.3 Limites superior e inferior do método $k$ NN. . . . . . . . . . . . . 70

5.4 Desempenho do método $k \mathrm{NN}$ com caracterização de dados utilizando os conjuntos STATLOG, VALIDITY E MIXED . . . . . 72

5.5 Desempenho do método $w k \mathrm{NN}$ com caracterização de dados utilizando o conjunto STATLOG e 4 funções de kernel . . . . . . . 74

5.6 Ilustração da forma das funções de kernel Retangular, Triangular, Epanechnikov e Gauss . . . . . . . . . . . . . 75

5.7 Desempenho do método $w k \mathrm{NN}$ com caracterização de dados utilizando o conjunto VALIDITY e 4 funções de kernel . . . . . . 76

5.8 Desempenho do método $w k \mathrm{NN}$ com caracterização de dados utilizando o conjunto MIXED e 4 funções de kernel . . . . . . . . 77

5.9 Correlação entre as medidas STATLOG e o erro dos classificadores 83 5.10 Correlação entre as medidas VALIDITY e o erro dos classificadores 84 
5.11 Desempenho dos métodos PCT e bagging com caracterização de dados utilizando o conjunto STATLOG . . . . . . . . . . 88

5.12 Desempenho dos métodos PCT e bagging com caracterização de dados utilizando o conjunto VALIDITY . . . . . . . . . . . . . 89

5.13 Desempenho dos métodos PCT e bagging com caracterização de dados utilizando o conjunto MIXED . . . . . . . . . . . 90

5.14 Desempenho dos métodos $w k \mathrm{NN}$, SVM e bagging para os 49 problemas considerados com caracterização de dados utilizando o conjunto STATLOG . . . . . . . . . . . . . . . . . . . . . 92

5.15Desempenho dos métodos $w k \mathrm{NN}$, SVM e bagging para os 49 problemas considerados com caracterização de dados utilizando o conjunto STATLOG . . . . . . . . . . . . . . . . . . . . 92

5.16Desempenho dos métodos $w k \mathrm{NN}$, SVM e bagging para os 49 problemas considerados com caracterização de dados utilizando o conjunto MIXED . . . . . . . . . . . . . . . . . . . . 93 


\section{Lista de Tabelas}

2.1 Mapeamento entre códons e aminoácidos. Tabela extraída de (Lodish et al., 2007). . . . . . . . . . . . . . . . . . . . . . . . . 12

2.2 Matriz genérica de expressão gênica . . . . . . . . . . . . . 17

2.3 Informações gerais sobre bases de dados de microarrays . . . . . 19

4.1 Medidas utilizadas no STATLOG, separadas por categoria. . . . . 43

4.2 Medidas extras utilizadas no METAL, separadas por categoria. . . 44

5.1 Pacotes R utilizados e parâmetros dos algoritmos de AM . . . . . 62

5.2 Medidas de caracterização . . . . . . . . . . . . . 66

5.3 Desempenho de 4 meta-regressores na estimação de erro de 7 classificadores, utilizando caracterização pelo conjunto STATLOG 79

5.4 P-valores do teste $\mathrm{t}$ pareado utilizado para comparar os os meta-regressores SVM, 1NN, LR e M5 com o MEDIA, utilizando caracterização pelo conjunto STATLOG . . . . . . . . . . . . . 80

5.5 Desempenho de 4 meta-regressores na estimação de erro de 7 classificadores, utilizando caracterização pelo conjunto VALIDITY 80

5.6 P-valores do teste $\mathrm{t}$ pareado utilizado para comparar os os meta-regressores SVM, 1NN, LR e M5 com o MEDIA, utilizando caracterização pelo conjunto VALIDITY . . . . . . . . . . . . 81

5.7 Desempenho de 4 meta-regressores na estimação de erro de 7 classificadores, utilizando caracterização pelo conjunto MIXED • 81

5.8 P-valores do teste $\mathrm{t}$ pareado utilizado para comparar os os meta-regressores SVM, 1NN, LR e M5 com o MEDIA, utilizando caracterização pelo conjunto MIXED . . . . . . . . . . . . . 82

5.9 Acurácias médias dos rankings $\left(r_{S}\right)$ gerados utilizando 4 meta-regressores e 3 conjuntos de caracterização . . . . . . . . 86

5.10Acurácias médias dos rankings $\left(r_{S}\right)$ gerados utilizando 4 métodos e 3 conjuntos de caracterização . . . . . . . . . . . . . . 95 


\title{
Lista de Abreviaturas
}

\author{
AM Aprendizagem de Máquina \\ AR Average Ranks \\ DLDA Diagonal Linear Discriminat Analysis \\ DQDA Diagonal Quadratic Discriminat Analysis \\ $k \mathrm{NN} \quad k$ Nearest Neighbors \\ LOO leave-one-out \\ LR Linear Regression \\ LRA Log Ranking Accuracy \\ PAM Prediction Analysis of Microarray \\ PCT Predictive Clustering Tree \\ RP Ranking Padrão \\ $r_{S} \quad$ Correlação de Spearman \\ SVM Support Vector Machine
}




\section{Sumário}

1 Introdução 1

1.1 Contexto . . . . . . . . . . . . . . . . . . 1

1.2 Motivação . . . . . . . . . . . . . . . . . 3

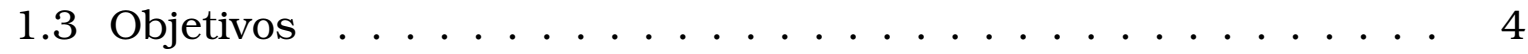

1.4 Organização do Trabalho . . . . . . . . . . . . . 5

2 Análise de Expressão Gênica $\quad 7$

2.1 Considerações iniciais . . . . . . . . . . . . . . 7

2.2 Conceitos biológicos ................. 8

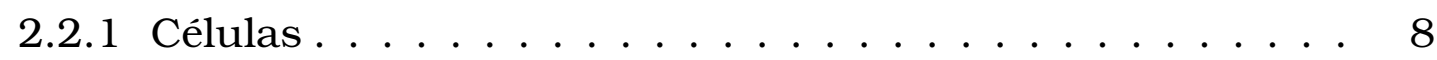

2.2.2 Cromossomos, DNA e genes ............ . . 9

2.2.3 Proteínas e expressão gênica . . . . . . . . . . . . 10

2.3 Microarrays . . . . . . . . . . . . . . . . . 13

2.3.1 Microarrays de DNA complementar . . . . . . . . . . 13

2.3.2 Microarrays de oligonucleotídeos . . . . . . . . . . . 16

2.4 Bases de dados . . . . . . . . . . . . . . . . 17

2.5 Análise dos dados de microarrays . . . . . . . . . . . . 18

2.6 Considerações finais . . . . . . . . . . . . . 20

3 Aprendizagem de Máquina Supervisionada 23

3.1 Considerações Iniciais . . . . . . . . . . . . . . . . 23

3.2 Aprendizagem de Máquina Supervisionada . . . . . . . . . . . 24

3.3 Paradigmas de AM Supervisionada . . . . . . . . . . . . . 26

3.4 Desempenho de Classificadores . . . . . . . . . . . . . . . . 29

3.4.1 Medidas de desempenho . . . . . . . . . . . . . . 29

3.4.2 Estratégia de avaliação . . . . . . . . . . . . . 31

3.5 Comparação de Classificadores . . . . . . . . . . . . . 34

3.5.1 Teste estatísticos . . . . . . . . . . . . 34 
3.5.2 Comparação de classificadores em dados de expressão

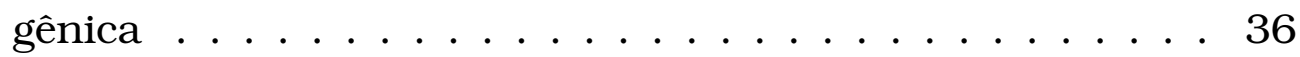

3.6 Considerações Finais . . . . . . . . . . . . . . . . 36

4 Meta-aprendizagem 39

4.1 Considerações iniciais . . . . . . . . . . . . . . . . . . . 39

4.2 Recomendação de algoritmos . . . . . . . . . . . . . . 40

4.3 Caracterização de bases de dados . . . . . . . . . . . . . . . 42

4.3.1 Caracterização direta . . . . . . . . . . . . . . . . . 42

4.3 .2 Landmarking . . . . . . . . . . . . . . . . . . . . . . 44

4.3.3 Caracterização via modelos . . . . . . . . . . . . . 45

4.3.4 Nova proposta para caracterização . . . . . . . . . . 45

4.4 Medidas de avaliação . . . . . . . . . . . . . . . . . . 52

4.5 Formas de sugestão . . . . . . . . . . . . . . . . . . 53

4.6 Construção de sugestão . . . . . . . . . . . . . . . . 53

4.6.1 Ranking por vizinhos mais próximos . . . . . . . . 54

4.6 .2 Ranking por regressão . . . . . . . . . . . . . . 55

4.6.3 Ranking por árvores de decisão . . . . . . . . . . . 56

4.7 Considerações finais . . . . . . . . . . . . . . . 58

5 Resultados experimentais $\quad 59$

5.1 Considerações iniciais . . . . . . . . . . . . . . . . . . 59

5.2 Materiais e métodos . . . . . . . . . . . . . . . . 60

5.2.1 Bases de dados de expressão gênica . . . . . . . . 60

5.2 .2 Algoritmos de AM . . . . . . . . . . . . . . 6 61

5.2.3 Aplicação e avaliação de meta-aprendizagem . . . . . . . 62

5.2.4 Medidas de caracterização de dados . . . . . . . . . . . 65

5.3 Ranking por vizinhos mais próximos . . . . . . . . . . 69

5.3 .1 Limites do $k \mathrm{NN} \ldots \ldots \ldots \ldots \ldots \ldots$

5.3.2 Desempenho do $k \mathrm{NN} \ldots \ldots \ldots \ldots \ldots \ldots$

5.3 .3 Extensão do $k \mathrm{NN} \ldots \ldots \ldots$. . . . . . . . . . . 73

5.4 Ranking por regressão . . . . . . . . . . . . . . . . . 77

5.4 .1 Predição de desempenho . . . . . . . . . . . 78

5.4 .2 Construção de rankings . . . . . . . . . . . . . . . . 85

5.5 Ranking por árvores . . . . . . . . . . . . . . . . . 87

5.5.1 Desempenho do PCT . . . . . . . . . . . . . 87

5.6 Comparação global . . . . . . . . . . . . . . . . 91

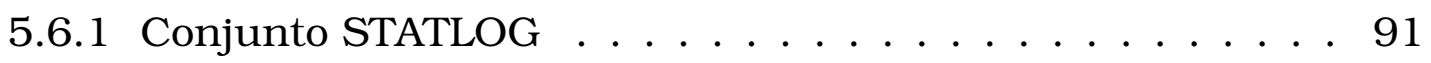

5.6 .2 Conjunto VALIDITY . . . . . . . . . . . . . . . 92

5.6 .3 Conjunto MIXED . . . . . . . . . . . . . . . . . 93

5.7 Considerações finais . . . . . . . . . . . . . . . . . 94 
6 Conclusão $\quad 97$

6.1 Contribuições . . . . . . . . . . . . . . . 98

6.2 Limitações . . . . . . . . . . . . . . . . . 100

6.3 Trabalhos futuros .................... 102

$\begin{array}{ll}\text { Referências Bibliográficas } & 103\end{array}$ 


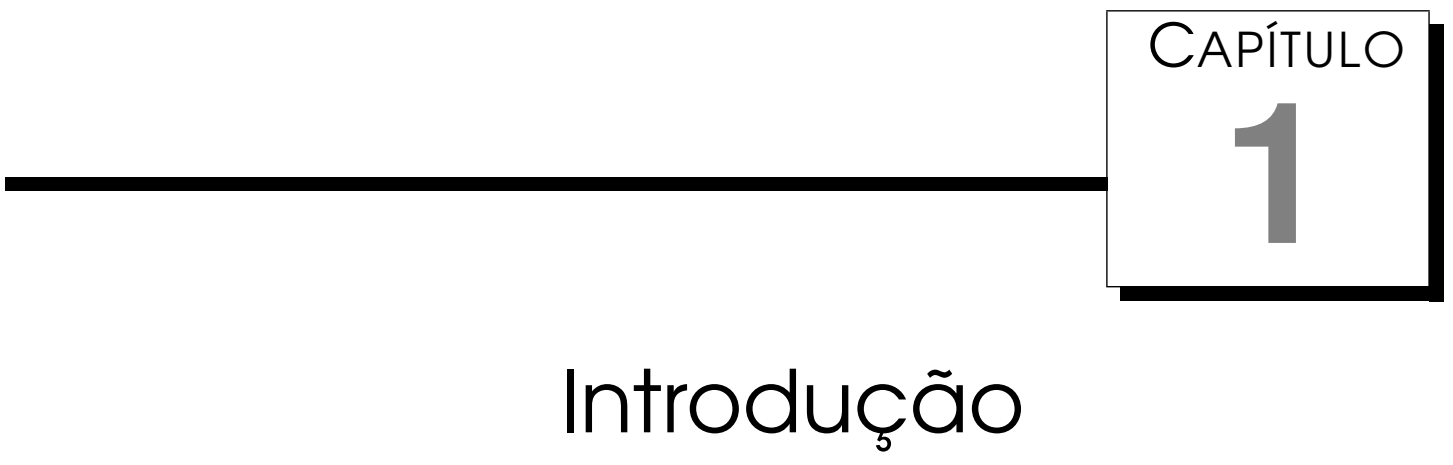

\subsection{Contexto}

Recentemente, considerável esforço tem sido despendido para uma maior compreensão dos seres vivos, do ponto de vista biológico. Uma prova disso é o desenvolvimento de numerosos projetos de sequenciamento que visam à construção do mapa genômico das espécies estudadas (Galperina e Koonin, 2010; Kyrpides, 2009; Liolios et al., 2009). O mais conhecido deles é o Projeto Genoma Humano (PGH) (Collins et al., 2003).

Os dados gerados por tais empreendimentos têm permitido aos cientistas identificar um grande número de genes ${ }^{1}$ a partir de sequências antes desconhecidas de DNA. Por exemplo, o PGH estima que o ser humano possua cerca de 20.000 a 25.000 genes funcionais (Consortium, 2004). Uma das maneiras mais utilizadas para analisar esses artefatos genéticos é medir seus níveis de expressão. Com isso, pode-se avaliar o quanto cada gene influencia no funcionamento de uma célula em um dado momento e sob uma circunstância específica (Lodish et al., 2007).

Para auxiliar na realização sistemática das investigações devidas, várias tecnologias têm sido empregadas. Aquelas que permitem monitorar simultaneamente o comportamento de milhares de genes estão entre as mais utilizadas. Neste contexto, técnicas como microarrays (Russell et al., 2008) têm ajudado no estudo da funcionalidade dos genes, seu relacionamento com doenças, as proteínas associadas a eles e sua participação nos mais diversos

\footnotetext{
${ }^{1}$ Os genes são os fatores responsáveis por determinar as características de uma espécie através das gerações, assim como por coordenar e regular as atividades realizadas dentro do aparato celular (Lodish et al., 2007). Para maiores informações, vide o Capítulo 2.
} 
processos (Prasad e Ahson, 2009).

A fim de obter informação, qualitativamente interessante, sobre o maciço conjunto de fatos biológicos disponibilizados pelos experimentos de expressão gênica, faz-se uso de ferramentas computacionais (Tjaden e Cohen, 2006). Como, na maior parte dos casos, o tipo de análise realizada envolve extrair padrões dos dados e entender seus significados, é pertinente falar-se da extração automática de conhecimento através de técnicas de Aprendizagem de Máquina como solução viável.

De maneira sucinta, a Aprendizagem de Máquina (AM) (Bishop, 2006) pode ser entendida como um campo de pesquisa fundamentado na Inteligência Artificial e na Estatística que estuda o desenvolvimento de métodos capazes de extrair conceitos (conhecimento) a partir de amostras de dados. Em experimentos envolvendo microarrays, é comum utilizar AM nos paradigmas não-supervisionado e supervisionado (Tarca et al., 2006). A diferença básica entre ambos diz respeito à disponibilidade a priori da classe ou categoria a que cada objeto pertence. No primeiro caso, tal informação não é especificada, enquanto no segundo ela é fornecida.

Em dados de expressão gênica, o enfoque dos algoritmos de AM não-supervisionados normalmente está em identificar novos subgrupos de entidades biológicas ou realizar agrupamento de genes com a finalidade de inferir suas funções (Hoheisel, 2006). Nos algoritmos supervisionados, a intenção usual é classificar genes ou tecidos em classes conhecidas (Larranaga et al., 2006). Neste trabalho, apenas a classificação de tecidos é considerada. O interesse nesse tema foi suscitado por seu possível impacto no diagnóstico, prognóstico e tratamento de doenças severas, como o câncer (Fan et al., 2010).

Em abordagens tradicionais, a classificação de tumores é baseada primariamente em sua aparência morfológica e no tecido onde a doença se originou (Slonim et al., 2000). Entretanto, não há garantias de que tumores semelhantes tenham o mesmo desenvolvimento clínico e, por conseguinte, exijam o mesmo tipo de tratamento. Assim, o estudo de técnicas que permitam determinar a variedade correta de câncer de um tecido, com uma taxa mais elevada de acerto, é essencial.

Neste cenário, para prover um maior entendimento do fenômeno estudado e tentar promover uma distinção mais acurada de tumores, Golub et al. (1999) utilizaram um esquema simples de voto ponderado aplicado sobre dados de microarrays. Em seus experimentos, o metabolismo de células pertencentes a dois tipos de leucemia foi analisado e um padrão pôde ser aprendido. Com isso, mostrou-se ser possível a classificação de novas amostras de tecidos considerando-se apenas seus níveis de expressão gênica. 


\subsection{Motivação}

Após o esforço pioneiro de Golub e colaboradores, observou-se um notável crescimento no número de pesquisas envolvendo análise de dados de microarrays por métodos de AM supervisionada (Larranaga et al., 2006). Tal interesse suscitou a necessidade de se investigar quais dessas técnicas de classificação seriam mais apropriadas. Asyali et al. (2006) destacaram algumas abordagens comumente consideradas nesta tarefa, com diferentes graus de adequação, e relataram que diversas propriedades de cada uma delas podem impactar seu desempenho. Isto pôde ser constatado através de trabalhos comparativos realizados no contexto (Boulesteix et al., 2008; Huang et al., 2005; Lee et al., 2005; Statnikov et al., 2005; Man et al., 2004; Romualdi et al., 2003; Dudoit et al., 2002).

Uma análise em conjunto dos resultados obtidos nesses estudos revela que não há um único método que ofereça um desempenho superior aos outros para todos os problemas considerados. Esta constatação pode ser entendida como uma instanciação do teorema No Free Lunch (NFL) (Wolpert, 1996; Schaffer, 1994), segundo o qual qualquer vantagem apresentada por um algoritmo sobre uma classe específica de problemas é mitigada quando de sua aplicação em outra classe. Sendo assim, se todos os problemas forem igualmente possíveis, então os algoritmos tenderão a apresentar, na média, o mesmo comportamento preditivo, prevenindo a existência de um método universalmente ótimo. Claramente, o NFL tem caráter geral e, na prática, um algoritmo pode resultar superior em determinados problemas (Brodley, 1995). Portanto, a definição de que algoritmo utilizar para a obtenção dos resultados mais satisfatórios em cada aplicação deve ser feita de maneira pontual.

A abordagem mais comum para esta tarefa envolve um processo iterativo que combina a experiência do usuário e alguma forma de investigação empírica (Kalousis e Hilario, 2003). Neste caso, um subconjunto de métodos de classificação é inicialmente selecionado de acordo com o conhecimento de um especialista sobre os algoritmos e o problema. Tais métodos são então aplicados ao problema e uma medida de desempenho é calculada. Com base nas informações obtidas, decide-se por alterar a configuração do algoritmo, ou ele próprio, até que resultados satisfatórios sejam alcançados. Essa abordagem apresenta duas grandes desvantagens. A primeira é que o conhecimento do usuário geralmente tem baixo nível de confiança ou é muito limitado. A segunda é que a utilização de usuários especialistas é custosa e a experimentação é um processo demorado. Em vista disso, destaca-se a importância do desenvolvimento e do emprego de métodos eficientes que auxiliem o usuário nessa tarefa. 
Segundo Brazdil et al. (2009), o propósito de um sistema de recomendação de algoritmos, do ponto de vista de seu utilizador, é reduzir o número de algoritmos testados a fim de otimizar o tempo de experimentação com um mínimo de perda na qualidade dos resultados obtidos. Assim, dado um novo problema, o sistema deve ser capaz de sugerir os algoritmos mais apropriados, ou no mínimo razoáveis, para encontrar a sua solução. Caso haja recursos computacionais disponíveis, então alternativas potencialmente adequadas devem também ser fornecidas, assim como sua ordem de utilização. A necessidade de tais empreendimentos foi conceitualmente reconhecida e formalizada por Rice (1976). Em seu trabalho, o autor urge por um entendimento maior entre as propriedades dos problemas e o desempenho dos algoritmos para que a seleção destes seja realizada de acordo com as características daqueles.

Ao encontro desse objetivo, a comunidade de AM introduziu as bases conceituais da meta-aprendizagem, que fornece meios para esse fim (Michie et al., 1994; Aha, 1992). De maneira genérica, a meta-aprendizagem pode ser entendida como a utilização de técnicas de AM para a construção de modelos que expliquem o relacionamento entre estratégias de aprendizagem e problemas, segundo alguma perspectiva (Vilalta et al., 2005). Sendo assim, ela consegue explorar conhecimento acumulado sobre diversas tarefas e aplicá-lo para a resolução de problemas semelhantes (Giraud-Carrier et al., 2004). Com isso, ela pretende determinar sob quais condições cada algoritmo é mais apropriado, possivelmente ampliando o entendimento do mesmo e levando a sugestões de uso mais adequadas. Do ponto de vista prático, a meta-aprendizagem ainda tem sido pouco explorada, apesar de ter o potencial de transformar a forma como a AM é empregada em setores industriais, comerciais e governamentais.

\subsection{Objetivos}

Meta-aprendizagem tem sido frequentemente utilizada no meio acadêmico para recomendação de algoritmos (vide (Brazdil et al., 2009) e referências ali contidas). De maneira geral, tais trabalhos têm focado em cenários experimentais onde a aprendizagem ocorre considerando-se problemas de natureza distinta. Neste contexto, o desempenho dos algoritmos de AM tende a exibir um nível maior de variação, devido a sua preferência por uma hipótese ou outra de acordo com as características diversas dos problemas considerados (Mitchell, 1997). Quando os problemas apresentam propriedades semelhantes, o desempenho dos algoritmos pode ser mais similar, como no caso de dados de microarrays (Somorjai et al., 2003), tornado, 
potencialmente, mais sutil a determinação de que algoritmos recomendar para cada caso. Além disso, existe ainda, nesta situação, uma maior homogeneidade dos dados, fazendo com que não seja óbvio se as medidas usualmente utilizadas para caracterizar os problemas são capazes de fornecer informação suficiente para permitir aos métodos de meta-aprendizagem uma discriminação adequada entre o desempenho dos diferentes algoritmos.

Portanto, o objetivo geral desta tese é investigar a utilização de meta-aprendizagem em problemas de natureza específica. O foco do estudo empreendido aqui é a classificação de dados de expressão gênica. Com isso, pretende-se que a tese contribua não apenas para expandir as fronteiras do conhecimento científico referentes à meta-aprendizagem, mas também estimular seu uso para a solução de problemas reais que possam ser resolvidos com o auxílio de AM. Como objetivos específicos, tem-se:

1. Elaboração de novas medidas de caracterização, idealmente mais adequadas à natureza dos dados considerados;

2. Extensão do método de construção de ranking baseado em $k \mathrm{NN}$ (Soares, 2004) a fim de permitir ponderação de influência de cada vizinho de acordo com sua distância relativa;

3. Introdução de Support Vector Machines (SVMs) (Steinwart e Christmann, 2008) como meta-regressores para problemas de classificação;

4. Utilização de abordagens de combinação de árvores de decisão (Breiman, 1996a) para a construção de rankings mais acurados.

5. Realização de um conjunto abrangente de experimentos a fim de comparar o desempenho de diversos métodos de construção de rankings e formas de caracterização de dados.

\subsection{Organização do Trabalho}

Esta tese de doutorado é organizada nos seguintes capítulos:

- Capítulo 2: apresenta a tecnologia de microarrays, com seus fundamentos biológicos e experimentais. Exemplos de bases de dados geradas de experimentos de expressão gênica são fornecidos, assim como os principais tipos de análise computacional atualmente empregados.

- Capítulo 3: apresenta conceitos básicos de aprendizagem de máquina, com ênfase nos algoritmos supervisionados. Os paradigmas de classificação são descritos. Formas de medir o desempenho de classificadores e de compará-los são discutidas.

- Capítulo 4: apresenta a meta-aprendizagem de maneira genérica e sua utilização para a recomendação de algoritmos. São abordados os tópicos 
de caracterização de bases de dados, medidas de avaliação, formas de sugestão e como relacioná-los. As bases conceituais para as principais contribuições deste trabalho são desenvolvidas.

- Capítulo 5: apresenta os resultados empíricos obtidos neste trabalho. Os experimentos reportados serviram para validar os métodos propostos no que tange à caracterização dos dados e construção de rankings para realizar a recomendação de algoritmos.

- Capítulo 6: apresenta as conclusões deste trabalho, suas contribuições, suas limitações e propostas para trabalhos futuros. 


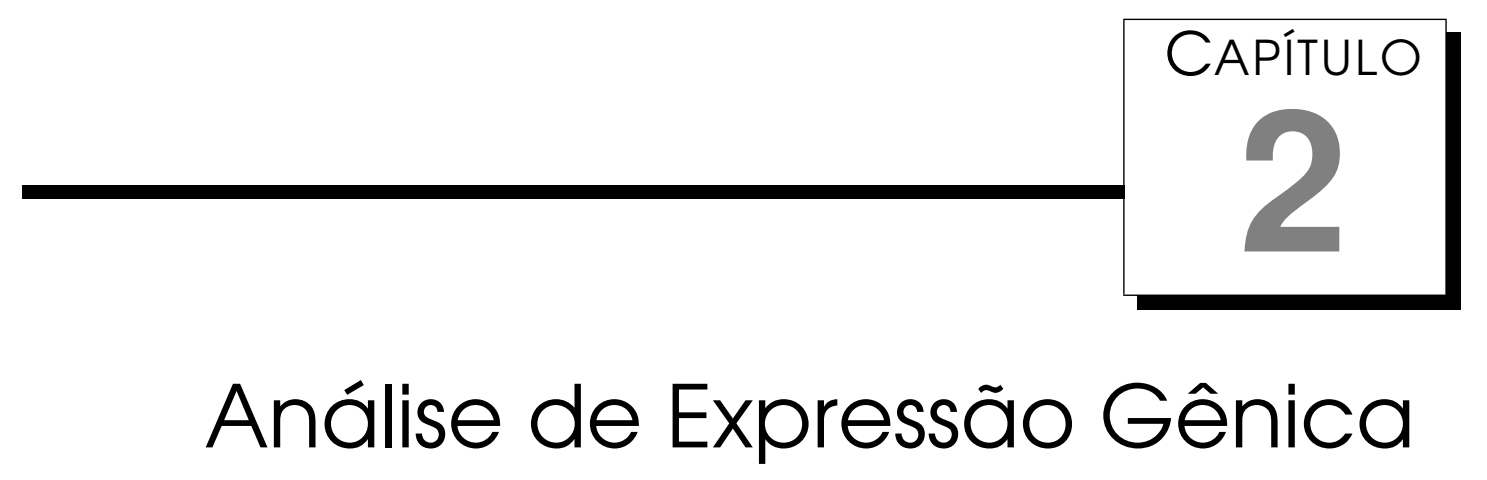

\subsection{Considerações iniciais}

Com a conclusão de diversos programas de sequenciamento genômico, grande quantidade de dados complexos tornou-se disponível, propiciando uma mudança de foco na forma como as pesquisas biomoleculares são conduzidas (Garvey, 2010; Varmus, 2010). Durante a era pré-genômica, os experimentos para a análise de processos biológicos eram baseados preferencialmente na abordagem de hipóteses (Smalheiser, 2002), segundo a qual suposições acerca do mecanismo de desenvolvimento de um dado fenômeno são inicialmente formuladas e um conjunto de etapas bem definidas é proposto para corroborar tais conjecturas. Métodos comumente empregados nesta tarefa incluem o differential display (Liang, 2002), a Polymerase Chain Reaction (VanGuilder et al., 2008) e o Northern Blot (Kemmer et al., 2004), que são capazes de medir com elevado grau de sensibilidade os níveis de expressão de genes isolados.

Na era pós-genômica, a abordagem de hipóteses passou a ser utilizada concomitantemente à abordagem explorativa, cujo objetivo é descobrir conhecimento novo ou inesperado e verificar relações, antecipadas ou não, entre os elementos considerados (Brown e Botstein, 1999). Tal estudo ocorre através da aplicação de técnicas estatísticas e computacionais para a análise e a visualização dos dados genéticos gerados em experimentos de larga escala. Neste contexto, uma exploração abrangente e sistemática dos genomas de organismos tem sido viabilizada pelo emprego de ferramentas como microarrays (Russell et al., 2008), Serial Analysis of Gene Expression 
(Hu e Polyak, 2006) e Massively Parallel Signature Sequencing (Zhou et al., 2006), que permitem mensurar a expressão de milhares de genes simultaneamente. Neste trabalho, devido a sua maior disponibilidade, apenas dados provenientes de experimentos de microarrays serão considerados.

Este capítulo está organizado como segue. Na Seção 2.2, alguns conceitos básicos de biologia molecular são apresentados. Na Seção 2.3, os fundamentos de microarrays são brevemente abordados, assim como as principais variantes da tecnologia. Na Seção 2.4, as características das bases de dados que foram utilizadas no decorrer deste trabalho são exibidas. Na Seção 2.5, são discutidos alguns aspectos computacionais dos dados de expressão gênica. Por fim, na Seção 2.6, algumas conclusões são tecidas.

\subsection{Conceitos biológicos}

A seguir, alguns fundamentos biológicos necessários para o entendimento dos experimentos de microarrays são brevemente comentados.

\subsubsection{Células}

Todos os seres vivos são formados por unidades básicas denominadas células (Okura, 2002). Elas correspondem a compostos estruturais e funcionais onde a maioria dos processos metabólicos acontece. Fisicamente, as células são constituídas de uma membrana externa, conhecida como membrana plasmática, que define seus limites e mantém as diferenças essenciais entre os meios interno e externo, e do citoplasma, onde estão difusas as diversas organelas celulares. Há também uma região nuclear, responsável por parte do material genético. Neste ponto, é comum fazer uma diferenciação entre organismos procariontes e eucariontes (Lodish et al., 2007). Os primeiros não possuem uma membrana de separação nítida entre o citoplasma e a região nuclear e apresentam uma organização interna mais simples. Os segundos possuem uma estrutura interna mais complexa, inclusive com uma membrana bem definida envolvendo a região nuclear.

Como exemplos de organismos procariontes, pode-se citar as bactérias. Já plantas e animais são organismos eucariontes. Para ilustrar a diferença entre estes 2 tipos de organização celular, a Figura 2.1 mostra micrografias eletrônicas de células genéricas de eucariontes e procariontes, com destaque para algumas estruturas celulares. A seguir, um breve descrição de suas funções é fornecida (Lodish et al., 2007):

1. lisossomos: atuam na digestão de componentes celulares desgastados e de certas substâncias extra-celulares; 
2. mitocôndria: cuida da produção de energia a partir do consumo de oxigênio;

3. complexo de Golgi: tem como principal função a secreção de substâncias;

4. retículo endoplasmático: responsável pela síntese de glico-proteínas e lipídios;

5. núcleo e nucleóide: responsáveis por abrigar o material genético das células. O núcleo é encontrado em seres eucariontes e o nucleóide em seres procariontes.

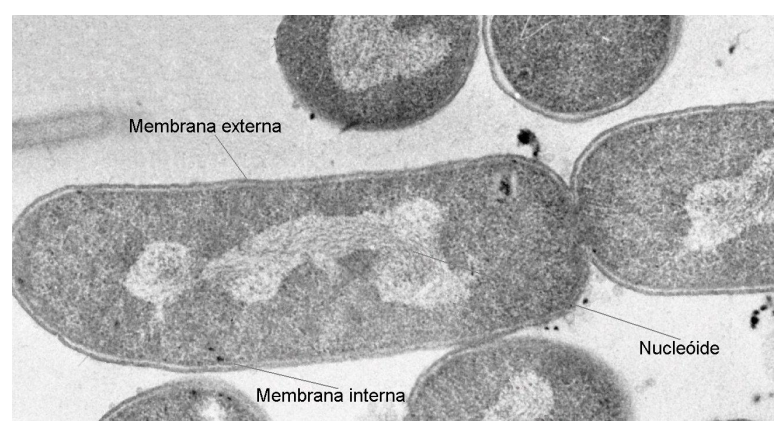

(a) Procarionte

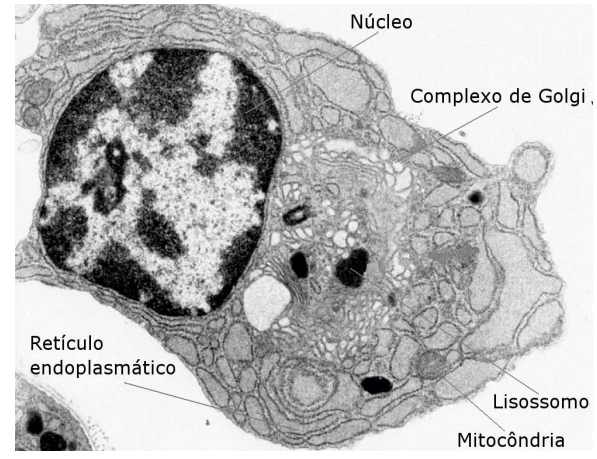

(b) Eucarionte

Figura 2.1: Exemplos de células genéricas. Imagens adaptadas de (Lodish et al., 2007)

A coordenação e a regulação de todas as atividades do aparato celular são realizadas pelos genes.

\subsubsection{Cromossomos, DNA e genes}

Os genes correspondem às unidades físicas e funcionais responsáveis pela hereditariedade dos organismos vivos e pela codificação das informações essenciais para a manutenção da dinâmica celular (Lodish et al., 2007). Eles foram primeiramente investigados por Mendel no final do século XIX (naquele trabalho, foram reconhecidos como fatores que transmitidos, sem modificação, do progenitor para a progênie), em seus experimentos com cruzamento de ervilhas (Mendel, 1865). Várias décadas depois, descobriu-se os chamados cromossomos, que, observou-se, eram transmitidos de pai para filho. Este fato suscitou a idéia de que os cromossomos carregariam a informação genética (Silva, 2001). O interesse pelos cromossomos resultou na posterior descoberta de que eles são compostos por moléculas de ácido desoxirribonucléico (DNA) e que os genes são, de fato, segmentos contíguos de uma molécula de DNA onde estão armazenadas as informações genéticas (Hunter, 1993).

Uma molécula de DNA consiste de duas cadeias complementares entrelaçadas em uma estrutura que lembra uma dupla hélice (Lodish et al., 
2007). Cada cadeia é composta por uma sequência de unidades químicas simples, chamadas de nucleotídeos. Estes são formados de fosfato, açúcar (do tipo desoxirribose) e uma das quatro bases: Adenina (A), Guanina (G), Citosina (C) e Timina (T). A ligação entre os nucleotídeos de cadeias complementares de DNA é realizada pela regra: a base A se liga com a base $\mathrm{T}$, e a base $\mathrm{C}$ com a base $\mathrm{G}$, conforme ilustrado na Figura 2.2.

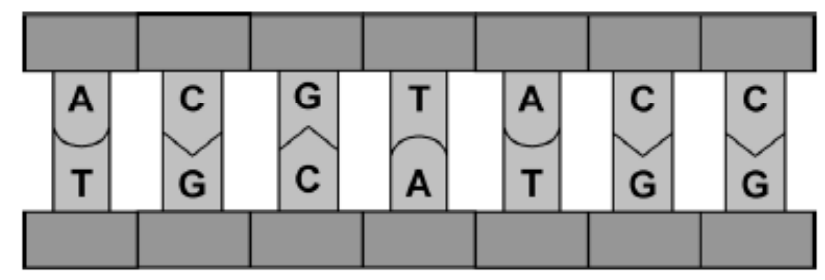

Figura 2.2: Representação de molécula de DNA. Imagem extraída de (Filho, 2003).

\subsubsection{Proteínas e expressão gênica}

A razão pela qual considera-se que os genes controlam o metabolismo de uma célula está relacionada com o fato de eles codificarem proteínas. Em outras palavras, os genes contêm as informações necessárias para que um maquinário celular consiga sintetizar proteínas (Lodish et al., 2007). Proteínas são os principais blocos estruturais e funcionais da célula, correspondendo a aproximadamente de $15 \%$ a $20 \%$ de seu peso total (Hunter, 1993). Elas são formadas por unidades básicas conhecidas como animoácidos, que se ligam linearmente, resultando em uma cadeia chamada de polipeptídeo. As funções das proteínas são diversas, dentre as quais pode-se destacar (Hunter, 1993) (Casley, 1992):

1. catalisar as reações bioquímicas, por meio das proteínas enzimáticas;

2. definir a estrutura, como no caso do colágeno responsável pela conexão entre os ossos e os tecidos;

3. manter o ambiente celular, regulando a passagem de moléculas entre a célula e o meio externo.

A fabricação de proteínas acontece em, basicamente, duas etapas: a transcrição e a tradução (Silva, 2001). Na primeira, uma molécula de ácido ribonucléico (RNA) é sintetizada a partir de uma das cadeias de DNA (Okura, 2002). O RNA é uma sequência de nucleotídeos similar ao DNA. As principais diferenças entre ambos são (Shamir et al., 2002a):

1. o RNA é uma molécula de cadeia simples;

2. a base Timina é substituída pela base Uracila;

3. o açúcar utilizado é do tipo ribose e;

4. as moléculas de RNA podem ser facilmente encontradas diluídas no citoplasma. 
Há 3 tipos de moléculas de RNA (Silva, 2001):

1. o RNA mensageiro (RNAm), que contém a sequência que codifica uma proteína;

2. o RNA transportador (RNAt), que carrega os aminoácidos até os ribossomos;

3. o RNA ribossômico (RNAr), que faz parte dos ribossomos.

A transcrição ocorre por meio da ação de uma enzima chamada RNA polimerase aplicada a locais específicos da sequência de DNA, conhecidos como promotores, que informam onde a transcrição terá início. O processo pode ser descrito, de forma geral, como segue: inicialmente, a RNA polimerase reconhece o promotor na sequência de DNA e liga-se a ele através de certos fatores transcricionais (Shamir et al., 2002a). Em seguida, a RNA polimerase desliza pela cadeia de DNA, sintetizando uma molécula de RNAm base a base, respeitando a complementaridade das bases (ver Figura 2.2 e o parágrafo anterior). O processo tem fim quando a enzima encontra um trecho do DNA conhecida como terminador (Silva, 2001).

A transcrição ocorre de forma diferente em organismos eucariontes e procariontes. Nestes, a molécula de RNAm é diretamente utilizada para a produção de proteínas, enquanto que naqueles, ela sofre uma série de modificações antes de ser traduzida (Okura, 2002). A principal modificação ocorre por meio do processo de splicing, pelo qual sequências não codificadoras de proteínas são removidas da molécula de RNAm (Silva, 2001).

Na etapa de a tradução, a informação contida no RNAm recém-sintetizado é utilizada para dar origem a moléculas de proteína. Isto é feito da seguinte maneira (Shamir et al., 2002b): 3 nucleotídeos adjacentes do RNAm são responsáveis por codificar um aminoácido, que é parte constituinte das proteínas. Esta tripla é chamada de códon. O códon que especifica o início da tradução é o (A, U, G). O mapeamento entre os códons e os aminoácidos codificados pode ser visto na Tabela 2.1. Em seguida, a molécula de RNAm se dirige ao ribossomo que, juntamente com o RNAr, realiza a síntese de proteínas a partir dos códons. O processo termina quando os chamados códons de parada são encontrados. As regras pelas quais a sequência de nucleotídeos de um gene forma a sequência de aminoácidos das proteínas são conhecidas como Código Genético (Shamir et al., 2002b).

Ao processo pelo qual o Código Genético é convertido em estruturas operantes na célula dá-se o nome de expressão gênica (Casley, 1992). São considerados expressos os genes transcritos em RNAm e depois traduzidos em proteínas e aqueles que são transcritos em outros tipos de RNA (como o RNAt) e que não são traduzidos. O processo de expressão gênica, cujo produto final são as proteínas, é esquematizado na Figura 2.3 
Tabela 2.1: Mapeamento entre códons e aminoácidos. Tabela extraída de (Lodish et al., 2007).

\begin{tabular}{lccccc}
\hline Posição 1 & \multicolumn{4}{c}{ Posição 2 } & \multicolumn{3}{c}{ Posição 3 } \\
\hline & U & C & A & G & \\
U & Phe & Ser & Tir & Cis & U \\
U & Phe & Ser & Tir & Cis & C \\
U & Leu & Ser & - & - & A \\
U & Leu & Ser & - & Tri & G \\
\hline C & Leu & Pro & His & Arg & U \\
C & Leu & Pro & His & Arg & C \\
C & Leu & Pro & Glu & Arg & A \\
C & Leu & Pro & Glu & Arg & G \\
\hline A & Iso & Tre & Asp & Ser & U \\
A & Iso & Tre & Asp & Ser & C \\
A & Iso & Tre & Lis & Arg & A \\
A & Met & Tre & Lis & Arg & G \\
\hline G & Val & Ala & Aca & Gli & U \\
G & Val & Ala & Aca & Gli & C \\
G & Val & Ala & Acg & Gli & A \\
G & Val & Ala & Acg & Gli & G \\
\hline
\end{tabular}
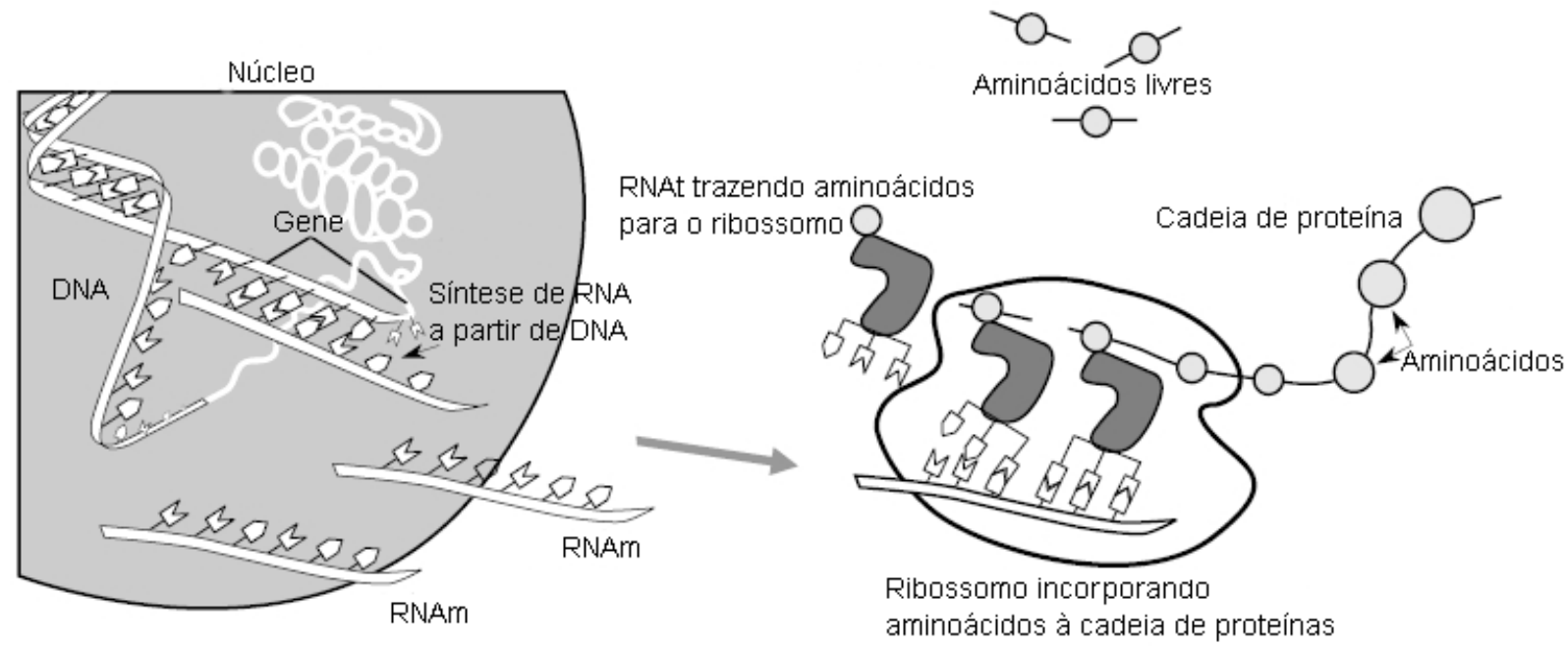

Citoplasma

Figura 2.3: Processo de expressão gênica. Adaptado de (Casley, 1992).

É importante ressaltar que durante o processo de expressão gênica, o nível de RNAm de uma célula em particular representa a atividade metabólica de um gene específico. Assim, pode-se entender melhor o papel dos genes de uma célula em um dado momento e sob uma determinada circunstância observando-se seus níveis de expressão.

Com base no que foi exposto, a comparação entre padrões de expresssões gênicas por meio da medição dos níveis de RNA mensageiro em células normais e doentes pode fornecer importantes indícios sobre o desenvolvimento de determinados estados patológicos, assim como informações que podem 
levar a um melhor diagnóstico e tratamento mais eficaz.

Para que isso seja factível, é desejável lidar com os genes implicados no desenvolvimento do estado em questão. Contudo, na maioria dos casos, ainda não são conhecidos com exatidão quais genes estão envolvidos no processo. Assim, monitorar o maior número de genes possível torna-se desejável. Neste sentido, as técnicas que conseguem lidar com grande quantidade de genes ao mesmo tempo surgem como ferramentas promissoras para o entendimento global de tais processos.

\subsection{Microarrays}

Os microarrays (Russell et al., 2008) são pequenas pastilhas de alta densidade, fabricadas geralmente de vidro ou de algum tipo de membrana fina, onde milhares de sequências de DNA são dispostas em pontos fixos por processos químicos. Cada um destes pontos apresenta sequências biológicas correspondentes a um gene específico que, quando expostas a moléculas de teste de RNA ou DNA fluorescentes, podem ser utilizadas para determinar quanto este gene está expresso no tecido em estudo. Dessa maneira, é possível detectar, em um único experimento, a atividade de um grande número de genes e analisar suas expressões e relações.

Entre as tecnologias de microarrays utilizadas atualmente, 2 tipos estão mais difundidos: os microarrays de DNA complementar (Schena, 1999) e os microarrays de oligonucleotídeos (Lipshutz et al., 1999). A diferença básica entre eles é que no primeiro, a pastilha é preenchida com sequências de DNA sintetizadas previamente, compostas de algumas centenas de pares de bases, enquanto que no segundo, conjuntos de oligonucleotídeos sintetizados in situ são empregados. A seguir, descrições sucintas das 2 abordagens são apresentadas.

\subsubsection{Microarrays de DNA complementar}

A primeira etapa para a fabricação de microarrays é a seleção das sequências de DNA que serão dispostas na pastilha (Quackenbush, 2001; Duggan et al., 1999). Elas devem ser bem caracterizadas e anotadas, para uma completa adequação aos objetivos do experimento. Para organismos procariontes e alguns eucariontes simples, as sequências utilizadas são provenientes de DNA genômico ou de DNA complementar (DNAc) e para organismos eucariontes complexos, é comum utilizar fragmentos de Expressed Sequence Tags (ESTs). ESTs são sequências curtas (poucas centenas de pares de base) que servem como etiqueta para identificar um DNAc (Wolfsberg e Landsman, 2001). DNAc corresponde a uma cópia de DNA genômico feita a 
partir de RNAm, por meio de um processo conhecido como transcrição reversa (Lodish et al., 2007).

Em seguida, as sequências selecionadas de DNA são amplificadas por Polymerase Chain Reaction (PCR) (VanGuilder et al., 2008). PCR é uma técnica pela qual uma grande quantidade de DNA idêntico pode ser sintetizada a partir de uma molécula molde. O produto deste processo é, então, parcialmente purificado, tipicamente por precipitação e filtragem por gel, e pode ser fixado na pastilha. A fixação é feita com o auxílio de dispositivos robotizados, que aplicam o produto de PCR de cada gene a um ponto específico na pastilha, que depois sofre tratamentos químico e térmico para fixar as sequências de DNA (Lodish et al., 2007). O processo de fabricação de um microarray é ilustrado na Figura 2.4(a).

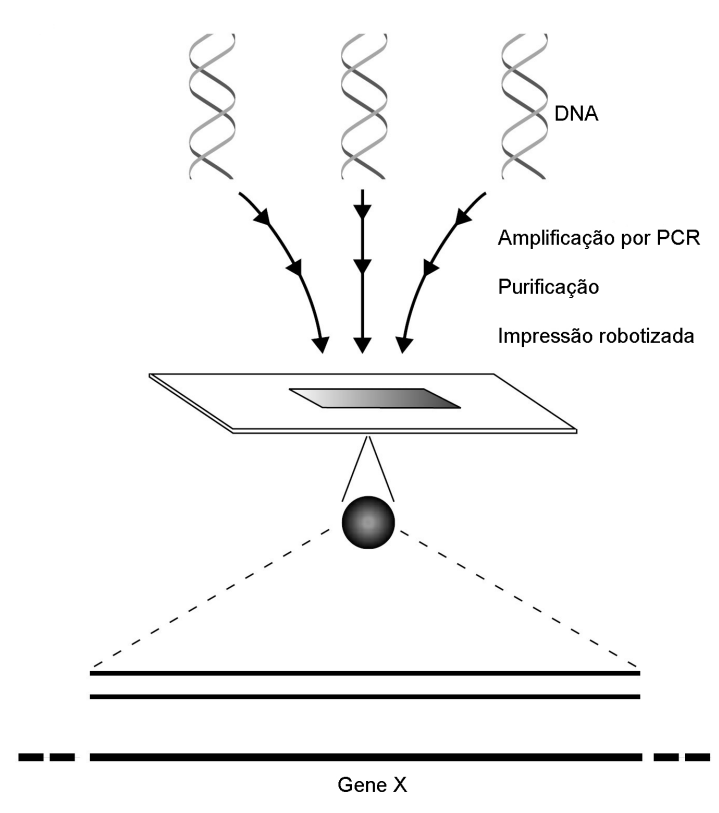

(a) Fabricação

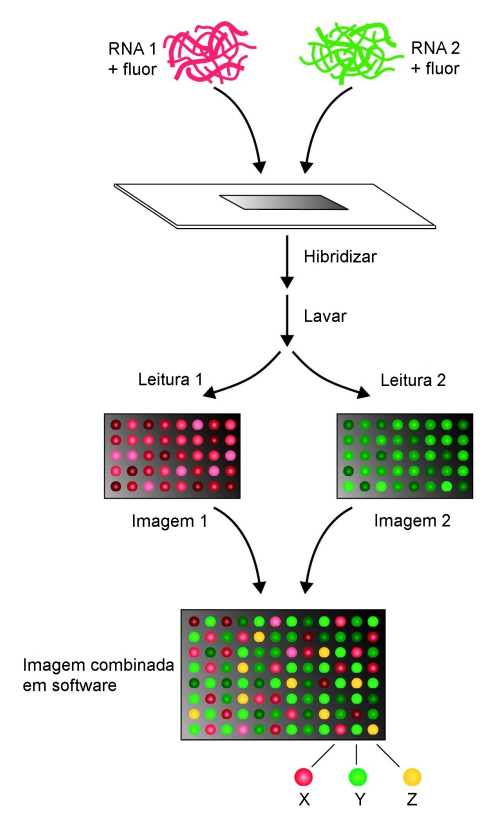

(b) Experimento

Figura 2.4: Microarray de DNA complementar. Imagens adaptadas de (Harrington et al., 2000)

Com as moléculas de DNA dispostas de maneira conhecida e ordenada sobre um microarray, diversos tipos de experimentos podem ser realizados. Uma das aplicações mais comuns permite comparar os níveis de expressões relativos de cada gene em 2 amostras distintas, por exemplo, um tecido em estados saudável e doente.

O processo é como segue, de maneira simplificada: inicialmente, as 2 amostras de tecidos são coletadas e têm seu RNAm extraído e isolado. Em seguida, moléculas de DNAc são sintetizadas a partir do RNAm. Para distinguir moléculas de amostras diferentes, tintas fluorecentes são incorporadas aos nucleotídeos das sequências de DNAc durante a transcrição reversa. Os pigmentos Cy3 (verde) e Cy5 (vermelho) são comumente utilizados 
na coloração.

Na próxima etapa do experimento, os DNAc das amostras são espalhados homogeneamente por sobre a pastilha, permitindo que eles se acoplem às sequências de DNA fixas nos diversos pontos do microarray. Isto é possivel devido ao processo de hibridização, segundo o qual fitas de DNA (ou RNA) podem ligar-se quimicamente a fitas complementares (de acordo com as regras mostradas na Figura 2.2). O grau com que as moléculas de DNAc de cada amostra se hibridizam com o DNA de um ponto reflete o nível relativo de expressão daquele determinado gene nas 2 condições em estudo. Após a hibridização, o microarray é lavado para a remoção de sequências não hibridizadas.

A seguir, ele é lido por dispositivos eletrônicos (os scanners) que iluminam os pontos da pastilha e medem a fluorescência de cada pigmento isoladamente, originando 2 imagens separadas. Por fim, as imagens são combinadas por software e a imagem resultante é analisada para determinar a intensidade relativa de fluorescência de cada gene. Este processo é ilustrado na Figura 2.4(b). Nela, é possível ver 3 genes hipotéticos, representados pelos pontos $\mathrm{X}$, Y e $\mathrm{Z}$. No primeiro, o ponto na pastilha é predominantemente vermelho, indicando que é ele mais expresso em uma das amostra. O ponto verde indica que aquele gene é mais expresso na outra amostra. O ponto amarelo indica um gene que tem nivel de expressão similar nas 2 amostras.

A expressão final $e$ de cada gene é dada pelo logaritmo da razão entre a intensidade obtida em uma amostra (DNAc tingido com o pigmento Cy5) e a intensidade obtida na outra amostra (DNAc tingido com o pigmento Cy3), como mostra a Equação 2.1:

$$
e=\log _{2}(C y 5 / C y 3)
$$

Este tipo de representação oferece algumas vantagens. A primeira é que ela enfatiza o fato de que microarrays de DNA complementar não fornecem dados de níveis de expressão absolutos e sim mudanças no nível de expressão relativo em 2 condições, o que pode ser mais interessante biologicamente (Eisen et al., 1998). A segunda é que o uso de logaritmo facilita o entendimento do fenômeno em estudo (Quackenbush, 2001). Por exemplo, se um gene apresenta nível de expressão de 1, segundo a Equação 2.1, então ele é expresso 2 vezes mais em uma amostra que em outra. Se a expressão for - 1 , então ele é 2 vezes mais expresso na outra amostra. A principal desvantagem dessa representação é a perda óbvia de informação quanto à intensidade absoluta dos niveis de expressão. 


\subsubsection{Microarrays de oligonucleotídeos}

No lugar das sequências de DNAc utilizadas na abordagem anterior, pequenas cadeias de nucleotídeos (geralmente de 25 pares de bases), denominadas oligonucleotídeos, são fixadas no microarray. Cada oligonucleotídeo representa um gene do experimento e é sintetizado diretamente nos pontos da pastilha (Gibson e Muse, 2004), segundo técnicas baseadas em manufatura de circuitos integrados (Lodish et al., 2007; Lipshutz et al., 1999).

Tipicamente, cada ponto do microarray contém milhares de conjuntos de 20 diferentes pares de oligonucleotídeos, que são utilizados para representar um gene (Choi, 2004). Os pares são compostos de 2 sequências conhecidas como perfect match (PM) e mismatch (MM). Elas são idênticas, exceto por uma única diferença de base na posição central, mais especificamente, no décimo terceiro nucleotídeo, o que faz com que a sequência PM hibridize com uma sequência de teste cuja expressão se quer medir e a MM não. A utilização da sequência MM visa controlar os efeitos do problema de hibridização cruzada, pelo qual pequenas sequências de outros genes hibridizam indevidamente com a sequência PM, diminuindo a especificidade da hibridização (Lipshutz et al., 1999). Alguns autores discordam da utilidade da sequência MM (Gibson e Muse, 2004; Hucka e Szallasi, 2003). O processo de fabricação dos microarrays de oligonucleotídeos é esquematizado na Figura 2.5(a).

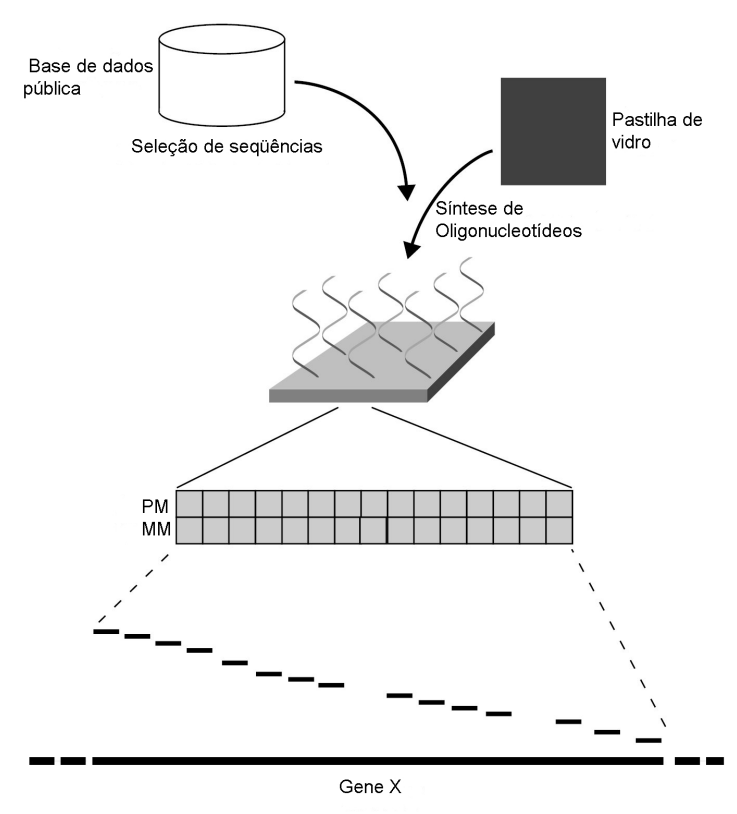

(a) Fabricação

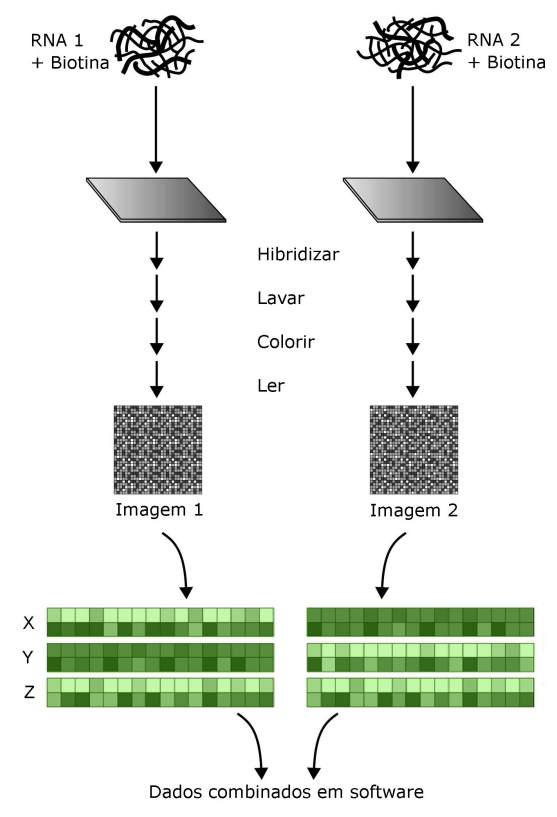

(b) Experimento

Figura 2.5: Microarray de oligonucleotídeos. Imagens adaptadas de (Harrington et al., 2000)

Para analisar os níveis de expressão dos genes em 2 amostras, inicialmente 
faz-se a coleta de RNA. Em seguida, o RNA é submetido a um processo de amplificação linear em 2 fases e nucleotídeos marcados com biotina são incorporados às cópias de RNA durante a reação (Choi, 2004; Harrington et al., 2000). O RNA é então espalhado por sobre a pastilha e as sequências hibridizam com os oligonucleotídeos ali depositados.

As sequências de RNA que não hibridizaram são removidas através de processos de lavagem e às restantes é adicionado o composto fluorescente Streptavidin-Phycoerythrin, que se liga aos nucleotídeos marcados com biotina (Choi, 2004; Gibson e Muse, 2004). A Phycoerythrin pode ser detectada com o auxílio de um scanner apropriado, possibilitando medir quanto RNA hibridizou com os oligonucleotídeos da pastilha. O nível de expressão de cada gene é calculado tendo como base a diferença média entre as sequências PM e MM referente àquele gene.

Na Figura 2.5(b), que mostra os passos básicos do experimento, tem-se ilustrado conjuntos de oligonucleotídeos PM-MM para 3 genes hipotéticos. O gene $\mathrm{X}$ está mais expresso na amostra 2 que na 1 . O gene $\mathrm{Y}$ está mais expresso na amostra 2 que na 1 . O gene $Z$ está expresso em níveis similares nas 2 amostras.

\subsection{Bases de dados}

Os experimentos de microarrays resultam em imagens digitais das pastilhas hibridizadas. Para que os dados gerados possam ser analisados na prática, é necessário que os níveis de expressão gênica estejam expressos em forma numérica. Para isso, técnicas de processamento de imagens (Sebastiani et al., 2003) e de normalização de dados (Ding e Wilkins, 2004) são empregadas e matrizes com os resultados são obtidas. Geralmente, as colunas destas matrizes correspondem às amostras de dados (por exemplo, tecidos de diferentes pacientes) e as linhas aos genes utilizados para caracterizar as amostras (Shamir et al., 2002b). Assim, cada uma de suas entradas representa o nível de expressão de um gene específico em uma amostra determinada. A Tabela 2.2 exibe um exemplo de matriz de expressão $n \times m$, onde $x_{i, j}$ é o valor de expressão gênica.

Tabela 2.2: Matriz genérica de expressão gênica

\begin{tabular}{ccccc}
\hline Genes & Tecido 1 & Tecido 2 & $\ldots$ & Tecido $m$ \\
\hline 1 & $x_{i, j}$ & $x_{i, j}$ & & $x_{i, j}$ \\
2 & $x_{i, j}$ & $x_{i, j}$ & & $x_{i, j}$ \\
3 & $x_{i, j}$ & $x_{i, j}$ & & $x_{i, j}$ \\
$\vdots$ & & & & \\
$n$ & $x_{i, j}$ & $x_{i, j}$ & & $x_{i, j}$ \\
\hline
\end{tabular}


Seguindo o formato geral apresentado na Tabela 2.2, vários estudos têm disponibilizado seus dados na Internet para apreciação pública. Alguns deles são bem conhecidos e têm ajudado no entendimento do fenômeno de interesse, através de diversos tipos de análises feitas pela comunidade científica. A Tabela 2.3 apresenta informações gerais sobre as 49 bases de dados coletadas e utilizadas durante este trabalho. Todas elas são relacionadas à distinção de estados patológicos envolvendo câncer.

As bases de expressão gênica compartilham algumas particularidades que precisam ser consideradas quando de sua análise. Elas são listadas a seguir:

1. Alta dimensionalidade: os experimentos de microarray são projetados para medir a expressão de grande quantidade de genes simultaneamente. Tipicamente, milhares de medições são consideradas.

2. Atributos irrelevantes: há evidências de que apenas uma pequena parcela de genes está envolvida em um fenômeno biológico específico (Calza et al., 2007). Assim, para compreendê-lo, é suficiente focar apenas nos genes mais informativos.

3. Atributos redundantes: em alguns casos, é possível que haja uma alta correlação entre os genes. Isto geralmente ocorre quando os genes participam do mesmo processo metabólico, são expressos de forma correlacionada ou são do mesmo cromossomo (Jaeger et al., 2003). Na maioria dos casos, a eliminação de atributos muito correlacionados com outros pode facilitar as análises devidas.

4. Dados com ruído: os experimentos de microarrays estão sujeitos a diversas causas de ruído. As mais comuns se devem às técnicas de processamento de imagem, que podem distorcer a imagem do microarray, às variações biológicas e aos protocolos experimentais empregados (Tu et al., 2002).

5. Poucos tecidos: atualmente, as bases de dados de microarray disponíveis publicamente são compostas de poucas tecidos, geralmente na ordem de dezenas. A principal razão pra isso é o alto custo da tecnologia e a dificuldade de obtenção de tecidos clínicas suficientes, o que impede a realização de mais experimentos (Kim e Park, 2004).

\subsection{Análise dos dados de microarrays}

A Genômica Funcional (GF) refere-se ao estudo sistemático e em larga escala de sequências de DNA a fim de entender a função de genes e proteínas (Pevsner, 2009). Segundo Hoheisel (2006), a tecnologia de microarrays possui diversas aplicações com importância em potencial para o desenvolvimento da GF. A mais madura atualmente é sua utilização para determinar perfis de 
Tabela 2.3: Informações gerais sobre bases de dados de microarrays

\begin{tabular}{|c|c|c|c|c|c|}
\hline Base de dados & Tecnologia & \#Exemplos & \#Genes & \#Classes & Dist. classes \\
\hline Dyrskjot et al. (2002) & Oligo & 40 & 6956 & 3 & $11,9,20$ \\
\hline Sanchez-Carbayo et al. (2006) & Oligo & 157 & 22283 & 3 & $48,81,28$ \\
\hline Farmer et al. (2005) & Oligo & 47 & 22215 & 3 & $6,16,25$ \\
\hline Gruvberger et al. (2001) & DNAc & 58 & 3389 & 2 & 30,28 \\
\hline Perou et al. (2000) & DNAc & 65 & 9216 & 4 & $32,9,14,10$ \\
\hline Richardson et al. (2006) & Oligo & 46 & 54675 & 3 & $7,20,19$ \\
\hline Sotiriou et al. (2006) & Oligo & 157 & 22283 & 3 & $64,48,55$ \\
\hline West et al. (2001) & Oligo & 49 & 7129 & 2 & 25,24 \\
\hline Pomeroy et al. (2002) & Oligo & 34 & 7129 & 2 & 25,9 \\
\hline Wong et al. (2003) & DNAc & 33 & 10692 & 2 & 25,8 \\
\hline Alon et al. (1999) & Oligo & 62 & 2000 & 2 & 40,22 \\
\hline Laiho et al. (2007) & Oligo & 37 & 22283 & 2 & 8,29 \\
\hline Watanabe et al. (2006) & Oligo & 84 & 54675 & 2 & 33,51 \\
\hline Hippo et al. (2002) & Oligo & 30 & 7129 & 2 & 8,22 \\
\hline Freije et al. (2004) & Oligo & 85 & 22645 & 2 & 26,59 \\
\hline Nutt et al. (2003) & Oligo & 50 & 12625 & 2 & 28,22 \\
\hline Phillips et al. (2006) & Oligo & 100 & 22645 & 2 & 24,76 \\
\hline Rickman et al. (2001) & Oligo & 40 & 7069 & 2 & 19,21 \\
\hline Pyeon et al. (2007) & Oligo & 56 & 54675 & 2 & 42,14 \\
\hline Andersson et al. (2007) & DNAc & 121 & 21370 & 3 & $23,87,11$ \\
\hline Armstrong et al. (2002) & Oligo & 72 & 12582 & 3 & $24,20,28$ \\
\hline Golub et al. (1999) & Oligo & 72 & 7129 & 2 & 47,25 \\
\hline Haslinger et al. (2004) & Oligo & 100 & 12651 & 2 & 49,51 \\
\hline Yeoh et al. (2002) & Oligo & 248 & 12625 & 6 & $79,15,27,20,43,64$ \\
\hline Chen et al. (2002) & DNAc & 156 & 3964 & 2 & 82,74 \\
\hline Barrett et al. (2005) & Oligo & 54 & 22283 & 2 & 10,44 \\
\hline Bhattacharjee et al. (2001) & Oligo & 156 & 12600 & 2 & 17,139 \\
\hline Bild et al. (2005) & Oligo & 511 & 54675 & 2 & 53,58 \\
\hline Gordon et al. (2002) & Oligo & 181 & 12533 & 2 & 150,31 \\
\hline Yang et al. (2007) & DNAc & 80 & 42894 & 3 & $18,40,12$ \\
\hline Alizadeh et al. (2000) & DNAc & 99 & 9216 & 2 & 31,68 \\
\hline Booman et al. (2006) & DNAc & 36 & 19200 & 2 & 10,26 \\
\hline Dave et al. (2006) & Oligo & 194 & 2745 & 2 & 45,149 \\
\hline Rosenwald et al. (2002) & DNA & 240 & 7399 & 3 & $73,115,52$ \\
\hline Shipp et al. (2002) & Oligo & 77 & 7129 & 2 & 19,58 \\
\hline Talantov et al. (2005) & Oligo & 70 & 22283 & 3 & $7,18,45$ \\
\hline Chowdary et al. (2006) & Oligo & 104 & 22283 & 2 & 62,42 \\
\hline Monti et al. (2003) & Oligo & 103 & 1000 & 4 & $26,26,28,23$ \\
\hline Gilks et al. (2005) & DNAc & 23 & 43007 & 2 & 13,10 \\
\hline Jazaeri et al. (2002) & DNAc & $\mathrm{x}$ & 6445 & 3 & $18,16,27$ \\
\hline Li et al. (2002) & DNAc & 54 & 1536 & 2 & 30,24 \\
\hline Schwartz et al. (2002) & Oligo & 113 & 7069 & 5 & $53,10,33,8,9$ \\
\hline Ishikawa et al. (2005) & Oligo & 49 & 22645 & 2 & 26,23 \\
\hline Singh et al. (2002) & Oligo & 102 & 12600 & 2 & 52,50 \\
\hline Tomlins et al. (2007) & DNAc & 83 & 12899 & 4 & $18,20,32,13$ \\
\hline True et al. (2006) & DNAc & 31 & 14826 & 3 & $11,12,8$ \\
\hline Yang et al. (2005a) & Oligo & 32 & 54675 & 2 & 22,12 \\
\hline Yoon et al. (2006) & Oligo & 54 & 22283 & 2 & 15,39 \\
\hline Khan e et al (2001) & DNAc & 88 & 2309 & 4 & $30,11,19,28$ \\
\hline
\end{tabular}

expressão gênica em tecidos. A partir desses perfis, diversas análises podem ser realizadas, dependendo do interesse do pesquisador. Tarca et al. (2006) destacam 3 tipos básicos de aplicações em medicina: comparação de classes, predição de classes e descoberta de classes.

Nos estudos envolvendo comparação de classes, o objetivo é comparar 
o perfil de expressão gênica em 2 ou mais condições distintas, a fim de adquirir conhecimento sobre o fenômeno observado. Por exemplo, pode-se estudar como a exposição a certos compostos influenciam na expressão de um conjunto de genes (Swagell et al., 2005). É possível também relacionar a expressão de determinados genes à progressão de uma doença e à sobrevida de pacientes e assim determinar quais pacientes poderiam se beneficiar de procedimentos cirúrgicos (Pass et al., 2004). Outra aplicação importante é comparar grupos de pacientes em diferentes estados patológicos e determinar os fatores genéticos que definem a doença (Catherino et al., 2006).

$\mathrm{Na}$ predição de classes, a tarefa é discriminar entre diferentes tipos de sequências moleculares, células ou condições. Para tanto, faz-se uso de técnicas capazes de construir modelos que representem as classes em questão e que possam ser empregados para distinguir objetos dessas classes. Em seu estudo clássico, Golub et al. (1999) analisaram o metabolismo de células pertencentes a dois tipos de tumores e um padrão pôde ser aprendido. Com isso, foi possivel classificar novas amostras doentes utilizando-se apenas seus níveis de expressão gênica. É de interesse também realizar a classificação de genes de acordo com sua função. Brown et al. (2000) utilizaram uma técnica de aprendizagem de máquina para classificar os genes em famílias de funções (por exemplo, codificadores de proteínas do ribossomo), baseados apenas em seus perfis de expressão.

Em aplicações de descoberta de classes, analisa-se os dados e tenta identificar subgrupos antes desconhecidos de entidades biológicas. Em seu estudo, Golub et al. (1999) descobriram novas subclasses de classes existentes de tumores. Eles conseguiram distinguir leucemia aguda em 2 tipos, tomando como base apenas os níveis de expressão gênica de amostras de tecidos. Essa diferenciação é importante na medida em que cada tipo requer uma abordagem terapêutica específica. Outro trabalho envolvendo descoberta de classes é identificar grupos de genes que possam se comportar de maneira semelhante durante uma doença, permitindo melhorar o entendimento da patologia e indicando possiveis tratamentos (Tarca et al., 2006).

\subsection{Considerações finais}

Neste capítulo, apresentou-se uma descrição de alto nível de microarrays. Inicialmente, alguns conceitos biológicos foram sucintamente comentados, possibilitando que, na seção posterior, os principais aspectos da tecnologia fossem abordados. Em seguida, mostrou-se o formato geral adotado pelos experimentos de expressão gênica a fim de permitir a análise dos dados, assim como alguns exemplos de bases disponíveis publicamente. Na mesma seção, 
algumas características importantes das bases de dados foram enumeradas. Posteriormente, os tipos mais comuns de aplicações de microarrays foram discutidos.

Para realizar as análises da Seção 2.5, utilizam-se ferramentas computacionais. Tipicamente, algoritmos de AM têm sido empregados. Por exemplo, a aplicações que envolvam predição de classes, têm sido aplicadas técnicas de AM supervisionada, onde a classe das entidades biológicas é conhecida a priori. Em aplicações de descoberta de classes, utiliza-se técnicas de AM não-supervisionada, onde não há conhecimento prévio de classes. Ambas as abordagens serão apresentadas no Capítulo 3, com ênfase na primeira abordagem, dado que este trabalho trata da classificação de dados de expressão gênica. 


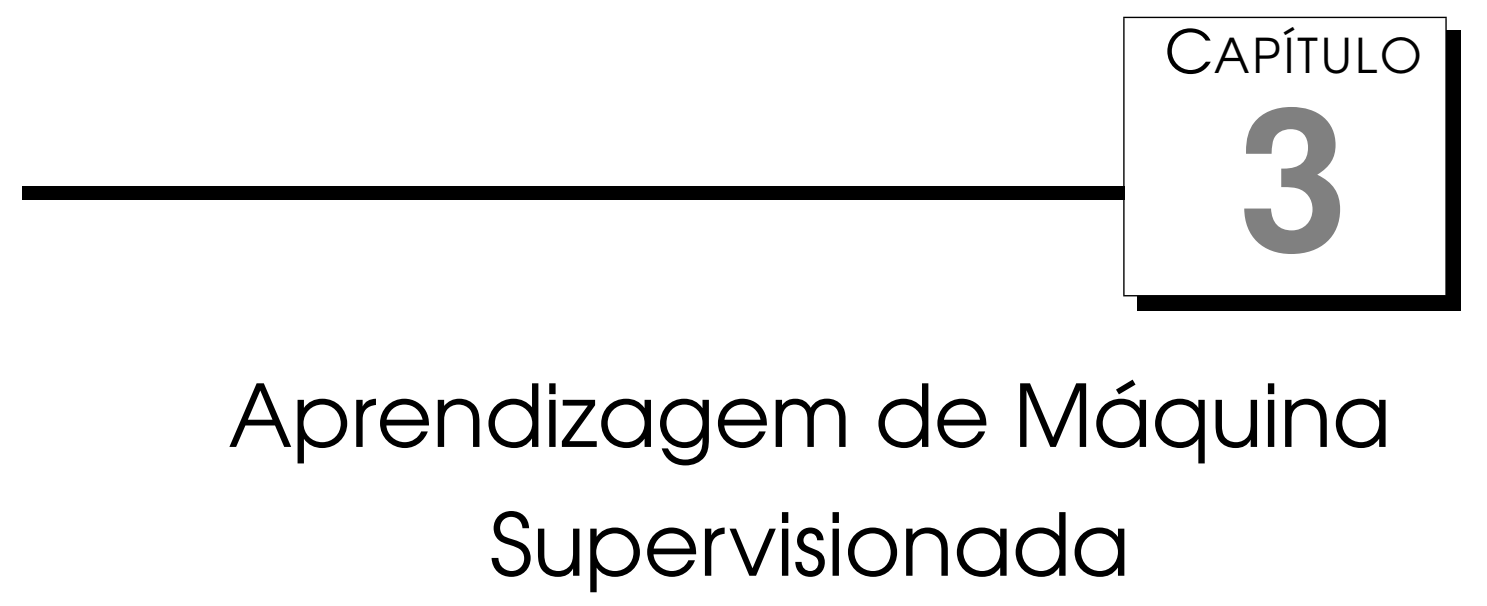

\section{1 Considerações Iniciais}

A Aprendizagem de Máquina (AM) (Bishop, 2006) pode ser considerada um campo de pesquisa fundamentado na Inteligência Artificial e na Estatística que estuda e modela as diversas facetas do processo de aprendizagem. Seu surgimento foi motivado pela observação de que, em sistemas biológicos, a inteligência está intrinsicamente relacionada à capacidade de aprender. Os seres humanos, por exemplo, são capazes de adquirir conhecimentos, desenvolver novas habilidades e melhorar seu desempenho com a prática (Michalski, 1986). Assim, as pesquisas em AM buscam compreender esses mecanismos naturais e reproduzi-las em sistemas artificiais aptos para lidar com problemas reais.

Diversas estratégias de aprendizagem podem ser utilizadas para desenvolver algoritmos de AM. A mais estudada atualmente baseia-se no conceito de indução, segundo o qual é possível obter-se conclusões genéricas a partir de fatos ou observações particulares. Esse tipo de inferência lógica caracteriza-se por extrapolar a informação contida nos dados a fim de modelar conceitos mais gerais. Quanto mais representativos do conceito geral forem os dados, melhor a qualidade da modelagem, embora não haja garantias de que as conclusões do raciocínio indutivo sejam sempre verdadeiras (Mitchell, 1997). Em todo caso, a indução representa uma importante ferramenta para a geração de novos conhecimentos. 
A aprendizagem indutiva tem sido tradicionalmente empregada para a concepção de abordagens de AM segundo duas vertentes básicas Monard e Baranauskas (2003): supervisionada e não-supervisionada ${ }^{1}$. Na primeira, o objetivo é induzir descrições gerais de conceitos utilizando exemplos específicos dos mesmos. Assim, os algoritmos supervisionados operam sobre um conjunto rotulado de exemplos para construir classificadores capazes de determinar corretamente a classe de novos exemplos. Na segunda, a meta é descobrir padrões e regras gerais capazes de explicar as observações. Comumente, a tarefa de algoritmos não-supervisionados é analisar os exemplos e tentar identificar, caso haja, estruturas de grupos nos dados.

O enfoque deste capítulo é a AM supervisionada, dada sua relevância para o presente trabalho. Na Seção 3.2, são apresentados alguns de seus conceitos básicos. Na Seção 3.3, os paradigmas de classificação são brevemente comentados. Na Seção 3.4, algumas formas usuais de estimar o desempenho dos classificadores são descritas. Na Seção 3.5, os testes estatísticos utilizados para aferir a diferença de desempenho entre os classificadores são abordados. Por fim, na Seção 3.6, há a conclusão do capítulo.

\subsection{Aprendizagem de Máquina Supervisionada}

Um conceito pode ser entendido como uma regra que particiona os objetos ou exemplos de um domínio de acordo com a obediência (ou não) deles a ela (Utgoff, 1986). A tarefa da AM supervisionada é induzir tais conceitos a partir de exemplos específicos dos mesmos. Os exemplos são rotulados por um supervisor ou professor, que detém o conhecimento do domínio e conhece a definição do conceito a ser aprendido. O supervisor fornece os exemplos na forma de pares entrada e saída desejada (Haykin, 1998) e o algoritmo aprende, então, uma relação entre as características das entradas e das saídas que seja consistente com os exemplos considerados e que possa ser utilizado para predizer saídas corretas para entradas não vistas anteriormente.

Mais formalmente, considere um conjunto $S$ formado por $n$ elementos dispostos em um espaço de $m$ dimensões tal que $S=\left\{\left(\overrightarrow{x_{1}}, y_{1}\right), \ldots,\left(\overrightarrow{x_{n}}, y_{n}\right)\right\}$. Esse conjunto ou base de dados é composto por exemplos $\overrightarrow{x_{i}}$ com valores de atributos $x_{i j} \in X$ e de classes $y_{i} \in Y$, amostrados do domínio seguindo uma distribuição $D$ fixa, desconhecida e arbitrária. Os exemplos em $S$ são utilizados pelo algoritmo de AM para a construção de um classificador, chamado também de hipótese ou preditor, capaz de predizer os valores de $y_{i}$ para novos $\overrightarrow{x_{i}}$. Esse processo de construção ou indução de um classificador é

\footnotetext{
${ }^{1}$ Mais recentemente, algoritmos semi-supervisionados têm sido desenvolvidos. Eles fazem uso de exemplos rotulados e não rotulados durante o processo de aprendizagem. Detalhes sobre essa abordagem podem se encontrados em (Chapelle et al., 2006).
} 
denominado treinamento.

$\mathrm{Na}$ prática, as hipóteses geradas durante o treinamento são comumente representadas por um mapeamento $h: X \mapsto Y$ que aproxime, idealmente, a verdadeira função $f(X)$. Uma vez escolhida uma função de mapeamento $h$, definida no espaço de hipóteses $H$, pode-se classificar elementos não vistos durante a fase de treinamento, por meio do cômputo de $h\left(\overrightarrow{x_{i}}\right)$, para um $\overrightarrow{x_{i}}$ qualquer. Esse mapeamento só é possível sob a condição de que os exemplos desconhecidos ao classificador (coletivamente referidos como conjunto de teste) sejam gerados pela mesma distribuição $D$ do conjunto $S$.

Em AM, os exemplos $\overrightarrow{x_{i}}$, conhecidos ainda como casos, padrões, instâncias ou registros, representam um objeto particular do mundo real. Eles são descritos por tuplas de $m$ atributos $x_{i j} \in R$, cada um indicando uma característica ou aspecto do exemplo. De maneira geral, há dois tipos de atributos: quantitativos e qualitativos. Os primeiros representam grandezas numéricas comumente resultantes de medições, enquanto os segundos correspondem a conceitos categóricos ou simbólicos de maior nível de abstração. Neste trabalho, apenas atributos quantitativos contínuos são considerados, dada a natureza do problema em estudo. Detalhes acerca de classificação e propriedades de atributos podem ser encontrados em (Yang et al., 2005b; Barbara, 2000; Jain e Dubes, 1988).

A cada exemplo $\overrightarrow{x_{i}}$ é associado um valor especial $y_{i}$, que representa o fenômeno de interesse. Ele pode assumir valores contínuos ou discretos. No primeiro caso, tem-se $y_{i} \in Y=\left\{c_{1}, c_{2}, \ldots, c_{\max }\right\}$, onde max indica o número de classes existentes. Problemas de aprendizagem desse tipo são conhecidos como problemas de classificação. No segundo caso, os valores se apresentam de forma contínua, tal que $y \in Y=\Re$. A tarefa de aprendizagem agora é conhecida como regressão. Neste trabalho, apenas problemas de classificação serão considerados.

A indução de um classificador a partir de um conjunto de dados pode ser vista como um problema de busca (Mitchell, 1997), em que o objetivo é encontrar a hipótese, entre todas que o algoritmo de AM é capaz de gerar, com a melhor capacidade de descrever o fenômeno a aprender. Como normalmente várias hipóteses são capazes de modelar o conceito, é necessário algum tipo de bias para guiar o processo de busca. O termo bias refere-se a qualquer critério de preferência do algoritmo por uma hipótese em relação a outra, dado que ambas sejam consistentes com os exemplos (Russel e Norvig, 1995). De fato, aprendizagem sem bias não é possível (Mitchell, 1997).

Um bias inadequado ou um conjunto de dados pouco representativo pode afetar a nivel de generalização do classificador, ou seja, sua habilidade em predizer corretamente as classes de exemplos do conjunto de teste. Dentre os 
problemas de generalização mais comuns, tem-se o overfitting e o underfitting (Monard e Baranauskas, 2003). O overfitting ocorre quando a hipótese induzida é demasiado específica, ou seja, representa pormenores da amostra de dados usada para treinamento que não são característicos do fenômeno que os gera. Se tal acontecer, o desempenho do classificador, segundo uma métrica arbitrária de qualidade, é muito bom para exemplos conhecidos mas insatisfatório considerando a totalidade de exemplos da distribuição $D$. No caso do underfitting, o algoritmo de AM não consegue encontrar uma hipótese adequada que possa modelar devidamente os dados. Isso ocorre porque dados não contêm informação suficiente acerca do conceito a ser aprendido ou aos parâmetros do algoritmo não estarem corretamente ajustados para permitir a aprendizagem.

\subsection{Paradigmas de AM Supervisionada}

Há diversos algoritmos capazes de induzir a hipótese $h$ utilizando uma base de dados. Para fins didáticos, é conveniente agrupá-los em paradigmas, segundo suas características. Embora vários autores tenham trabalhado no assunto, ainda não há uma taxonomia considerada consenso por eles. Por exemplo, Lipmann (1991) lista quatro tipos de algoritmos de classificação: probabilísticos, globais, locais e baseados em vizinhos mais próximos. Holmstrom et al. (1997) consideraram outro agrupamento: classificadores baseados em estimativa de densidade, classificadores baseados em regressão e outros classificadores. Jain et al. (2000) distinguem quatro abordagens comumente utilizadas para o reconhecimento de padrões, em que a AM supervisionada está inserida: template matching, matching sintático ou estrutural, classificação estatística e redes neurais. Outros autores apresentaram agrupamentos alternativos (Kuncheva, 2004; Aha, 1997).

Neste trabalho, por simplicidade, optou-se por seguir a divisão apresentada por Batista (2003), segundo a qual os paradigmas de AM supervisionado mais comuns são: simbólico, estatístico, baseado em exemplos e conexionista. Eles serão comentados a seguir.

As técnicas simbólicas operam construindo representações em alto nível de um conceito por meio da análise de exemplos desse conceito, de tal forma que ele possa ser facilmente interpretado pelos seres humanos (Mitchell, 1997). Dentre os algoritmos mais utilizados, tem-se as diversas variações de algoritmos de indução de árvores e de regras de decisão. Os algoritmos de indução de árvores de decisão, tais como ID3, C4.5, C5.0 (Fürnkranz, 1999; Murthy, 1998), baseiam-se na estratégia de dividir para conquistar a fim de gerar a árvore de decisão. Cada nó interno da árvore representa um teste em 
um atributo dos exemplos da base de dados. Para cada resultado possivel para esse teste, é criado um ramo que leva a um novo nó. As folhas representam as classes do problema. Para classificar um novo exemplo, é preciso apenas percorrer a árvore até uma folha e atribuir a classe correspondente. Outro tipo de modelo são as regras proposicionais Se-Então, ou regras de decisão. Alguns algoritmos que descobrem tais regras são os algoritmos C4.5rules (Quinlan, 1993) e CN2 (Clark e Niblett, 1989), por exemplo.

Os modelos estatísticos têm inspirado técnicas capazes de aproximar a hipótese $h$. Dentre as abordagens estatísticas mais utilizadas em AM supervisionada, destacam-se a Função Discriminante Linear de Fisher (FDLF) e os classificadores Bayesianos (Duda et al., 2000). A FDLF assume que as classes podem ser expressas como combinações lineares dos valores dos atributos e busca uma combinação específica que maximize a diferença entre as médias dos valores das variáveis entre classes e minimize a variância desses valores em cada classe. Com isso, pretende-se projetar os dados de um espaço de alta dimensionalidade em um espaço de baixa dimensionalidade, sem perda significativa de informação, de tal forma que os exemplos de classes distintas possam ser mais facilmente separados. Os classificadores Bayesianos operam calculando as probabilidades de que um determinado exemplo pertença a cada uma das classes do domínio, indicando a sua classe mais provável. Dentre os algoritmos Bayesianos, o Naive Bayes é comumente utilizado em aplicações, devido a suas suposições permitirem um cômputo fácil de parâmetros como as funções densidade de probabilidade requeridas.

Os algoritmos baseados em exemplos classificam novos dados de acordo com sua similaridade com exemplos já conhecidos. O algoritmo mais comum desse paradigma é o $k$ Nearest Neighbors ( $k \mathrm{NN}$ ) (Duda et al., 2000). Para classificar um exemplo de teste, ele opera da seguinte maneira: calcula a distância do exemplo de teste a cada um dos exemplos da base de dados; em seguida, verifica a quais classes pertencem os $k$ exemplos mais similares ao exemplo de teste; por fim, a classe mais frequente entre os $k$ exemplos é utilizada para classificar o exemplo de teste. A definição da função de distância entre os exemplos, assim como o valor ótimo de $k$, é dependente do domínio de aplicação.

O paradigma conexionista é representado pelas Redes Neurais Artificiais (RNAs), que são modelos matemáticos desenvolvidos com base no funcionamento do sistema neuronal biológico (Haykin, 1998). Além de fornecerem um arcabouço teórico para estudar algumas propriedades do cérebro, as RNAs têm sido aplicadas para a resolução de problemas de AM. Do ponto de vista prático, as RNAs são compostas de elementos simples interconectados, que realizam o processamento e armazenamento da 
informação de maneira paralela e distribuída. Os modelos clássicos de RNAs mais utilizados são o Multilayer Perceptron (MLP) e o Radial Basis Function (RBF) (de Pádua Braga et al., 2003).

No contexto de classificação em dados de expressão gênica, algoritmos representantes dos 4 paradigmas têm sido aplicados. Dentre estes, os mais comumente utilizados, segundo Asyali et al. (2006), são: $k$ Nearest Neighbors ( $k$ NN) (Bishop, 2006), Support Vector Machines (SVMs) (Steinwart e Christmann, 2008), Árvore de decisão (Bishop, 2006), Fisher and Diagonal Linear Discriminant Analysis (FLDA e DLDA, respectivamente) e Diagonal Guadratic Discriminant Analysis (DQDA) (Dudoit et al., 2002), Redes neurais (Bishop, 2006) e Prediction Analysis of Microarrays (PAM) (Tibshirani et al., 2002). Outras abordagens comuns de classificação incluem Random Forests (RF) (Breiman, 2001).

Alguns estudos foram realizados para comparar o desempenho desses métodos. Os mais relevantes são resumidos a seguir. Dudoit et al. (2002) compararam os desempenhos entre LDA, DLDA, DQDA, um esquema de voto ponderado, $k \mathrm{NN}$, árvores and comitês de árvores em três bases de dados de microarray. Sua conclusão principal foi que métodos simples, como o DLDA e o $k \mathrm{NN}$, produzem resultados comparáveis às abordagens mais sofisticadas. Romualdi et al. (2003) estudaram o comportamento preditivo de DLDA, algoritmos de indução de árvores de decisão, redes neurais, SVMs, $k \mathrm{NN}$ e PAM em duas bases de dados. Eles não foram capazes de obter evidência empírica de que algum método seja muito superior aos outros. Com base em experimentos envolvendo seis bases de dados e seis classificadores, Man et al. (2004) reportaram que Partial Least Square Discriminant Analysis (Boulesteix e Strimmer, 2007) e SVM apresentaram os melhores desempenhos. Em um extenso estudo, utilizando 21 classificadores (incluindo a maioria das abordagens anteriores) aplicados sobre 7 bases de dados, Lee et al. (2005) concluíram que classificador algum resultou sistematicamente melhor que seus pares. Statnikov et al. (2005) compararam os algoritmos multiclasses SVMs, $k$ NN e redes neurais utilizando 11 bases de dados e chegaram à conclusão que SVMs são superiores. Finalmente, avaliaram o desempenho de cinco métodos estatísticos em duas bases de dados e concluíram que eles apresentam resultados similares. De forma geral, os estudos indicam que não há uma único método classificador mais adequado a todas às situações e que, em alguns casos, é importante escolher o algoritmo para obter o melhor desempenho. 


\subsection{Desempenho de Classificadores}

Após a aplicação de um algoritmo de AM sobre um conjunto de dados $S$, é importante avaliar a qualidade da hipótese induzida, a fim de determinar quão boa é sua capacidade de generalização. Em situações ideais, seria possível calcular o erro verdadeiro da hipótese com respeito à distribuição arbitrária $D$, definido como a probabilidade de que ela irá classificar erroneamente um exemplo amostrado aleatoriamente de $D$ (Mitchell, 1997). Na prática, a distribuição $D$ é desconhecida. Assim, faz-se mister utilizar estimativas de erro baseadas exclusivamente na amostra de dados disponivel. Para tanto, dois aspectos devem ser definidos a priori: uma medida de desempenho dos modelos induzidos e uma estratégia para a avaliação dos mesmos. Ambos são discutidos a seguir.

\subsection{Medidas de desempenho}

Diversas medidas podem ser utilizadas para mensurar o desempenho dos algoritmos de classificação. Em um trabalho abrangente, Ferri et al. (2009) investigaram experimentalmente 18 medidas comumente consideradas pela comunidade de AM, tais como acurácia/erro (Monard e Baranauskas, 2003), medida F média (Baeza-Yates e Ribeiro-Neto, 1999), AUC (Fawcett, 2006), etc, a fim de compreender melhor suas propriedades e relações. Para tanto, a análise empreendida apresentou duas vertentes. A primeira, de caráter qualitativo, propôs uma taxonomia baseada na sensibilidade das medidas em relação a quatro propriedades, a saber: a escolha do limiar de classificação do algoritmo de AM, a calibração da saída do algoritmo, a ordenação das saídas do algoritmo e a distribuição dos exemplos entre as classes. A segunda, de caráter quantitativo, considerou a correlação entre os resultados obtidos pelas diversas medidas quando da aplicação de 6 algoritmos de classificação sobre 30 bases de dados em diversos cenários. Com esse estudo, os autores foram capazes de identificar tendências de comportamento entre as abordagens e destacar suas similaridades e diferenças, fornecendo orientação quanto à escolha da medida mais adequada para uma aplicação específica.

No domínio de expressão gênica considerado neste trabalho, a acurácia e o erro permanecem como as medidas padrão de desempenho e têm sido empregadas em diversos estudos de cunho comparativo (vide (Boulesteix et al., 2008) e referências ali contidas). A taxa de erro $\operatorname{Erro}(h)$ da hipótese $h$, relativa a um conjunto de teste $T$, de cardinalidade $p$, é definida pela Equação 3.1 (Monard e Baranauskas, 2003), que compara as classes reais dos exemplos $\overrightarrow{x_{i}}$ com aquelas preditas por $h$. A função $\delta\left(y_{i}, h\left(\overrightarrow{x_{i}}\right)\right)$ é 1 se $y_{i} \neq h\left(\overrightarrow{x_{i}}\right)$ e 0 , caso contrário. O complemento da taxa de erro do classificador corresponde à 
acurácia.

$$
\operatorname{Erro}(h)=\frac{1}{p} \sum_{i=1}^{p} \delta\left(y_{i}, h\left(\overrightarrow{x_{i}}\right)\right)
$$

Alternativamente, a análise baseada em curvas do tipo Receiver Operating Characteristics (ROC) (Fawcett, 2006) tem sido empregada em problemas com classes potencialmente desbalanceadas e custo distintos nos erros de classificação, tais como comumente encontrados em dados de expressão gênica (Statnikov et al., 2008). As curvas ROC correspondem a um método visual para a avaliação, organização e seleção de algoritmos de AM. Elas são estruturadas sobre um plano cartesiano onde cada modelo classificador é representado por um ponto. No eixo das abscissas, tem-se a taxa de verdadeiros positivos do modelo, ou seja, a proporção de exemplos da classe positiva classificados como tal, considerando-se um conjunto de testes. No eixo das ordenadas, tem-se a taxa de falsos positivos, que representa a proporção de exemplos erroneamente classificados como da classe positiva. A curva construída pela união dos pontos representa um compromisso entre acertos e erros obtidos, de acordo com diversos limiares de classificação pré-estabelecidos. Por meio de um exame conjunto desses resultados, pode-se ter uma descrição do comportamento preditivo do algoritmo e, por conseguinte, confrontar diversas abordagens de classificação. Notas e considerações práticas acerca de curvas ROC estão disponíveis em (Fawcett, 2003).

A comparação entre algoritmos pode não ser trivial utilizando análise ROC diretamente, devido a sua concepção gráfica bidimensional. Para auxiliar na investigação, pode-se resumir a informação obtida pela curva em uma grandeza escalar única dada pela Area Under an ROC Curve (AUC) (Fawcett, 2006). Ela é calculada pela Equação 3.2, relativa a uma hipótese $h$ induzida por um algoritmo de AM e aplicada sobre um conjunto de testes $T$ :

$$
\hat{A}=\frac{S_{0}-n_{0}\left(n_{0}+1\right) / 2}{n_{0} \cdot n_{1}}
$$

onde $n_{0}$ e $n_{1}$ são os números de exemplos positivos e negativos, respectivamente, e $S_{0}=\sum r_{i}$, com $r_{i}$ igual à posição do $i$-ésimo exemplo positivo em uma lista ordenada. $\hat{A}$ varia de 0 a 1 , sendo que valores maiores são preferíveis, pois indicam uma maior área sob a curva. Para lidar com problemas multiclasses, utiliza-se a ponderação da Equação 3.3, proposta por Hand e Till (2001):

$$
M=\frac{2}{c(c-1) \sum_{i<j} \hat{A}(i, j)}
$$

onde $c$ é o número de classes e $\hat{A}(i, j)$ é a AUC calculada apenas para exemplos 
das classes $i$ e $j$.

As Equações 3.2 e 3.3 foram empregadas em três trabalhos recentes para a avaliação do comportamento de classificadores em dados oriundos de experimentos de expressão gênica (Souza et al., 2010b; Okun e Priisalu, 2007; Statnikov et al., 2008). Durante o desenvolvimento desta tese, realizou-se um extenso estudo considerando 7 algoritmos de AM avaliados sobre 65 bases de dados (Souza et al., 2010b). Ele focou no viés metodológico da comparação, identificando e corrigindo algumas deficiências na análise estatística dos resultados usualmente disponíveis na literatura (vide (Boulesteix et al., 2008; Berrar et al., 2006) e referências ali contidas). Statnikov et al. (2008) estudaram o desempenho de SVMs e árvores de decisão em bases de microarrays. Sua comparação principiada revelou que os trabalhos anteriores considerando esses dois algoritmos incorreram em falhas experimentais que impactaram as conclusões obtidas. Okun e Priisalu (2007) investigaram a dificuldade de classificação de duas bases de dados utilizando três medidas de complexidade de dados propostas por Ho e Basu (2002). Por meio desse estudo, os autores foram capazes indicar situações em que a utilização de $k \mathrm{NN}$ ou de comitês (Dietterich, 2000) de $k \mathrm{NN}$ é mais apropriada.

\subsubsection{Estratégia de avaliação}

Para que a estimativa do erro seja confiável, a hipótese $h$ deve ser testada em exemplos diferentes daqueles que foram usados para a induzir. Para definir que exemplos deverão integrar o conjunto $T$ utilizado para calcular os $\operatorname{Erro}(h)$ ou $\hat{A}$ definidos anteriormente, vários métodos podem ser utilizados. As principais alternativas baseiam-se na noção de amostragem, segundo a qual os exemplos são escolhidos aleatoriamente do conjunto de dados $S$. Teoricamente, o conjunto $S$ representa uma distribuição aproximada $D^{\prime}$ da distribuição verdadeira $D$. Assumindo que $D^{\prime}$ represente o mundo real, pode-se simular o processo de amostragem sobre $D$ e obter o conjunto de testes $T$. Na prática, os dados podem ser particionados em vários conjuntos de treinamento e teste para permitir uma estimativa mais confiável do desempenho do classificador. Os métodos mais utilizados para a construção de $T$ são brevemente descritos a seguir (Kuncheva, 2004; Baranauskas, 2001):

1. Resubstituição Este é o método mais simples para a definição de $T$ e não faz uso de amostragem. Ele utiliza o próprio conjunto $S$ como conjunto $T$, ou seja, os exemplos presentes na indução do classificador são exatamente os mesmos empregados para testá-lo. Nesta situação, a estimativa de erro é chamada de erro aparente e pode não aproximar fielmente o erro de generalização de $h$ para conjuntos independentes de teste, na medida em que o próprio algoritmo de AM já busca minimizar o 
erro durante o treinamento. Assim, é argumentado na literatura de AM que a resubstituição tende a apresentar uma estimativa muito otimista do erro (Mitchell, 1997).

2. Holdout Neste método, $S$ é dividido aleatoriamente em um conjunto de treinamento e outro de teste, de tamanhos previamente fixados (McLachlan, 1992). Usualmente, 2/3 dos exemplos são utilizados para a construção da hipótese e $1 / 3$ para testá-la, embora outras proporções possam ser utilizadas (Kohavi, 1995). A estimativa do erro é calculada sobre o conjunto de teste. Para minimizar a variação dos resultados devido à divisão aleatória dos dados, pode-se realizar repetidos particionamentos e calcular a média das estimativas em cada caso. O Holdout tende a apresentar uma estimativa pessimista do error, devido à utilização de um conjunto de treinamento reduzido para a indução da hipótese $h$ (Mitchell, 1997).

3. Cross-Validation Este método consiste em dividir aleatoriamente o conjunto $S$ em $k$ partições mutuamente exclusivas de exemplos, de tamanho aproximadamente igual (Kohavi, 1995). Das $k$ partições, $k-1$ são utilizadas para o treinamento do algoritmo de AM e a restante é utilizada para teste, aplicando-se quaisquer das Equações de 3.1 a 3.3. O processo é repetido $k$ vezes, em cada uma intercalando a partição utilizada no teste. O erro obtido para cada uma das $k$ partições é ponderado, obtendo-se assim uma estimativa de desempenho do classificador. Duas variantes do Cross-Validation (CV) são comumente utilizadas: Stratified Cross-Validation e o Leave-one-out (LOO). Na primeira, ao gerar-se as partições, tem-se o cuidado de amostrar os exemplos tal que a mesma proporção de dados em cada uma das classes de $S$ seja mantida nas partições. A segunda é um caso especial do $\mathrm{CV}$, em que $k$ é igual à quantidade de exemplos de $S$.

4. Bootstrap Neste método, são gerados $L$ conjuntos de treinamento com exemplos amostrados uniformemente a partir de $S$, com reposição, tal que cada conjunto tenha a mesma cardinalidade $n$ do conjunto original (Efron, 1983). Por esse esquema, a probabilidade de um exemplo não ser selecionado é dada por $(1-1 / n)^{n} \approx e^{-1} \approx 0.368$. Os exemplos não amostrados integram os conjuntos de teste. O restante compõe os conjuntos de treinamento, cuja cardinalidade esperada é $0.632 n$. Os $l$ conjuntos de treinamento e teste são então utilizados para induzir as hipóteses e calcular suas taxas de erro ou AUC, respectivamente. A média das $l$ taxas obtidas é utilizada para estimar o desempenho do classificador.

5. .632 e .632+. Como o boostrap utiliza em média apenas $63 \%$ dos dados 
em cada conjunto de treinamento, sua estimativa de desempenho é pessimista. Para tentar corrigir o problema, foi criado o estimador .632 (Efron e Tibshirani, 1993), que faz uma combinação linear do erro de resubstituição e o erro de boostrap, com pesos respectivos de 0.368 e 0.632. Com isso, estimativas otimista e pessimista são ponderadas para a construção de um estimador mais adequado. Como um melhoramento do .632, foi criado o .632+ (Efron e Tibshirani, 1997), que não fixa a priori o peso dos erros de resubstituição e bootstrap, permitindo que eles sejam definidos dinamicamente. Assim, o .632+ tende a ser mais adequado a casos de overfitting severo. Usualmente, esta estratégia de avaliação é empregada em conjunto com a medida $\operatorname{Erro}(h)$. A utilização de AUC no contexto ainda é insipiente (Sahiner et al., 2008; Yousef et al., 2005) e mais estudos são requeridos.

\section{Avaliação de classificadores em dados de expressão gênica}

A comunidade científica ainda não estabeleceu um consenso acerca de qual o melhor método de estimação de erro quando a classificação ocorre em dados de expressão gênica. Braga-Neto e Dougherty (2004) desencorajam o uso de abordagens baseadas em $\mathrm{CV}$, como 10-CV, o $10-\mathrm{CV}$ repetido e o LOO, alegando a grande variância dessas técnicas em situação de poucos exemplos. Como alternativa, eles sugerem as estimativas .632 e .632+. Corroborando essas observações, Fu et al. (2005) criticam o CV e indicam as técnicas baseadas em bootstrap como melhores opções, mas ainda não suficientes, para corrigir o bias da estimação. Eles propõem um procedimento baseado simultaneamente em CV e boostrap para aliviar o problema. Entretanto, o custo computacional pode tornar proibitivo o método. Molinaro et al. (2005) redimem parcialmente o CV, mostrando situações em que ele apresenta resultados satisfatórios, e aponta que procedimentos experimentais inadequadas podem ter influenciado conclusões anteriores sobre o CV. Jiang e Simon (2007) fazem uma comparação extensa envolvendo nove métodos de estimação de erro e três classificadores aplicados a dados de microarray. Como esperado, os autores reportaram resultados muito bons em termo de bias e variância, ao custo de uma computação intensiva. Os outros métodos empregados comparados no estudo exibiram, na maioria dos casos, desempenho adequado, dependendo das características dos dados. Durante o desenvolvimento desta trabalho, dois conjuntos distintos de experimentos foram conduzidos. O primeiro refere-se à meta-aprendizagem em si está reportado no Capítulo 5 e utiliza o .632+ como estratégia de avaliação. $\mathrm{O}$ segundo consiste de um abrangente estudo comparativo entre os algoritmos de AM mais empregados para classificar dados de microarrays (Souza et al., 
2010b) e utilizou o CV com múltiplas repetições.

Independente da abordagem adotada, é importante perceber que a estimativa obtida pode não ser acurada em relação ao verdadeiro erro esperado, devido à pequena quantidade de exemplos disponíveis. Isaksson et al. (2008) realizaram um estudo simulando essa situação e concluíram que, para um conjunto de dados único, não é possível determinar quão confiável é a estimativa do erro obtida através de CV e de bootstrap. Os experimentos realizados ainda mostram que quanto menor o número de exemplos da base de dados, mais variável é a estimativa do erro. Esse resultado documenta uma situação potencialmente incômoda no domínio de expressão gênica que, entretanto, não foi confirmada em outros estudos envolvendo simulação e dados reais (Jiang e Simon, 2007; Molinaro et al., 2005).

\subsection{Comparação de Classificadores}

Segundo Wolpert (1996), não existe um único algoritmo que, em situações gerais, supere todos os demais sempre. Assim, estudos comparativos podem ser importantes para entender as qualidades e deficiências das abordagens e, desse modo, determinar qual a mais apropriada em uma dada situação. Na Seção 3.4, algumas formas de estimar o erro de uma hipótese induzida foram apresentadas. Comparar diretamente as estimativas de erros dos classificadores pode não ser suficiente para precisar qual o melhor, pois há de considerar-se os vários fatores de variabilidade dos dados e dos algoritmos, tais como a escolha dos conjuntos de treinamento e teste e a aleatoriedade interna de algumas abordagens de AM, entre outros (Dietterich, 1998).

Uma forma de minimizar o efeito desses fatores é utilizar métodos estatísticos para aferir se a diferença de desempenho entre os classificadores é ou não significativa. Em seu estudo, Dietterich (1998) analisou vários testes para a capazes de comparar algoritmos de AM supervisionada. Embora todas as abordagens apresentem algum tipo de problema em relação aos fatores de variabilidade, o autor foi capaz de recomendar duas delas: o teste NcNemar e o teste $t$ pareado de $5 \times 2 C V$.

\subsubsection{Teste estatísticos}

A fim de ilustrar o funcionamento de testes estatísticos para a comparação de dois classificadores, ambas as abordagens serão brevemente comentadas a seguir. 
Este teste é comumente utilizado para comparar o desempenho de dois classificadores, $A$ e $B$, induzidos a partir de um conjunto de treinamento $R$ e aplicados a um conjunto de teste $T$. Ele visa à identificação de diferenças entre o número de exemplos de teste classificados erroneamente por $B$ mas não por $A$ (denotado por $N_{01}$ ) e o número de exemplos de teste classificados erroneamente por $A$ mas não por $B$ (denotado por $N_{10}$ ). Se for considerando a hipótese nula de que os classificadores têm desempenhos iguais, então $N_{01}=$ $N_{01}$, o que faz com que ambos os números tenham valor esperado de $\frac{\left(N_{01}+N_{10}\right)}{2}$. Para verificar a discrepância entre os valores observado e esperado, utiliza-se a estatística da Equação 3.4, que segue aproximadamente uma distribuição $\chi^{2}$ com um grau de liberdade (Dietterich, 1998).

$$
\frac{\left(N_{01}-N_{10}\right)^{2}}{N_{01}+N_{10}}
$$

Para efetuar o teste, basta calcular o resultado da Equação 3.4 e comparar com o valor tabelado de $\chi^{2}$ para um dado nível de significância estatística. Se o valor calculado for maior que o valor tabelado, então rejeita-se a hipótese nula e conclui-se que há diferença de desempenho entre $A$ e $B$, com determinado grau de certeza.

\section{Teste t pareado de $5 \times 2 \mathrm{CV}$}

Este teste consiste em repetir por 5 vezes o método Cross-Validation apresentado na Seção 3.4, com $k=2$. Em cada repetição, os dados são particionados nos conjuntos $S_{1}$ e $S_{2}$, de cardinalidades iguais. Dois classificadores, $A$ e $B$, são treinados e testados em ambos os conjuntos, dando origem às seguintes taxas de erro: $p_{A}^{(1)}, p_{B}^{(1)}, p_{A}^{(2)}$ e $p_{B}^{(2)}$. Em seguida, as diferenças $p^{(1)}=p_{A}^{(1)}-p_{B}^{(1)}$ e $p^{(2)}=p_{A}^{(2)}-p_{B}^{(2)}$ são calculadas. Com elas, pode-se obter as estimativas de média $(\bar{p})$ e variância $\left(s^{2}\right)$ das diferenças, segundo as equações abaixo:

$$
\bar{p}=\frac{p^{(1)}+p^{(2)}}{2} ; s^{2}=\left(p^{(1)}-\bar{p}\right)^{2}+\left(p^{(2)}-\bar{p}\right)^{2}
$$

A estatística utilizada neste teste é chamada de $\tilde{t}$ pareada de $5 \times 2 C V$ e é definida pela Equação 3.6, sendo $p_{1}^{(1)}$ o valor de $p^{(1)}$ para a primeira repetição e $s_{i}^{2}$ o valor de $s^{2}$ para a $i$-ésima repetição. Considerando a hipótese nula de que os classificadores têm desempenho igual, ela tem aproximadamente uma distribuição $t$ de Student com 5 graus de liberdade (Dietterich, 1998).

$$
\tilde{t}=\frac{P_{1}^{(1)}}{\sqrt{\frac{1}{5} \sum_{i=1}^{5} s_{i}^{2}}}
$$


Para determinar se há diferença entre $A$ e $B$, calcula-se $\tilde{t}$ e compara-se o resultado com o valor tabelado da distribuição $t$, dado um nível de significância estatística. Se o valor calculado for maior que o valor tabelado, então rejeita-se a hipótese nula e conclui-se que o desempenho dos classificadores é diferente.

\subsubsection{Comparação de classificadores em dados de expressão gênica}

Durante o desenvolvimento do presente trabalho, houve uma preocupação em como comparar adequadamente algoritmos de AM para a classificação de dados de expressão gênica, a fim de detectar a existência de diferenças de desempenho. Assim, buscou-se verificar na literatura especializada as práticas estabelecidas, com atenção particular à aplicação de testes estatísticos nas avaliações. Infelizmente, na maioria dos trabalhos encontrados, os resultados obtidos são reportados sem considerações sobre sua significância, mesmo em estudos de cunho comparativo. De fato, Boulesteix et al. (2008) recentemente revisaram alguns trabalhos tidos pelos autores como abrangentes, com foco na metodologia e não comprometidos com um algoritmo específico. Todos os cinco artigos revisados não incluíam considerações estatísticas acerca de seus resultados.

Atentos à difusão de publicações com tal ausência, Berrar et al. (2006) discutiram as dificuldade conceituais envolvendo a comparação de classificadores no contexto de dados genômicos com reduzido número de exemplos. Assuntos como taxas de erro observadas versus reais, taxas de erros versus a significância das diferenças e correção para múltiplos testes foram abordados. Os autores enfatizaram que a correta apreciação estatística dos resultados é importante para agregar um maior valor às conclusões obtidas. Coerentes com os pontos apresentados por Berrar et al. (2006), dois estudos comparativos recentes foram realizados (Souza et al., 2010b; Statnikov et al., 2008). O primeiro exibe os resultados de uma abrangente investigação envolvendo 7 classificadores avaliados sobre 65 bases de dados de expressão gênica utilizando o método averaged over sorted runs (Bouckaert, 2004) combinado com o teste de Holm (Berrar et al., 2006) para validar estatisticamente suas conclusões. O segundo comparou o desempenho de SVMs e RFs em 22 bases de microarrays utilizando um teste não paramétrico de permutação (Menke e Martinez, 2004).

\subsection{Considerações Finais}

Neste capítulo, apresentou-se uma visão geral de alguns tópicos de AM supervisionada. Depois de uma breve exposição acerca de conceitos 
básicos de classificação, alguns paradigmas foram discutidos, com exemplos de algoritmos relevantes em cada caso. Para determinar o desempenho das hipóteses induzidas pelas diversas abordagens, foram comentados métodos capazes de estimar a capacidade de generalização das mesmas. Uma vez calculadas as estimativas de desempenho, pode-se comparar os classificadores de forma estatisticamente significante, aplicando-se, por exemplo, os testes sucintamente discutidos ao final do capítulo. 


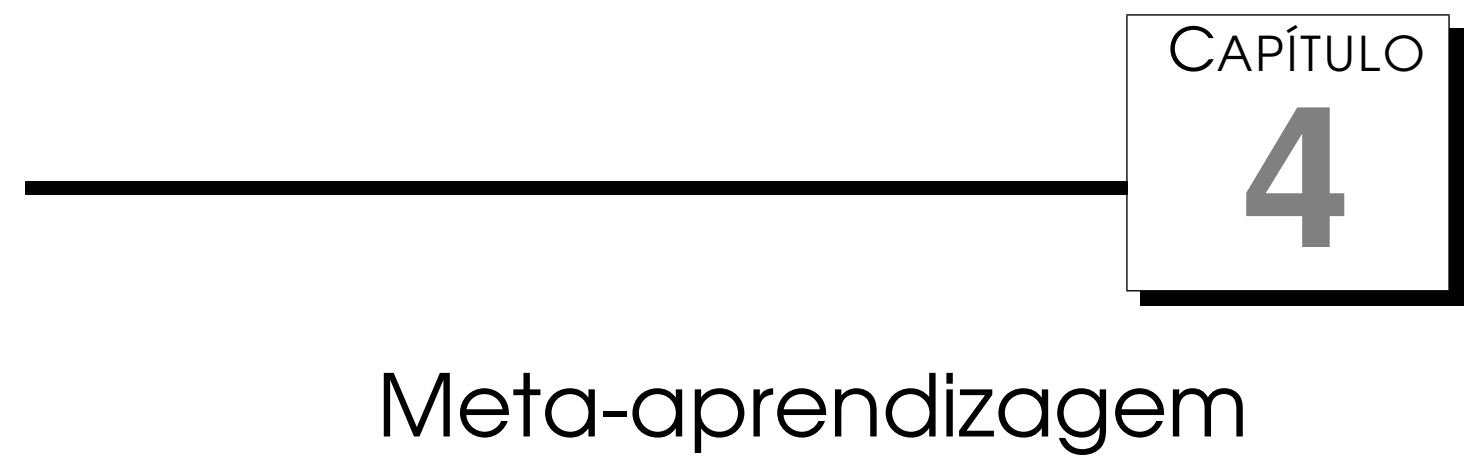

\subsection{Considerações iniciais}

A meta-aprendizagem estuda como os algoritmos de AM podem aumentar sua eficiência por meio da experiência (Vilalta e Drissi, 2002). O objetivo é entender como o próprio processo de aprendizagem pode se tornar flexível de acordo com a natureza da tarefa considerada. Todos os algoritmos de AM funcionam adaptando seus parâmetros a um ambiente específico (Mitchell, 1997). A meta-aprendizagem difere da aprendizagem convencional, de base, no escopo de seu nível de adaptação. Enquanto a AM tradicional trabalha sobre um conjunto de dados por vez, a aprendizagem no meta-nível é baseada no acúmulo de experiência do desempenho de múltiplas aplicações de um algoritmo de AM. De maneira geral, pode-se dizer que a meta-aprendizagem tem interesse em focar na relação entre estratégias de aprendizagem e problemas (Vilalta et al., 2005).

Dentre as aplicações mais comuns de meta-aprendizagem, tem-se o problema de gerar regras capazes de relacionar o desempenho de algoritmos de AM com as propriedades das bases de dados (Brazdil et al., 2009). Em termos práticos, isso poderia ajudar na criação de sistemas que fornecessem ao usuário sugestões sobre que algoritmos utilizar em determinadas situações. Tais sistemas, segundo Kalousis (2002), podem ser estudados segundo 4 critérios:

- Caracterização de bases de dados;

- Medidas de avaliação; 
- Formas de sugestão;

- Métodos de construção de sugestão.

Esses critérios serão apresentados no decorrer do capítulo.

O capítulo é organizado como segue. Na Seção 4.2, o problema de recomendação de algoritmos é formalizado e sua relação com meta-aprendizagem é estabelecida. Nela também se apresenta o vocabulário que será utilizado no decorrer do trabalho. Na Seção 4.3, as abordagens para a caracterização das bases de dados são discutidas. Na Seção 4.4, as medidas de desempenho dos classificadores, nas quais a sugestão pode ser baseada, são comentadas. Na Seção 4.5, as formas como a sugestão deve se apresentar ao usuário é abordada. Na Seção 4.6, é tratado o tema de métodos de construção, que aborda como realizar o mapeamento entre as propriedades das base de dados e o desempenho dos classificadores. Por fim, na Seção 4.7, há as conclusões do capítulo.

\subsection{Recomendação de algoritmos}

Com o avanço das pesquisas em AM, vários métodos e algoritmos têm se tornado disponíveis. Para que ferramentas baseadas nesses abordagens resultem em soluções apropriadas às necessidades do usuário, elas devem ser cuidadosamente escolhidas de acordo com a natureza da tarefa considerada. Isso ocorre porque cada algoritmo possui a chamada superioridade seletiva (Brodley, 1995), segundo a qual ele pode desempenhar melhor que seus pares em uma determinada classe de tarefas. Assim, existe uma necessidade de se relacionar o bias indutivo de cada algoritmo de AM à morfologia dos dados em questão. Esse cenário foi modelado formalmente por Rice (1976), que apresentou a seguinte definição para o problema de seleção de algoritmos:

Para uma determinada instância de problema $x \in P$, com características $f(x) \in F$, encontre o mapeamento $S(f(x))$ no espaço de algoritmos $A$, tal que o algoritmo selecionado $\alpha \in A$ maximize o mapeamento de desempenho $y(\alpha(x)) \in Y$.

Considerando-se os espaços $P$ de problemas, $A$ de algoritmos e $Y$ de desempenhos, a solução trivial para lidar com a situação emprega a interação de aconselhamento especializado com experimentação computacional custosa, resultando insatisfatória em diversos aspectos (Soares, 2004). Além disso, ela não é capaz de determinar automaticamente o $S$, impedindo um aproveitamento sistemático de conhecimento acumulado no passado para a resolução de problemas semelhantes no futuro. Pela utilização 
de meta-aprendizagem, é possivel aprender tal mapeamento, propiciando a construção de sistemas de recomendação eficientes e efetivos.

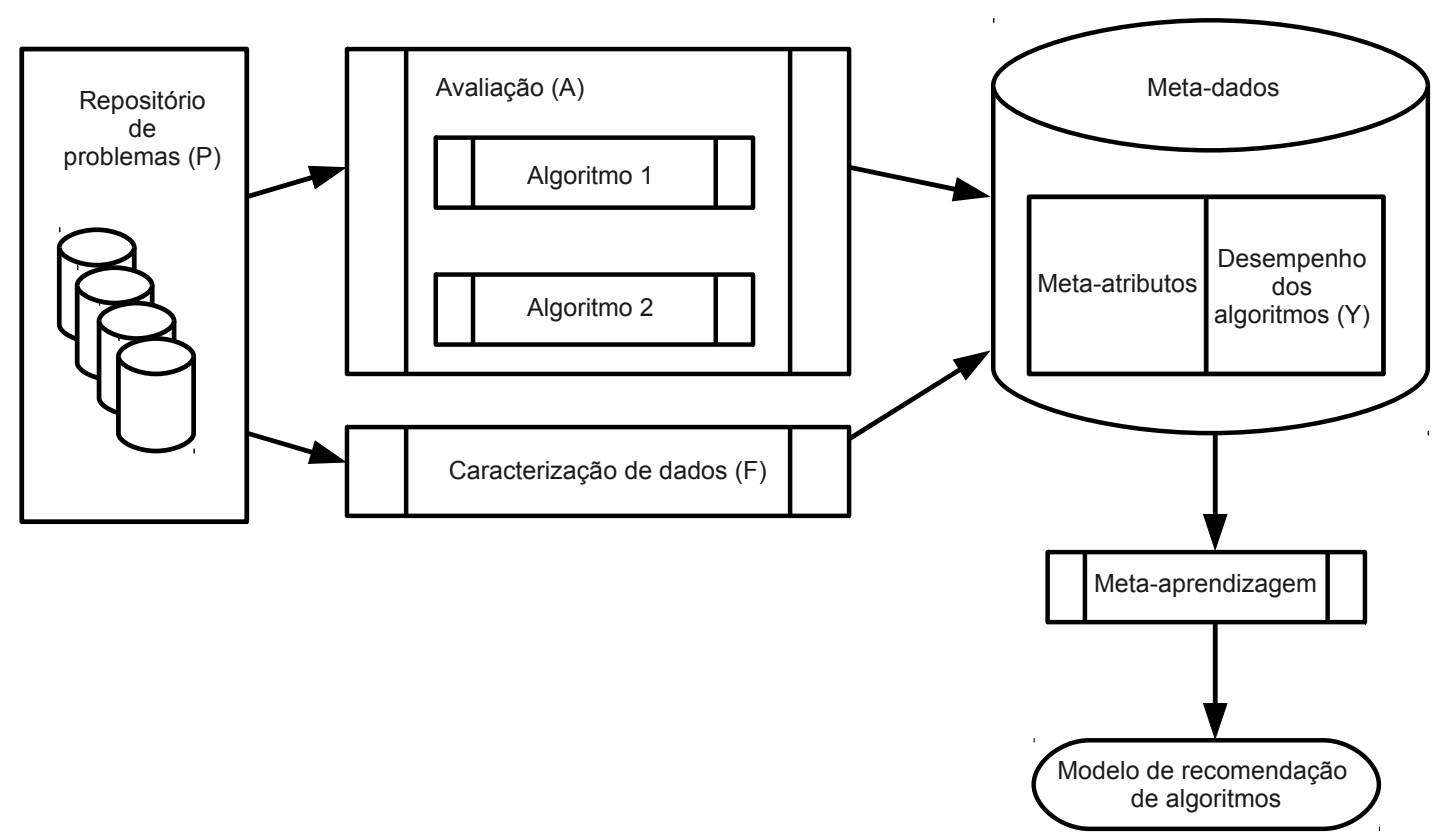

Figura 4.1: Processo de recomendação de algoritmos utilizando meta-aprendizagem. Adaptado de (Brazdil et al., 2009)

O arcabouço genérico do processo de recomendação por meta-aprendizagem é ilustrado na Figura 4.1. O processo inicia-se com a aquisição de um conjunto apropriado de problemas que sejam representativos daqueles para os quais a recomendação posterior será realizada. Ele representa o espaço $P$ na definição de Rice. Em seguida, duas etapas são aplicadas a cada elemento de $P$ : a avaliação dos algoritmos em $A$ e a extração de características segundo as medidas em $F$. Idealmente, a caracterização dos problemas deve ser preditiva quanto ao comportamento dos algoritmos. Associando-se essas duas informações para cada problema, obtém-se um meta-exemplo, formado por meta-atributos de entrada e meta-atributos alvo $(Y)$, respectivamente. Ao conjunto dos meta-exemplos disponíveis, dá-se o nome de meta-dados. Para induzir então o mapeamento $S$ entre meta-atributos de entrada e meta-atributos alvo, aplica-se um algoritmo de AM, referido como meta-aprendiz. Por meio dele, pode-se utilizar o meta-conhecimento obtido do processo de aprendizagem e realizar, por fim, a recomendação de algoritmos no contexto de meta-aprendizagem.

Nas próximas seções deste capítulo, as particularidades necessárias para a utilização adequada da abordagem ilustrada na Figura 4.1 serão apresentadas. 


\subsection{Caracterização de bases de dados}

Caracterizar bases de dados consiste em identificar e extrair propriedades que, possivelmente, afetem o desempenho dos algoritmos de classificação. O objetivo da caracterização é fornecer informações morfológicas dos dados para a aplicação de técnicas de meta-aprendizagem. Isto é possível devido ao conhecimento a priori do comportamento dos algoritmos, sob um determinado aspecto. Por exemplo, alguns algoritmos não operam satisfatoriamente na presença de atributos irrelevantes (Aha, 1989), como o $k \mathrm{NN}$ (Duda et al., 2000), enquanto outros, como Redes Neurais (Haykin, 1998) e SVMs (Vapnik, 1995), possuem mecanismos internos de seleção/ponderação de atributos, fazendo com que sejam mais robustos (Haykin, 1998). Outro exemplo é o algoritmo Naive Bayes (Duda et al., 2000), que pressupõe a independência dos atributos e, por isso, não lida bem com atributos redundantes (Langley e Sage, 1994). Com observações como essas, compreende-se a importância de considerar medidas que explorem as particularidades dos dados a fim de entender o desempenho dos algoritmos de classificação.

De acordo com Soares et al. (2004), as medidas que caracterizam as bases de dados devem conter informação relevante para determinar o desempenho relativo entre os algoritmos de classificação e apresentar baixo custo computacional. Atualmente, a pesquisa em caracterização concentra-se em três áreas (Vilalta et al., 2005):

- Caracterização direta;

- Caracterização baseada em landmarking;

- Caracterização via modelos.

A seguir, uma breve explanação acerca dessas abordagens é fornecida.

\subsubsection{Caracterização direta}

Um dos primeiros esforços sistemáticos e em larga escala para tentar relacionar as medidas que caracterizam as bases de dados e o desempenho dos algoritmos foi empreendido no projeto STATLOG (Michie et al., 1994). Entre outros objetivos, o projeto pesquisou porque certos algoritmos classificavam bem em alguns domínios e apenas regular em outros. Seus experimentos foram realizados utilizando 23 algoritmos e 21 bases de dados. As medidas, ou meta-atributos, utilizadas para caracterizar as bases de dados, foram divididas em três categorias: simples, estatísticas e baseadas na teoria da informação. Os meta-atributos simples incluem medidas gerais das bases de dados, como o número de atributos e o número de exemplos, entre 
outras. Os estatísticos aplicam conceitos como os coeficientes médios de assimetria e curtose, etc aos atributos numéricos. As medidas baseadas na teoria da informação são utilizadas para caracterizar os atributos nominais e sua relação com o atributo classe. A Tabela 4.1 informa todas as medidas consideradas no STATLOG ${ }^{1}$. Extensões posteriores ao projeto foram propostas por Lindner e Studer (1999) e por Sohn (1999).

Tabela 4.1: Medidas utilizadas no STATLOG, separadas por categoria.

\begin{tabular}{ll}
\hline Tipo & Descrição \\
\hline \multirow{3}{*}{ Simples } & Número de exemplos \\
& Número de atributos \\
& Número de classes \\
& Número de atributos binários \\
\hline \multirow{3}{*}{ Estatísticas } & Razão média entre desvio padrão dos atributos \\
& Correlação média absoluta entre atributos, por classe \\
& Primeira correlação canônica \\
& Proporção de variância explicada pelo 1o discriminante canônico \\
& Assimetria média absoluta dos atributos \\
& Curtose média dos atributos \\
\hline \multirow{2}{*}{ Informação } & Entropia normalizada das classes \\
& Entropia média dos atributos \\
& Informação mútua média entre classe e atributos \\
& Razão sinal/ruído
\end{tabular}

Mais recentemente, o projeto METAL (www.metal-kdd.org) visou o desenvolvimento de ferramentas que auxiliem o usuário a selecionar uma combinação adequada de técnicas de pré-processamento, classificação e regressão. O projeto fomentou o desenvolvimento de várias abordagens relacionadas à pesquisa em meta-aprendizagem, especialmente em relação a:

- Formas apropriadas de meta-aprendizagem;

- Definição de meta-atributos para caracterizar as bases de dados e o desempenho dos algoritmos;

- Estudos empíricos e teóricos em meta-aprendizagem.

Uma das abordagens para a caracterização das bases de dados consistiu em estender as medidas utilizadas no STATLOG. As medidas extras utilizadas podem ser vistas na Tabela 4.2 .

Outras contribuições importantes para a caracterização podem ser encontradas em (Soares, 2004) (Kalousis, 2002) e referências ali contidas.

\footnotetext{
${ }^{1}$ Todas as medidas STATLOG foram calculadas segundo as definições apresentadas no apêndice de (Kalousis, 2002)
} 
Tabela 4.2: Medidas extras utilizadas no METAL, separadas por categoria.

\begin{tabular}{ll} 
Tipo & Descrição \\
\hline \multirow{2}{*}{ Simples } & $\begin{array}{l}\text { Número de atributos nominais } \\
\text { Número de atributos numéricos }\end{array}$ \\
\hline & $\begin{array}{l}\text { Número de atributos com outliers } \\
\text { Estatística M de Box }\end{array}$ \\
\multirow{2}{*}{ Estatísticas } & $\begin{array}{l}\text { Graus de liberdade da Estatística M } \\
\text { Valor de Lambda de Wilk } \\
\\
\text { Estatística V de Barlett }\end{array}$ \\
\hline Informação & Entropia conjunta de classe e atributos \\
\hline
\end{tabular}

\subsubsection{Landmarking}

Pfahringer et al. (2000) introduziram uma técnica de caracterização de bases de dados baseada no desempenho de algoritmos de classificação. Segundo os autores, cada algoritmo opera satisfatoriamente em uma determinada área de competência, ou seja, junto a um certo tipo de dados. Assim, por meio da aplicação de algoritmos simples, chamados landmarkers, seria possível obter informação importante sobre a natureza do domínio em que eles são aplicados. Portanto, uma base de dados poderia ser descrita pela coleção de áreas de competência às quais ela pertence. Landmarking consiste da aplicação de landmarkers a bases de dados a fim de localizá-las em um espaço onde áreas de competências estão inseridas, o espaço de competências.

O landmarking é utilizado para determinar a proximidade de uma base de dados em relação a outras, através da similaridade de desempenho dos landmarkers. Com isso, forma-se uma vizinhança de áreas de competência, onde bases de dados podem ser representadas. Espera-se que bases de dados de natureza semelhante pertençam às mesmas áreas de competência e, por conseguinte, sejam adequadas à aplicação dos mesmos algoritmos de classificação. Aos algoritmos de meta-aprendizagem cabe explorar quão bem as informações dos landmarkers podem ser utilizadas para localizar as bases de dados no espaço de competências.

Um exemplo de utilização de landmarking como técnica de caracterização de dados em meta-aprendizagem é fornecido por Bensusan e Giraud-Carrier (2000a). No estudo, os autores selecionaram sete algoritmos simples com diferentes mecanismos de funcionamento para atuar como landmarkers e dez algoritmos complexos para servir de sugestão à classificação final dos dados. Os landmarkers foram utilizados como meta-atributos por um esquema de meta-aprendizagem para aprender e sugerir o algoritmo complexo mais apropriado para aplicação em uma base de dados. Os experimentos do trabalho compararam o landmarking e diferentes medidas envolvendo a caracterização direta, apresentada na subseção anterior, e indicaram o potencial da nova abordagem. 


\subsubsection{Caracterização via modelos}

Uma forma alternativa de representar bases de dados utilizando algoritmos de classificação é fornecida pela caracterização via modelos (Bensusan et al., 2000) (Peng et al., 2002) (Bensusan, 1998). Diferente da abordagem anterior, landmarking, a caracterização via modelos não considera diretamente medidas de desempenho do classificador induzido e sim a estrutura do próprio classificador, conhecida como a hipótese induzida ou modelo. Segundo Vilalta et al. (2005), há diversas vantagens neste tipo de caracterização, dentre as quais destacam-se: a base de dados é resumida em uma estrutura que contém informações sobre a complexidade e desempenho do modelo e; a representação dos dados nessa forma pode servir de base para explicar o desempenho do algoritmo de aprendizagem.

A utilização de modelos para a caracterização de bases de dados realiza uma mudança no espaço de busca do algoritmo de meta-aprendizagem, passando do espaço de exemplos para o espaço de hipóteses do algoritmo de caracterização (Bensusan et al., 2000). Como esse, idealmente, é capaz de realizar uma busca eficiente em seu rico espaço de hipóteses, espera-se que a utilização da hipótese induzida comprima a base de dados original de forma a oferecer meta-atributos mais informativos ao algoritmo de meta-aprendizagem.

Dentre os algoritmos de classificação, as árvores de decisão são as mais utilizadas para realizar a caracterização de bases de dados. Segundo Bensusan et al. (2000), há evidências empíricas que apontaram para importantes conexões entre as propriedades das bases de dados e as estruturas de árvores de decisão não podadas. Além disso, elas têm sido muito estudadas e apresentam comportamento determinístico (Peng et al., 2002), facilitando sua aplicação e entendimento. Como meta-atributos, diversas medidas de uma árvore de decisão podem ser utilizadas, como, por exemplo (Vilalta et al., 2005): o número de nós por atributo, a profundidade máxima da árvore, a sua forma, o grau de balanceamento, etc. Extensões das medidas de árvores são fornecidas por Peng et al. (2002).

\subsubsection{Nova proposta para caracterização}

De acordo com Vilalta (2006), as três abordagens de caracterização comentadas anteriormente têm a limitação de não apresentar uma justificativa convincente que indique a relevância dos meta-atributos gerados em explicar as diferenças de desempenho entre os classificadores. O autor então estudou como descrever melhor os dados tal que fosse possível realizar uma conexão direta entre a distribuição dos exemplos nas bases e as 
estratégias de aprendizagem. Para proceder essa análise, ele identificou subgrupos de exemplos dentro das classes disponíveis e conseguiu, até certo ponto, explicar o comportamento do algoritmo Naive Bayes. Motivado por esse trabalho, estudou-se nesta pesquisa alternativas às medidas tradicionais de caracterização de problemas. O esforço concentrou-se na utilização de técnicas de validação de agrupamentos de dados (Halkidi et al., 2001). A hipótese que se propõe investigar na aqui é que os diferentes índices utilizados para tal fim poderiam explorar aspectos variados da distribuição dos dados que pudessem ser utilizados como base para a construção de meta-atributos adequados. Uma revisão abrangente sobre validação de agrupamento pode ser encontrada em (Halkidi et al., 2001).

De maneira geral, índices de validação são métodos desenvolvidos para avaliar qualitativamente uma partição de dados (Halkidi et al., 2001). Cada um deles opera segundo algum critério para julgar o mérito da estrutura disponível. Há duas categorias mais estudadas de índices de validação (Handl et al., 2005a; Halkidi et al., 2001): externa e interna. No primeiro caso, o objetivo é medir o quanto uma partição confirma uma hipótese pré-estabelecida. Ela é adequada quando a intenção é confrontar os resultados de um algoritmo de agrupamento com a real partição dos dados conhecida. No segundo caso, apenas informações intrínsecas dos dados são utilizadas para a estimação da qualidade. No contexto de expressão gênica, alguns trabalhos enfatizam a necessidade da aplicação de índices de validação para contextualizar os resultados obtidos (Handl et al., 2005a; Bolshakova e Azuaje, 2003).

Neste trabalho, não se faz uso de técnica alguma de agrupamento para gerar as partições. Assume-se que estas sejam conhecidas e disponíveis por meio das classes ou categorias dos exemplos. Aqui, aplica-se índices de validação internos para extrair informações inerentes à distribuição dos dados. Para isso, foram selecionados dez índices, cada um explorando uma faceta do problema, ou, mais propriamente, a mesma faceta de diferentes formas. Todos eles possuem as seguintes propriedades: foram utilizados previamente na análise de dados de expressão gênica, são de cômputo relativamente eficiente, geram valores em intervalos comparáveis para diferentes bases de dados e têm implementação publicamente disponível. A seguir, os índices empregados para realizar a caracterização dos dados são enumerados. Todos eles foram calculados empregando-se como distância entre pontos a Generalized Distance Measure (GDM) (Jajuga et al., 2003), que, em um estudo comparativo no contexto de análise de agrupamentos (Wolters et al., 2009), mostrou-se superior à distância euclidiana comumente utilizada.

1. VDU: O índice proposto por Dunn (Dunn, 1973) baseia-se em 
considerações geométricas a fim de identificar um conjunto de grupos compactos e bem separados. Para tanto, ele é definido utilizando-se a razão entre distâncias inter e intra grupos, como expresso na Equação 4.1, para uma partição $U \longleftrightarrow X=X_{1} \cup \ldots X_{c}$ :

$$
\operatorname{VDU}(U)=\min _{1 \leq i \leq c}\left\{\min _{1 \leq j \leq c, i \neq j}\left\{\frac{\delta\left(X_{i}, X_{j}\right)}{\max _{1 \leq k \leq c} \Delta\left(X_{k}\right)}\right\}\right\}
$$

onde $c$ é o número de grupos, $\delta\left(X_{i}, X_{j}\right)$ define a distância entre os grupos $X_{i}$ e $X_{j}$ e $\Delta\left(X_{k}\right)$ representa a distância interna do grupo $X_{k}$. Originalmente, as distâncias utilizadas no índice não eram robustas a ruídos ou a determinadas conformações dos grupos. Para lidar com as dificuldades decorrentes, novas medidas foram introduzidas. Bezdek e Pal (1998a) definiram seis e três medidas inter e intra grupos, respectivamente. Eles concluíram que aquelas que envolvem todos os objetos do grupo para o cálculo do índice são mais robustas e devem ser preferidas. Assim, pela análise dos resultados obtidos naquele trabalho, utilizou-se aqui, dentre as sugeridas, as medidas $\delta_{3}$ e $\Delta_{1}$. Elas são definidas pelas Equações 4.2 e 4.3:

$$
\begin{gathered}
\delta_{3}(S, T)=\frac{1}{|S||T|} \sum_{\substack{\vec{x} \in T \\
\vec{y} \in S}} d(\vec{x}, \vec{y}) \\
\Delta_{1}(S)=\max _{x, y \in S}\{d(\vec{x}, \vec{y})\}
\end{gathered}
$$

onde $S$ e $T$ são grupos, $\vec{x}$ e $\vec{y}$ são pontos pertencentes a esses grupos, $d(\cdot, \cdot)$ é a distância entre 2 pontos e $|\cdot|$ indica a quantidade de pontos no grupo. Este índice assume valores no intervalo $[0,+\infty]$ e deve ser maximizado.

2. VDB: Baseados nos mesmos princípios do trabalho de Dunn, Davies e Bouldin (1979) desenvolveram um índice que busca identificar conjuntos de grupos compactos e bem separados. Eles também utilizaram uma razão entre distâncias em sua definição, conforme pode ser visto na Equação 4.4. É importante ressaltar que a Equação 4.4 é mais flexível que aquela inicialmente proposta, pois nela é possível utilizar outras medidas de distância, assim como foi feito por Bezdek e Pal (1998a) no indice Dunn. Um estudo comparativo de diversas medidas aplicadas a esse índice pode ser encontrado em (Bolshakova e Azuaje, 2003).

$$
\operatorname{VDB}(U)=\frac{1}{c} \sum_{i=1}^{c} \max _{i \neq j}\left\{\frac{\Delta\left(X_{i}\right)+\Delta\left(X_{j}\right)}{\delta\left(X_{i}, X_{j}\right)}\right\}
$$


onde $c$ é o número de grupos, $\Delta\left(X_{i}\right)$ representa a distância interna do grupo $X_{i}$ e $\delta\left(X_{i}, X_{j}\right)$ define a distância entre os grupos $X_{i}$ e $X_{j}$. Novamente, $\delta_{3}$ e $\Delta_{1}$, como definidos nas Equações 4.2 e 4.3, foram considerados para $\delta$ e $\Delta$, respectivamente. Esse índice assume valores em $[0,+\infty]$ e deve ser minimizado.

3. INT: De acordo com os experimentos realizados por Bezdek e Pal (1998b), medidas de separação de grupos são mais importantes no contexto de validação de agrupamentos do que medidas de dispersão de grupos. Com base nessa observação, definiu-se um índice simples que utiliza somente a distância inter grupos para determinar quão boa é a partição $U$ dos dados. Ele é definido pela Equação 4.5:

$$
\operatorname{INT}(U)=\frac{1}{c(c-1) / 2} \sum_{\substack{i, j=1, \ldots, c \\ i<j}} \delta\left(X_{i}, X_{j}\right)
$$

onde $c$ é o número de grupos e $\delta\left(X_{i}, X_{j}\right)$ define a distância entre os grupos $X_{i}$ e $X_{j}$. Novamente, $\delta_{3}$, como definido na Equação 4.2, foi considerada. Esse índice assume valores em $[0,+\infty]$ e deve ser maximizado.

4. CON: Baseia-se em um conceito bastante diverso daquele utilizado nos índices anteriores. Nele, as distâncias inter e intra grupos não são explicitamente utilizadas e sim a informação dos grupos de pontos vizinhos na partição $U \longleftrightarrow X=X_{1} \cup \ldots X_{c}$, de $c$ grupos. Ele é definido no material suplementar de Handl et al. (2005b) e estima, por meio do grau com que pontos vizinhos pertencem ao mesmo grupo, quanto um grupo está conectado a outro. O índice é calculado pela Equação 4.6:

$$
\operatorname{Con}(U)=\sum_{i=1}^{N} \sum_{j=1}^{l} x_{i, n n_{i(j)}}
$$

onde $N$ é o número total de elementos em $X, l$ é o número de vizinhos considerados $^{2} \mathrm{e}$

$$
x_{i, n n_{i(j)}}=\left\{\begin{array}{l}
\frac{1}{j}, \text { se } \nexists X_{k}: i \in X_{k} \wedge n n_{i(j)} \in X_{k} \\
0, \text { caso contrário }
\end{array}\right.
$$

onde $n n_{i(j)}$ é o $j$-ésimo vizinho mais próximo do ponto $\overrightarrow{x_{i}}$. A conectividade assume valores $[0,+\infty]$ e deve ser minimizada.

5. N-1: Essa medida é utilizada para verificar se pontos de dois grupos $X_{i}$ e $X_{j}$ vêm da mesma distribuição de dados, segundo o teste proposto por Friedman e Rafsky (1979). Ele opera construindo o grafo da Árvore

\footnotetext{
${ }^{2}$ Aqui, fez-se $l$ igual à raiz quadrada da cardinalidade do conjunto $X_{i}$ com menos pontos, adaptando assim a heurística disponivel em (Duda et al., 2000).
} 
Geradora Mínima de todos os pontos $x_{i} \in X_{i} \cup X_{j}$ e calculando a proporção de arestas que conectam pontos de grupos distintos, conhecidos como pontos de borda. Segue a hipótese que, em agrupamentos aleatórios ou com grupos fortemente sobrepostos, há muitos pontos de borda. A $\mathrm{N}-1$ foi aplicada no contexto de validação de agrupamentos em (Barzily et al., 2009). Ela também foi relacionada à complexidade de problemas de classificação em geral (Ho e Basu, 2002) e no contexto de dados de expressão gênica (Costa et al., 2009). Pode ser utilizada também para dados com múltiplos grupos. Esse índice assume valores em $[0,1]$ e deve ser minimizado.

6. SIL: A estatística silhueta $s(i)$ Rousseeuw (1987) referente a um ponto $x_{i}$ é um indicador do grau com que o ponto pertence ao grupo qualquer $X_{j}$, $j=1, \ldots, c$. Ela é definida pela Equação 4.8:

$$
s(i)=\frac{b(i)-a(i)}{\max \{a(i), b(i)\}}
$$

onde $a(i)$ é a distância média entre $x_{i}$ e todos os pontos de $X_{j}$ e $b(i)$ é a mínima distância média entre $x_{i}$ e todos os pontos em $X_{k}, k=(1, \ldots, c), k \neq$ $j$. $s(i) \in[-1,1]$, onde valores maiores são indicativos de que o ponto $x_{i}$ está bem agrupado. Para calcular a silhueta $S_{j}$ do grupo $X_{j}$, utiliza-se a Equação 4.9:

$$
S_{j}=\frac{1}{\left|X_{j}\right|} \sum_{x_{i} \in X_{j}} s(i)
$$

O valor da silhueta global para toda a partição $U$, definida anteriormente, é expresso por SIL $(U)$, indicado na Equação 4.10. Ele representa o índice de validação a ser maximizado e assume valores em $[-1,+1]$.

$$
\operatorname{SIL}(U)=\frac{1}{c} \sum_{j=1}^{c} S_{j}
$$

7. G-K: Utiliza estatística de Goodman and Kruskal para avaliar a qualidade de um agrupamento de dados (Baker e Hubert, 1975). Ele é definido sobre o conceito de pares concordantes e discordantes de pontos. Dados um par $P_{1}$ de pontos pertencentes a um mesmo grupo e um par $P_{2}$ de pontos pertencentes a grupos distintos, $P_{1}$ e $P_{2}$ são ditos concordantes caso a distância entre os pontos de $P_{1}$ seja menor que a distância entre os pontos de $P_{2}$. Se a distância entre os pontos de $P_{2}$ for maior que a distância entre os pontos de $P_{1}$, então $P_{1}$ e $P_{2}$ são discordantes. O índice G-K é calculado para uma partição $U$ pela Equação 4.11, onde $S_{+}$é o número de pares concordantes e $S_{-}$é o número de pares discordantes, ambos os valores considerando todas as combinações possivieis de pares de pontos nos pares. Esse índice assume valores no intervalo $[-1,1] \mathrm{e}$ 
deve ser maximizado.

$$
\mathrm{G}-\mathrm{K}(U)=\frac{S_{+}-S_{-}}{S_{+}+S_{-}}
$$

8. P-B. Esse índice, conhecido como Point-Biserial (Milligan e Cooper, 1985), equivale à correlação de Pearson entre 2 variáveis, uma contínua e outra binária. No contexto de validação de agrupamentos, a primeira corresponde à matriz de distâncias entre todos os pares de elementos $\overrightarrow{x_{i}}, \overrightarrow{x_{j}} \in X, i \neq j$ e a segunda à matriz de igual dimensão que indica se $\overrightarrow{x_{i}} \mathrm{e}$ $\overrightarrow{x_{j}}$ pertencem ao mesmo grupo $X_{k}$. Para uma partição $U$, ela é calculada segundo a Equação 4.12:

$$
\mathrm{P}-\mathrm{B}(U)=\frac{\left(d_{b}-d_{w}\right) \sqrt{w_{d} \cdot b_{d} / t^{2}}}{s_{d}}
$$

onde $d_{w}$ é a média das distâncias entre elementos de um mesmo grupo, $d_{b}$ é a média das distâncias entre elementos de grupos distintos, $t=N(N-$ 1)/2 é o número total de pares de elementos ( $N$ é numero de elementos), $s_{d}$ é o desvio padrão dos elementos da matriz de distâncias, $w_{d}=\sum_{l=1}^{c} N_{l}\left(N_{l}-\right.$ 1)/2 é o número de pares de elementos do mesmo grupo ( $N_{l}$ é o número de elementos do grupo $\left.X_{l},=1, \ldots, c\right)$ e $b_{d}=\sum_{l=1}^{c} N_{l}\left(N-N_{l}\right) / 2$ é o número de pares de elementos de grupos distintos. Valores desse índice situam-se no intervalo $[-1,1]$. Valores positivos próximos a 1 indicam uma boa correspondência entre os dados e a partição $U$.

9. H-L: Esse índice, desenvolvido por Hubert e Levin (1976), é baseado na noção de distâncias intra grupo, assim como em seus valores mínimos e máximos possíveis. Ele é calculado utilizando-se a Equação 4.13:

$$
\mathrm{H}-\mathrm{L}(U)=\frac{S-S_{\min }}{S_{\max }-S_{\min }}
$$

onde $S$ é o somatório das $w_{d}=\sum_{l=1}^{c} N_{l}\left(N_{l}-1\right) / 2$ distâncias entre elementos de mesmo grupo, $S_{\min }$ é o somatório das $w_{d}$ menores distâncias entre quaisquer pares de elementos e $S_{\min }$ é o somatório das $w_{d}$ maiores distâncias entre quaisquer pares de elementos. Por sua definição, percebe-se que o índice $H L(U)$ avalia a situação em que pares com pequena distância entre seus elementos estejam no mesmo grupo. O denominador serve apenas como fator de normalização. Este índice assume valores em $[0,1]$ e deve ser minimizado.

10. C-H: Esse índice foi proposto por Calinski e Harabasz (1974). Ele é baseado na noção de coesão interna dos grupos e isolamento externo 
dos mesmos. Ele é definido pela Equação 4.14, para uma partição $U$ :

$$
\mathrm{C}-\mathrm{H}(U)=\frac{\operatorname{traço}(\mathbf{B})}{\operatorname{traço}(\mathbf{W})} \times \frac{N-c}{c-1}
$$

onde $c$ é o número de grupos, $N$ é o número de elementos nos grupos $X$ e $W$ e $B$ são as matrizes de dispersão intra e inter grupos, respectivamente. Elas são definidas pelas Equações 4.15, 4.16 e 4.17.

$$
\begin{gathered}
\mathbf{W}=\sum_{l=1}^{c} \mathbf{W}_{l} \\
\mathbf{W}_{l}=\sum_{x_{i} \in C_{l}}\left(\overrightarrow{x_{i}}-\overrightarrow{z_{l}}\right)\left(\overrightarrow{x_{i}}-\overrightarrow{z_{l}}\right)^{T} \\
\mathbf{B}=\sum_{l=1}^{c} N_{l}\left(\overrightarrow{x_{l}}-\vec{z}\right)\left(\overrightarrow{x_{l}}-\vec{z}\right)^{T}
\end{gathered}
$$

onde $N_{l}$ é o número de elementos do grupo $X_{l}, l=1, \ldots, c, \overrightarrow{z_{l}}$ é ponto mais representativo de $X_{l}$ e $\vec{z}$ é o ponto mais representativo de $X$. Como a intenção é privilegiar partições com grupos coesos (pequeno denominador na Equação 4.14) e isolados (grande numerador na Equação 4.14), o índice deve ser maximizado. Ele assume valores no intervalo $[0,+\infty]$.

Embora a aplicação dos índices de validação às matrizes completas de expressão gênica possa, a princípio, ser realizada, ela não é aconselhável. O principal motivo é a alta dimensionalidade dos dados em relação ao pequeno número de exemplos disponíveis. Nessa situação, as reais diferenças fenotípicas dos genes e amostras de tecidos podem ser mascaradas (D'haeseleer, 2005). Por exemplo, agrupamentos feitos utilizando todos os genes disponiveis podem não ser significantes, enquanto que, quando apenas subconjuntos selecionados de genes são empregados, a probabilidade de que novos conhecimentos sejam descobertos é maior (Ben-Dor et al., 2001).

Para limitar o número de genes com um mínimo de perda de informação, pode-se utilizar técnicas de redução de dimensionalidade. Há, basicamente, duas abordagens para isso (Liu e Motoda, 1998): a extração de atributos e a seleção de atributos. A primeira consiste em criar novos atributos a partir de transformações e combinações dos atributos existentes. A segunda consiste em selecionar um subconjunto ótimo de atributos, segundo algum critério pré-estabelecido Essa última abordagem é vantajosa quando há a necessidade de isolar genes específicos que estão de alguma forma relacionados com o fenômeno em estudo. Quando a intenção é avaliar a informação global disponivel nos dados, sem descartar genes, a primeira abordagem é mais atrativa (Dai et al., 2006).

Portanto, antes da aplicação dos índices de validação apresentados nas 
Equações 4.1 a 4.17, os dados são reduzidos por um método de extração de atributos. Duas abordagens são consideradas, devido a seu bom desempenho em dados de expressão gênica e a sua eficiência computacional (Li et al., 2008; Boulesteix e Strimmer, 2007; Dai et al., 2006): Principal Component Analysis (PCA) (Jolliffe, 2002) e Partial Least Squares (PLS) (Wold et al., 2001). Ambas as técnicas operam por meio da construção de combinações lineares ortogonais tal que determinados critérios objetivos sejam otimizados. A diferença básica entre elas é que o PCA não utiliza informação sobre a classe dos exemplos para a definição dos componentes do espaço de menor dimensionalidade, enquanto o PLS o faz.

Nos experimentos realizados no Capítulo 5, a caracterização dos dados será realizada sobre o espaço de dimensão reduzida construído tanto por PCA quanto por PLS.

\subsection{Medidas de avaliação}

Para determinar qual algoritmo de AM utilizar em um determinado conjunto de dados, é necessário especificar as medidas de desempenho consideradas, para que uma lista de preferência dos algoritmos possa ser estabelecida. Diversas medidas podem ser utilizadas. Recentemente, Caruana e Niculescu-Mizil (2006) realizaram um estudo comparando vários algoritmos de AM supervisionada levando em conta diferentes medidas de desempenho, dentre as quais tem-se a acurácia/erro, a área sob as curvas ROC, F-Score, error médio quadrático, etc. Os autores reportaram que a utilização múltiplas medidas podem permitir a exploração de várias facetas do classificador. Além de medidas relacionadas com as predições feitas pelos classificadores, em alguns domínios outras medidas podem ser interessantes, como, por exemplo, o tempo requerido para o algoritmo de AM construir um classificador, o tempo requerido para o classificador rotular um exemplo, a quantidade de memória requerida pelo algoritmo e a simplicidade e interpretabilidade dos classificadores construídos, entre outras.

Embora a utilização de apenas uma medida de avaliação seja a prática mais comum em meta-aprendizagem, é possivel utilizar abordagens multi-objetivas, em que duas ou mais medidas são combinadas. Por exemplo, o usuário pode estar interessado no compromisso entre tempo de treinamento e acurácia, preferindo algoritmos mais rápidos mesmo que ligeiramente menos acurados. Nesse caso, é preciso mapear os valores das medidas em um único valor, a fim de definir a lista de preferência entre os algoritmos. Soares e Brazdil (2000), por exemplo, utilizaram como critério uma medida chamada Adjusted Ratio of Ratios, que combina acurácia e tempo de execução. Uma abordagem 
mais flexível foi proposta por Nakhaeizadeh e Schnabl (1997). Ela permite a incorporação de qualquer quantidade de medidas de avaliação.

Nos experimentos realizados no Capítulo 5, a medida utilizada para avaliar o desempenho dos algoritmos de AM será o erro obtido pelo estimador .632+, comentado no Capítulo 4.

\subsection{Formas de sugestão}

De acordo com Kalousis (2002), de maneira geral, há três abordagens para sugerir algoritmos para a apreciação do usuário. A primeira consiste em fornecer o melhor algoritmo, ou seja, aquele que produza, supostamente, o melhor modelo para uma dada tarefa ou base de dados, segundo algum critério. Exemplos de sua utilização podem ser encontrados em (Koepf et al., 2000) e (Bensusan e Giraud-Carrier, 2000b). Uma crítica a essa abordagem refere-se à eventual não disponibilidade do algoritmo em um dado momento, impossibilitando sua aplicação. A segunda abordagem é mais flexível, indicando, dentre os algoritmos considerados, o conjunto de algoritmos que apresentam melhor estimativa de desempenho na base de dados. Nesse conjunto, além do melhor algoritmo, estão presentes os algoritmos que não possuam desempenho estatisticamente inferior ao melhor (Peng et al., 2002). No projeto STATLOG, as sugestões eram apresentadas dessa forma. A terceira abordagem exibe os algoritmos em ordem de preferência com relação à base de dados. O critério de ordenação pode ser simplesmente a acurácia dos classificadores, como em (Bensusan e Kalousis, 2001), ou medidas mais complexas, que envolvem múltiplos objetivos, tais como tempo de execução do algoritmo ou a interpretabilidade do modelo gerado, conforme visto na subseção anterior.

Dada sua flexibilidade, a disposição dos algoritmos em forma de rankings será considerada no decorrer deste trabalho. Uma exposição acerca dos métodos de construção de rankings é apresentada na próxima seção.

\subsection{Construção de sugestão}

Em geral, um ranking representa uma função de preferência sobre um conjunto de itens (Brazdil et al., 2009). Neste trabalho, os itens são os algoritmos de AM utilizados para a classificação dos dados de expressão gênica, enquanto que a função de preferência expressa o desempenho esperado dos algoritmos em uma base de dados, tal que, se um algoritmo apresentar melhores resultados que outro, ele deve ser representado em posição mais alta no ranking. No contexto de meta-aprendizagem estudado 
aqui, o objetivo é aprender uma relação implícita entre os meta-atributos de entrada e os rankings do meta-atributo alvo. Há três paradigmas mais comuns para a realização de tal tarefa. Eles serão discutidas a seguir. Alternativas podem ser encontradas em (Brazdil et al., 2009).

\subsubsection{Ranking por vizinhos mais próximos}

O algoritmo $K$ nearest neighbors $(k N N)$ (Duda et al., 2000) foi adaptado para a tarefa de aprender rankings e foi aplicado a problemas de meta-aprendizagem com relativo sucesso (vide (Brazdil et al., 2009) e referências ali contidas). Em classificação com atributo alvo único, ele opera selecionando, no conjunto do treinamento, os $k$ exemplos mais similares a um exemplo de teste qualquer e combinando suas classes para prover a nova predição. Quando o atributo alvo apresenta-se na forma de ranking, os $k$ rankings dos exemplos selecionados necessitam ser agregados para formar o ranking do exemplo de teste. Uma abordagem simples para isto é considerar o método Average Ranks (AR) (Brazdil et al., 2009). Seja $R_{i, j}$ a posição no ranking do algoritmo $a_{j}(j=1, \ldots, n)$ na base de dados $i$, onde $n$ é o número de algoritmos. A posição média no ranking para cada $a_{j}$ é dada por:

$$
\bar{R}_{j}=\frac{\sum_{i=1}^{k} R_{i, j}}{k}
$$

O ranking predito é obtido ordenando-se os valores de $\bar{R}_{j}$ e ajustando suas posições de acordo.

Uma extensão do método de ranking por $k \mathrm{NN}$ foi desenvolvida neste projeto. Ela baseia-se na intuição de que, entre os $k$ exemplos do conjunto de treinamento vizinhos do exemplo de teste, os mais próximos devam ter maior influência na formação do ranking. Esta extensão é uma adaptação do weighted $k$-Nearest Neighbor ( $w K N N$ ) (Hechenbichler e Schliep, 2006), que foi proposto para classificação com atributo alvo único, para lidar com atributo alvo do tipo ranking. O $w k \mathrm{NN}$ pondera a influência de cada vizinho na classificação do exemplo de teste transformando as distâncias até ele em medidas de similaridade, que por sua vez são utilizadas como pesos. Esta transformação é realizada pela utilização de funções de kernel $K(\cdot)$, que operam sobre uma distância $d$ entre o exemplo de teste e um vizinho. Ela atinge valor máximo quando $d=0$ e decresce à medida que $d$ cresce. Respeitando algumas propriedades pertinentes à definição de kernel (Li e Racine, 2006), a seguir tem-se algumas das funções $K(\cdot)$ mais comuns: 


$$
\begin{gathered}
\text { Retangular }: \frac{1}{2} \cdot I(|d| \leq 1) \\
\text { Triangular }:(1-|d|) \cdot I(|d| \leq 1) \\
\text { Epanechnikov }: \frac{3}{4}\left(1-d^{2}\right) \cdot I(|d| \leq 1) \\
\text { Gauss }: \frac{1}{\sqrt{2 \pi}} e^{\left(-\frac{d^{2}}{2}\right)} \cdot I(|d| \leq 1)
\end{gathered}
$$

Pode-se perceber, pela definição dos 4 kernels considerados, que os valores de $d$ necessitam estar dentro de um certo intervalo para que as similaridades produzidas sejam comparáveis. Isto é obtido pela normalização das distâncias $d$ em relação à distância do $k+1$-ésimo vizinho mais próximo do exemplo de teste. Assim, as distâncias $d_{i}, i=1, \ldots, k$ são transformadas em $\hat{d}_{i}, i=1, \ldots, k$, fechadas no intervalo [0,1], pela Equação 4.20:

$$
\hat{d}_{i}=\frac{d_{i}}{d_{k+1}}
$$

Utilizando-se as idéias do $w k \mathrm{NN}$, desenvolveu-se o método de ponderação de rankings denominado wAR (do inglês weighted Average Rank). De maneira similar ao AR, ele utiliza as médias das posições do ranking dos $k$ vizinhos selecionados para compor o ranking predito. A diferença para o wAR é que este utiliza médias ponderadas para tal tarefa. Assim, seja $R_{i, j}$ a posição no ranking do algoritmo $a_{j}(j=1, \ldots, n)$ na base de dados $i$, onde $n$ é o número de algoritmos. A posição média ponderada no ranking para cada $a_{j}$ é dada por:

$$
w \bar{R}_{j}=\frac{\sum_{i=1}^{k} w_{i} * R_{i, j}}{\sum_{i=1}^{k} w_{i}}
$$

O ranking predito é obtido ordenando-se os valores de $w \bar{R}_{j}$ e ajustando suas posições de acordo.

\subsubsection{Ranking por regressão}

No lugar de realizar combinações de rankings como na abordagem anterior, esta tenta predizer diretamente o desempenho de cada algoritmo de AM e, posteriormente, ordenar tais predições para a construção do ranking para o exemplo de teste. Para cada predição, o método utiliza uma técnica de regressão em um arcabouço conhecido como meta-regressão (Brazdil et al., 2009). Isto altera o foco da meta-aprendizagem de classificação para regressão e fornece uma nova perspectiva no assunto. Com isso, na prática, o problema de se obter rankings de algoritmos é dividido em $n$ sub-problemas de predição de desempenho, um para cada algoritmo. Com os $n$ desempenhos preditos, 
pode-se ordená-los e sugerir um ranking para o usuário.

Diferentes algoritmos de regressão têm sido tradicionalmente utilizados como meta-regressores, como árvores de decisão, regressores lineares e métodos baseados em instâncias (vide referências em (Brazdil et al., 2009)). Recentemente, SVMs (Steinwart e Christmann, 2008) apresentaram bom desempenho no contexto em dois trabalhos distintos. Prudêncio et al. (2008) utilizaram SVMs para predizer o desempenho de redes neurais MLP e reportaram que SVMs produziram melhores resultados quando comparados a diferentes algoritmos. Souto et al. (2008) aplicaram SVMs para fornecer rankings de algoritmos de agrupamento. Os bons resultados apresentados nesses trabalhos motivaram o uso de SVMs como meta-regressores aqui. De fato, experimentos realizados com meta-aprendizagem aplicada em classificação de dados de expressão gênica apontaram para um bom potencial de SVMs nesse contexto (Souza et al., 2009).

No Capítulo 5, a exemplo de (Prudêncio et al., 2008), serão utilizados os algoritmos SVM, 1NN, LR e M5 como meta-regressores. Eles foram utilizados para aproximar os desempenhos específicos dos classificadores e para construir rankings dos mesmos.

\subsubsection{Ranking por árvores de decisão}

Enquanto as abordagens anteriores, baseadas em vizinhos mais próximos e em regressão, consideram os algoritmos de AM individualmente para, em seguida, combinar ou suas posições relativas ou estimativas de desempenho para a construção do ranking, métodos baseados em árvores de decisão trabalham com todos os algoritmos base simultaneamente. Assim, eles exploram relações entre os algoritmos que as outras abordagens não podem. Esta informação extra poderia, a princípio, levar à construção de rankings mais acurados. Outro benefício em potencial consiste na capacidade de árvores em claramente expressar o conhecimento aprendido sobre o problema estudado. Portanto, sua estrutura relativamente fácil de compreender poderia ser interpretada por usuários não especialistas, como biólogos e clínicos.

No contexto de recomendação de algoritmos, as árvores foram introduzidas por (Todorovski et al., 2002). Eles propuseram uma variante chamada de Predictive Clustering Tree (PCT). Ela opera identificando partições de dados tal que uma hierarquia de agrupamentos é gerada. Para a indução da árvore, o algoritmo Top-Down Induction of Decision Trees (TDIDT) é utilizado (Bramer, 2007). Ele produz regras de decisão de forma implícita numa árvore, que é então construída por sucessivas divisões dos exemplos de acordo com os valores de seus atributos preditivos, num processo conhecido como particionamento recursivo. Ao final de sua execução, tem-se, supostamente, 
grupos com elementos homogêneos em relação aos atributos alvo, que, no caso de construção de rankings, correspondem à ordem relativa dos algoritmos de AM para cada (meta-)exemplos. Este processo pode ser visto como uma tentativa de maximizar o coeficiente de Spearman dos ranking dos exemplos pertencentes a um dado grupo.

Embora a teoria de PCT vislumbre uma potencial adequação ao problema de recomendação de algoritmos, a prática tem produzido resultados conflitantes. Enquanto Todorovski et al. (2002) reportam a habilidade de PCT de superar o $k \mathrm{NN}$ e o ranking padrão na acurácia de suas predições em problemas de meta-aprendizagem, Rebelo et al. (2008) apresentam um abrangente conjunto de experimentos que contradizem tal afirmação. Os autores deste último estudo creditam a divergência de resultados às diferenças na metodologia empregada. Assim, neste trabalho, interessou-se por investigar se PCT pode ser aplicado com sucesso a problemas de meta-aprendizado para classificação de dados de expressão gênica.

Outra hipótese a ser avaliada neste trabalho é se bagging (Breiman, 1996a) pode ser utilizado para melhorar o desempenho de PCTs, dado que esse método de combinação de algoritmos pode gerar ganhos substanciais quando aplicados a algoritmos instáveis, como árvores de decisão (Dietterich, 2000). Sucintamente, o bagging opera como segue. Inicialmente, são gerados $L$ conjuntos de treinamento com exemplos amostrados com reposição a partir do conjunto de treinamento original $S$, tal que todos os conjunto tenham a mesma cardinalidade de $S$. Devido à maneira como eles são criados, os conjuntos são conhecidos como réplicas bootstrap. A cada réplica é aplicado um algoritmo de AM, no caso uma PCT, tal que $L$ modelos distintos $h_{l}$ sejam induzidos. Eles são então combinados por meio de voto majoritário para construir o comitê final $h^{*}$.

Segundo Dietterich (2000), há três razões para que tais comitês gerados por bagging (entre outros métodos) tendam a apresentar melhor desempenho que abordagens individuais:

1. Estatística. A pequena quantidade de exemplos de uma base de dados faz com que os algoritmos de AM encontrem diversos classificadores com alta acurácia durante o treinamento. Infelizmente, quando novos exemplos são apresentados, a maioria dos classificadores não consegue manter o bom desempenho. Construindo comitês com vários desses classificadores, o algoritmo pode calcular a média de seus votos e reduzir o risco de escolher o classificador errado.

2. Computacional. Muitos algoritmos de AM realizam uma busca local e estão sujeitos à estagnação em mínimos locais. A otimalidade dos algoritmos só poderia ser garantida se o espaço de busca fosse 
inteiramente coberto, o que, na prática, não é factível. Assim, a construção de comitês contendo classificadores gerados a partir de diferentes pontos do espaço de busca permitiria uma melhor estimativa do conceito a ser aprendido.

3. Representational. Em muitas situações, não é possível representar o verdadeiro conceito a ser aprendido utilizando um determinado algoritmo de AM. Entretanto, a simples união de classificadores em um comitê pode expandir o espaço das funções representáveis, aumentado a probabilidade de estimar tal conceito mais precisamente.

\subsection{Considerações finais}

Neste capítulo, apresentou-se a meta-aprendizagem de maneira genérica, assim como sua utilização para a recomendação de algoritmos. Foram abordados os tópicos de caracterização de bases de dados, medidas de avaliação, formas de sugestão e como relacioná-los. Os conceitos comentados serão utilizados durante este trabalho para sugerir ao usuário opções de classificação de dados de expressão gênica. Foram ainda discutidas as abordagens desenvolvidas neste trabalho: as medidas de caracterização de dados baseadas em índices de validação, uma extensão do método de $k \mathrm{NN}$ que pondera as distâncias dos vizinhos para realizar a construção dos rankings, a utilização de SVMs como meta-regressores no contexto de problemas de classificação, e a utilização de bagging para a construção de comitês de PCTs. 


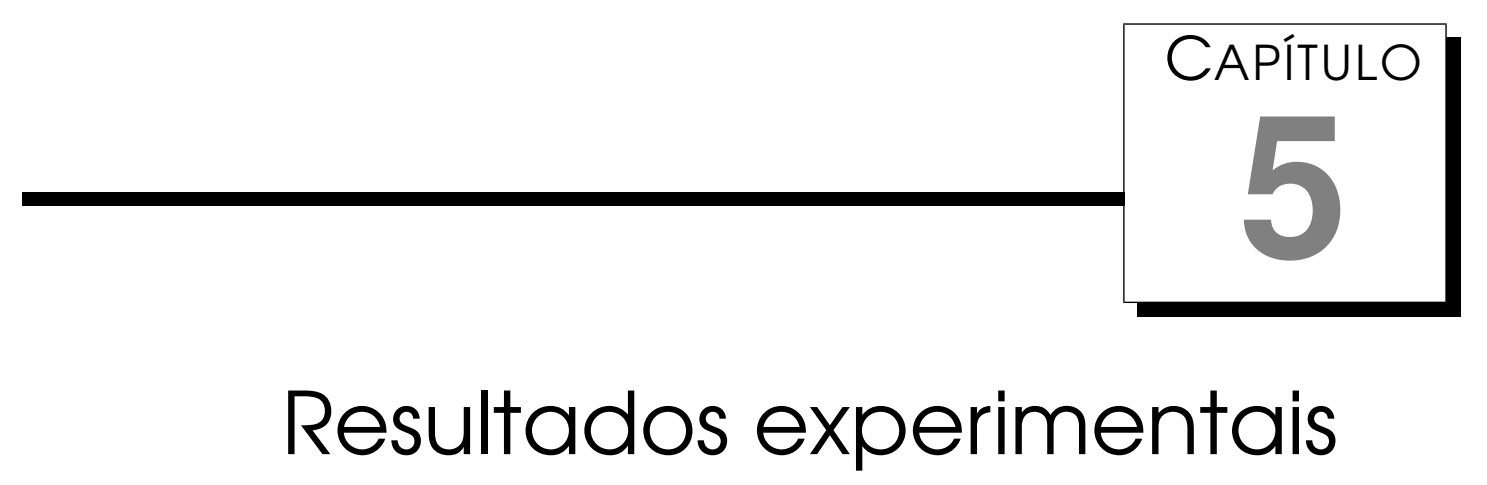

\subsection{Considerações iniciais}

Conforme discutido no Capítulo 4, abordagens de meta-aprendizagem podem ser empregadas para a elaboração de sistemas de recomendação de algoritmos de AM (Brazdil et al., 2009). De maneira resumida, eles operam nas seguintes etapas básicas: geração de meta-exemplos a partir dos problemas disponíveis, indução de um meta-modelo capaz de aprender a relação entre os meta-atributos de entrada e o meta-atributo alvo, e a aplicação do meta-modelo para a construção de rankings que dêem suporte à seleção de algoritmos para novos problemas.

Neste capítulo, são reportados os resultados das investigações realizadas para avaliar a utilização de meta-aprendizagem quando aplicada à classificação em problemas de domínio único. Os experimentos e análises correspondentes são divididos em três grupos, de acordo com os paradigmas de composição de ranking apresentados no Capítulo 4 . No primeiro, a recomendação provida ao usuário é gerada por métodos de vizinhos mais próximos, em que o $k \mathrm{NN}$ é a abordagem básica. É considerada também a extensão $w k \mathrm{NN}$ desenvolvida no presente trabalho. No segundo, a sugestão final é obtida pela resolução de diversos problemas de regressão, que têm então suas saídas combinadas para estabelecer uma ordem de preferência dos classificadores considerados. É de interesse maior avaliar o desempenho de SVMs nesta tarefa, dado que sua utilização como meta-regressor para problemas de classificação também é contribuição original. No terceiro, as predições são realizadas pela indução de modelos de árvores capazes 
de determinar a posição relativa dos algoritmos de AM. Tanto modelos únicos quanto combinados são considerados. Em especial, destaca-se que a utilização de bagging é introduzida neste trabalho. Para realizar a caracterização dos dados necessária à aplicação de quaisquer dos métodos supracitados, utilizam-se as medidas padrão do conjunto STATLOG e aquelas dos conjuntos VALIDITY E MIXED, que foram desenvolvidas nesta pesquisa e são baseadas em índice de validação de agrupamentos.

Este capítulo está organizado como segue. Na Seção 5.2, os materiais e métodos utilizados para a realização e a avaliação dos experimentos são apresentados. Nas Seções 5.3 a 5.5, os resultados obtidos em cada grupo de experimentos previamente mencionado são discutidos e analisados. Na Seção 5.6, uma comparação entre representantes de cada paradigma de construção de ranking é fornecida. Por último, algumas considerações finais são apresentadas na Seção 5.7.

\subsection{Materiais e métodos}

Nesta seção, descrevem-se as bases de dados, os algoritmos de AM, a metodologia de avaliação e as medidas de caracterização utilizados nos experimentos de meta-aprendizagem realizados durante o presente trabalho.

\subsection{Bases de dados de expressão gênica}

Nesta tese, lidou-se com problemas relacionados à classificação de tecidos com câncer. Há três razões principais para tal enfoque. Primeiro, devido a dados de expressão gênica serem tradicionalmente aplicados ao diagnóstico desse tipo de enfermidade, muitas bases de câncer têm sido disponibilizadas publicamente. Embora bases com outros objetivos de investigação clínica possam ser coletadas (Demeter et al., 2007; Barrett e Edgar, 2006), aquelas envolvendo tumores ainda são prevalentes. Segundo, decidiu-se restringir ainda mais a aplicação de meta-aprendizagem dentro do âmbito de expressão gênica, a fim de analisar o desempenho dos métodos de construção de rankings em dados mais homogêneos. Em terceiro, o estudo de dados relacionados a essa patologia despertou interesse devido a seu possível impacto social (Varmus, 2010). Assim, para os experimentos reportados em seções posteriores, foram utilizadas 49 bases de dados de microarrays. A descrição das principais características deste conjunto é fornecida no Capítulo 2 .

Para um número reduzido das bases consideradas, observou-se a indisponibilidade de alguns artefatos genéticos. Esta ausência é verificada em certas bases de microarrays de DNA complementar. A situação pode ocorrer 
por diversos motivos, tais como erros de fabricação, resolução inadequada do scanner, hibridização incompleta das moléculas e falhas na pastilha (Brock et al., 2008; Bø et al., 2004). Quando os valores faltantes para um determinado gene ocorrem em mais de 10\% das amostras de tecidos, ele foi excluído de futuras análises (Russell et al., 2008). Se a quantidade de tais valores for inferior a esse limiar, então pode-se aplicar algum método de estimação de valores faltantes. Em um estudo abrangente, Brock et al. (2008) analisaram 8 métodos de imputação de valores aplicados a múltiplos tipos de experimentos. Suas conclusões favorecem o Least Square Adaptation (LSA) (Bø et al., 2004) que foi, portanto, utilizado neste trabalho. Ele opera combinando estimativas em ambas as dimensões da matriz de expressão gênica (vide Tabela 2.2). Elas são obtidas por meio da aplicação de múltiplas regressões, cujos valores são então ponderados de forma adaptativa. Além de eficaz, o método tem utilização simplificada, pois não possui parâmetros livres. Assim, neste trabalho, o LSA foi empregado como método de imputação de valores.

Como última etapa de pré-processamento das matrizes de dados, todos os genes tiveram seus valorem transformados tal que tivessem média 0 e variância 1. Isso foi realizado inicialmente para os dados de treinamento e os dados de teste foram então normalizados de acordo.

\subsubsection{Algoritmos de AM}

Com base em diversos estudos envolvendo classificação em dados de expressão gênica (Boulesteix et al., 2008; Asyali et al., 2006; Larranaga et al., 2006) e nas considerações apresentadas no Capítulo 3, selecionaram-se os seguintes algoritmos de AM para induzir os classificadores base da meta-aprendizagem aqui utilizados: DLDA (Dudoit et al., 2002), DQDA (Dudoit et al., 2002), PAM (Tibshirani et al., 2002), kNN (Bishop, 2006), SVM-L (kernel Linear) (Steinwart e Christmann, 2008), SVM-R (kernel Radial) (Steinwart e Christmann, 2008) e RF (Breiman, 2001). Detalhes sobre eles podem ser obtido naquele capítulo. Eles foram executados com os parâmetros padrão disponíveis nos pacotes $\mathrm{R}$ ( $\mathrm{R}$ Development Core Team, 2009) que os implementam ou na literatura usual de AM. A Tabela 5.1 exibe os pacotes $\mathrm{R}$ utilizados, assim como os valores utilizados nos parâmetros dos algoritmos, quando aplicável.

A determinação do melhor método de estimação de erro, quando a classificação ocorre em dados de microarrays, é assunto controverso e depende dos objetivos de cada estudo (Boulesteix et al., 2008). Nos experimentos conduzidos aqui, tal tarefa é realizada utilizando-se o estimador $.632+$, com 50 amostras de bootstrap, seguindo as recomendações em Braga-Neto e 
Tabela 5.1: Pacotes R utilizados e parâmetros dos algoritmos de AM

\begin{tabular}{ccc}
\hline Algoritmo & Parâmetro(s) & Pacote \\
\hline DLDA & Não aplicável & sfsmisc \\
DQDA & Não aplicável & sfsmisc \\
PAM & $\Delta=1$ & pamr \\
$k$ NN & $k=3$ & class \\
SVM-L & $C=1$ & e1071 \\
SVM-R & $\sigma=1 / \#$ Atributos,$C=1$ & elo71 \\
RF & ntree $=500$, mtryFactor $=1$ & randomForest \\
\hline
\end{tabular}

Dougherty (2004). Assim, a geração dos rankings ideais dos 49 meta-exemplos utilizados é baseada no .632+. Sucintamente, ele opera através da ponderação de dois termos: o erro aparente e o erro de bootstrap, tal que a estimativa otimista do primeiro é compensada pela estimativa pessimista do segundo. Desta forma, tem-se uma maior robustez da estimativa de erro para diferentes abordagens de classificação. Um detalhamento do método, assim como as equações utilizadas em sua implementação está disponíveis em (Efron e Tibshirani, 1997).

\subsubsection{Aplicação e avaliação de meta-aprendizagem}

Para convencer um prospectivo usuário da eficácia de meta-aprendizagem para recomendação de algoritmos, é necessário demonstrar empiricamente que, de fato, os métodos de construção de ranking empregados são capazes de produzir sugestões que limitem seu tempo gasto com experimentação, com deterioração reduzida na qualidade dos resultados. Este problema remete àquele de avaliação de algoritmos de $\mathrm{AM}$ apresentado no Capítulo 3, onde é necessário definir uma medida de desempenho apropriada para analisar as soluções geradas e uma estratégia para avaliar os métodos de meta-aprendizagem. Estes 2 aspectos são discutidos nas seções seguintes.

\section{Medidas de desempenho}

Considere como exemplo o ranking ideal $R_{I}=\left(a_{1}, a_{2}, a_{3}, a_{4}\right)$ do desempenho de quatro algoritmos de AM $a_{i}$ quando aplicados a uma base de dados. Sejam $R_{A}=\left(a_{2}, a_{1}, a_{3}, a_{4}\right)$ e $R_{B}=\left(a_{3}, a_{2}, a_{4}, a_{1}\right)$ os rankings de $a_{i}$ sugeridos por dois métodos distintos $A$ e $B$. Intuitivamente, pode-se perceber que a qualidade de $R_{A}$ é superior a de $R_{B}$, dado que $R_{A}$ é mais similar à $R_{I}$ do que $R_{B}$. Esta noção de similaridade de rankings pode ser formalizada utilizando-se coeficientes de correlação entre séries de dados. No caso de dados pareados dispostos segundo uma ordem, como em $R_{A}$ e $R_{B}$, a Correlação de Spearman tem se mostrado adequada em diversas situações (Neave e Worthington, 1992). De fato, ela tem sido comumente empregada para medir a acurácia de rankings 
gerados por métodos de meta-aprendizagem (Brazdil et al., 2009; Rebelo et al., 2008; Souto et al., 2008). Esse coeficiente é calculado pela Equação 5.1, para rankings arbitrários $R$ e $Q$ de itens $i=1, \ldots, n$ :

$$
r_{S}=\frac{\sum_{i=1}^{n}\left(R_{i}-\bar{R}\right)\left(Q_{i}-\bar{Q}\right)}{\sqrt{\left(\sum_{i=1}^{n}(R-\bar{R})^{2} \sum_{i=1}^{n}(Q-\bar{Q})^{2}\right)}}
$$

onde $R_{i}\left(\mathrm{Q}_{i}\right)$ corresponde à posição do item $i$ em $R(Q)$ e $\bar{R}(\bar{Q})$ representa a média dessas posições. Por sua definição, percebe-se que o $r_{S}$ avalia a monotonicidade entre os $R$ e $Q$, ou seja, se suas variações estão relacionadas. Caso os valores nos rankings apresentem tendência em crescer ou decrescer juntos, então há uma correlação positiva, com máximo em 1. Se os valores de um ranking crescem enquanto os do outro decrescem, então há uma correlação negativa, com mínimo em -1. Uma correlação de 0 indica que os rankings não estão correlacionados.

Uma característica da correlação de Spearman é a atribuição de peso igual a todas as posições dos rankings considerados. Tal propriedade pode não ser suficientemente informativa em casos em que itens melhor posicionados devam ter maior importância no cálculo do coeficiente de correlação. Esta situação ocorre com frequência no contexto de recomendação de algoritmos, em que o usuário tende a preferir executar algoritmos que estejam em posições superiores no ranking sugerido. Assim, uma informação complementar para avaliar a qualidade de um ranking pode ser obtida com a utilização de medidas que realizem ponderação de posição, como a Log Ranking Accuracy (LRA) (Soares, 2004). Dado um ranking ideal e um ranking sugerido, a LRA atribui maior peso a posições superiores, designando como base da função logarítmica os valores do primeiro ranking, como pode ser observado pela Equação 5.2, para rankings arbitrários $R$ e $Q$ de itens $i=1, \ldots, n$ :

$$
L R A=1-2 \frac{\sum_{i=1}^{n} \log _{1+R_{i}}\left(1+\left(R_{i}-R_{i}\right)^{2}\right)}{\sum_{i=1}^{n} \log _{1+i}\left(1+(i-(n-i+1))^{2}\right)}
$$

onde $R_{i}\left(Q_{i}\right)$ corresponde à posição do item $i$ em $R(Q)$. Neste caso, também os valores admissíveis estão no intervalo de $[-1,1]$, com a mesma interpretação da correlação de Spearman.

Nos experimentos realizados aqui, assim como na maioria do trabalhos relacionados à recomendação relativa de algoritmos no contexto de meta-aprendizagem (vide (Brazdil et al., 2009) e referências ali contidas), utiliza-se o coeficiente de Spearman como medida padrão de desempenho. Ela é aplicada sobre o ranking ideal associado a um meta-exemplo e o ranking construído por um determinado método, a fim de determinar a acurácia da predição realizada. Apenas na seção envolvendo comparação geral entre os 
métodos, serão incluídas ainda considerações acerca do desempenho de cada um deles utilizando a LRA, para agregar valor às conclusões obtidas.

\section{Estratégia de avaliação}

Tendo definido medidas para precisar a acurácia de um determinado ranking predito, pode-se avaliar os métodos utilizados em sua construção. Nesta situação, diz-se que, se um método $A$ for capaz de construir rankings mais similares aos rankings ideais dos meta-exemplos do que aqueles construídos por $B$, então $A$ é mais acurado que $B$. Para realizar esse tipo de análise no contexto de recomendação de algoritmos utilizando meta-aprendizagem, pode-se empregar algumas das técnicas de amostragem apresentadas no Capítulo 3, dado o número reduzido de meta-exemplos usualmente disponível. O arcabouço mais utilizado é o leave-one-out (LOO), introduzido para esse fim por Brazdil et al. (2003). Ele também foi utilizado no presente trabalho.

No LOO, cada meta-exemplo é sucessivamente separado para teste e os demais para treinamento. Aplicando-se um método de ranking ao conjunto de treinamento, constrói-se uma recomendação para o meta-exemplo de teste. Esta é então comparada com o ranking ideal daquele meta-exemplo e o coeficiente de correlação entre ambas é calculado. Após todos os meta-exemplos terem sido considerados no teste, a média das correlações é utilizada como uma estimativa do desempenho do método de ranking. Desta forma, diferentes abordagens para construção de rankings podem ser comparadas com esta estratégia. Entretanto, como está-se trabalhando com uma amostra finita de dados, as estimativas produzidas podem não representar adequadamente os desempenhos verdadeiros, pois elas têm uma certa variância. Assim, a utilização de testes para verificar a significância estatística dos resultados é apropriada.

O teste de Friedman seguido do procedimento de Dunn para múltiplas comparações pode ser utilizado para comparar estatisticamente um conjunto de métodos de ranking sobre múltiplas bases de dados (ou meta-exemplos) (Soares, 2004) e é considerado neste trabalho. Ele é adequado no contexto, pois não impõe restrições à distribuição dos coeficientes de correlações calculados, consegue lidar com diversos métodos simultaneamente e opera com dados de amostras relacionadas (Neave e Worthington, 1992). O funcionamento do teste é explicado a seguir. Considere $r_{i}^{j}$ a posição (segundo sua estimativa de LOO) do $j$-ésimo método de ranking (dentre $k$ ) na ordenação realizada para o $i$-ésimo meta-exemplo (dentre $n$ ), tal que menores posições indicam melhores desempenhos. Os diversos $r_{i}^{j}$ são, então, dispostos em uma tabela $N \times k$. Se os métodos forem equivalentes, as linhas da tabela 
terão sequências aleatórias de 1 a $k$, e as somas de cada coluna, dadas por $R_{j}=\sum_{i=1}^{i=n} r_{i}^{j}$, tenderão a ser iguais. Sob a hipótese nula de equivalência entre os métodos, tais médias são utilizadas para calcular a estatística da Equação 5.3:

$$
\chi_{F}^{2}=\frac{12 n}{k(k+1)} \sum_{j=1}^{j=k} R_{j}^{2}-\frac{k(k+1)^{2}}{4},
$$

que segue a distribuição $\chi^{2} \operatorname{com} k-1$ graus de liberdade. Assim, pode-se avaliar se os métodos apresentam ou não o mesmo desempenho, dado um determinado nível de confiança associado a um valor de $\alpha_{F}$. Para este teste, utilizou-se $\alpha_{F}=0.05$. Em caso afirmativo, a hipótese nula é rejeitada e aplica-se o procedimento de Dunn para determinar quais pares de métodos apresentam diferenças significantes. Isto ocorre quando o módulo da estatística de Dunn $T_{A, B}$ para dois métodos de ranking $A$ e $B$ for maior que um determinado valor crítico $\alpha_{D}$. Para este teste, utilizou-se $a l p h a_{D}=0.10$, com correção de Bonferroni para ajustar a significância de acordo com o número de comparações realizadas (Bland e Altman, 1995). $T_{A, B}$ é dada pela Equação 5.4:

$$
T_{A, B}=\frac{R_{A}-R_{B}}{\sqrt{\frac{n k(k+1)}{6}}}
$$

onde $R_{A}, R_{B}$ são as somas das colunas para os métodos $A$ e $B$, respectivamente, $n$ é o número de meta-exemplos e $k$ é o número de métodos de ranking.

Além da utilização de um arcabouço estatístico para comparar os métodos de ranking, é importante estabelecer se a estimativa de desempenho de uma abordagem específica pode ser considerada adequada ou não para o conjunto de meta-exemplos em estudo. Em AM, geralmente estratégias de predição ingênuas, como classificar um novo exemplo segundo a classe majoritária no conjunto de treinamento (conhecida como classe padrão), são empregadas para avaliar métodos mais complexos. No caso de rankings, uma abordagem similar consiste em resumir a informação dos meta-atributos de saída de todos os meta-exemplos de treinamento em um único ranking. Isto é obtido utilizando-se o método Average Ranks (AR) apresentado na Equação 4.18 do Capítulo 4. Desta forma, obtém-se o chamado ranking padrão (RP), que serve de base para avaliar a qualidade dos métodos de ranking fundamentados em vizinhos mais próximos, em regressão e em árvores, utilizados neste trabalho.

\subsubsection{Medidas de caracterização de dados}

No capítulo 4, destacaram-se algumas abordagens para caracterizar as bases de dados utilizadas em meta-aprendizagem. Elas são empregadas para 
a geração dos meta-atributos de entrada constituintes dos meta-exemplos. Neste trabalho, dois grupos de tais medidas foram utilizados: o conjunto STATLOG $^{1}$ e o conjunto VALIDITY. Seus componentes são enumerados na Tabela $5.2^{2}$.

Tabela 5.2: Medidas de caracterização

\begin{tabular}{lcl}
\hline Conjunto & Medida & Descrição \\
\hline & NEX & Logaritmo do número de exemplos \\
& NAT & Logaritmo do número de atributos \\
NCL & Logaritmo do número de classes \\
& MDP & Razão média entre desvio padrão dos atributos \\
STATLOG & COR & Correlação média absoluta entre atributos, por classe \\
& CAN & Primeira correlação canônica \\
& PRO & Proporção de variância explicada pelo $1^{\circ}$ discriminante canônico \\
& ASS & Assimetria média absoluta dos atributos \\
& CUR & Curtose média dos atributos \\
ENT & Entropia normalizada das classes \\
\hline & INT & Distância intergrupos \\
& INT & Índice de separação \\
VDB & Índice de Davies-Bouldin \\
VDU & Índice de Dunn \\
N-1 & Sobreposição de grupos \\
P-B & Índice Point Biserial \\
C-H & Índice de Calinski-Harabasz \\
H-L & Índice de Hubert-Levine \\
CON & Índice Conectividade \\
SIL & Índice Silhueta \\
G-K & Índice de Goodman-Kruskal
\end{tabular}

O primeiro grupo corresponde às medidas apresentadas na Tabela 4.1 do Capítulo 4, adequadas à natureza númerica e contínua dos dados de expressão gênica considerados aqui. Elas foram utilizadas no projeto Statlog e variações suas têm sido largamente empregadas em aplicações de meta-aprendizagem para classificação e regressão Brazdil et al. (2009). O segundo conjunto representa as medidas de caracterização desenvolvidas neste trabalho. Elas se baseiam em índices de validação de agrupamento (Halkidi et al., 2001) a fim de capturar aspectos da estrutura disponível nos dados que possam influenciar o comportamento dos algoritmos. Descrições de ambos os conjuntos são fornecidos no Capítulo 4.

Conforme comentado no Capítulo 4, a aplicação direta das medidas do conjunto VALIDITY às matrizes de expressão gênica não é recomendada, pois o elevado número de atributos do domínio pode mascarar conhecimento

\footnotetext{
${ }^{1}$ Todas as medidas STATLOG foram calculadas segundo as definições apresentadas no apêndice de (Kalousis, 2002)

${ }^{2}$ Para algumas medidas, conforme explicitado na tabela, aplicou-se a função logarítmica aos dados a fim de mapear os valores obtidos de diversos problemas para intervalos compatíveis.
} 
biológico relevante nelas contido (D'haeseleer, 2005). Para lidar com o problema, sugeriu-se a aplicação de PLS (Wold et al., 2001) ou PCA (Jolliffe, 2002) para realizar a redução de dimensionalidade dos dados. A fim de investigar a influência dessas técnicas na qualidade das predições geradas, selecionou-se, para cada uma das três abordagens básicas de construção de ranking, o método conceitualmente mais simples para avaliação nas duas situações. Assim, aqueles baseados em vizinhos mais próximos são representados pelo $1 \mathrm{NN}$, os métodos baseados em regressão são representados pelo LR e os baseados em árvore são representados por uma única PCT. Ao focar nos métodos de menor complexidade, a intenção é privilegiar a análise do conjunto VALIDITY quando obtido após redução de dados por PLS ou por PCA, e não analisar o desempenho relativo dos métodos em si.

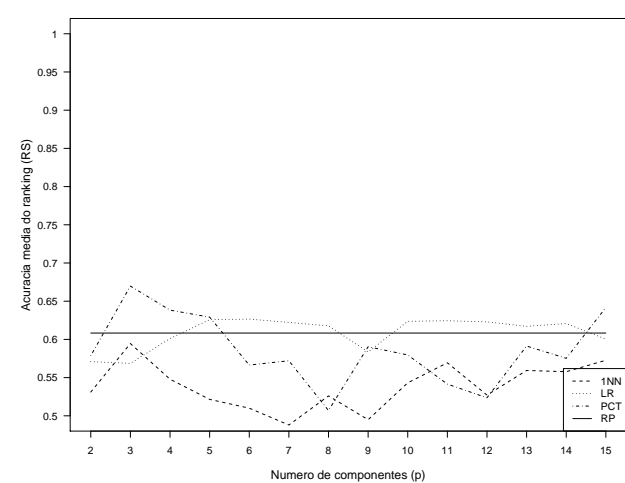

(a) Redução por PCA

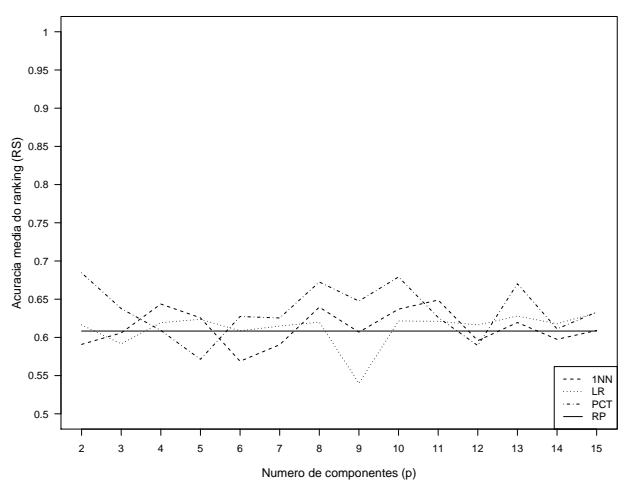

(b) Redução por PLS

Figura 5.1: Desempenho dos métodos 1NN, LR e PCT com caracterização de dados utilizando o conjunto VALIDITY após redução

A Figura 5.1 exibe os resultados das acurácias médias dos três métodos quando aplicados sobre os 49 problemas considerados. Nela, varia-se o número $p=2, \ldots, 15$ de componentes extraídos por cada técnica de redução antes da caracterização dos dados ${ }^{3}$. A linha completa representa a média das predições do RP. Comparando-se as Figuras 5.1(a) e 5.1(b), pode-se perceber nitidamente uma melhora generalizada de desempenho dos métodos de ranking quando PLS é empregado. O ganho mais patente ocorre com o $1 \mathrm{NN}$. Com o PCA, ele mostra-se inferior ao RP para todos os valores de $p$ por grande diferença. Com o PLS, sua desvantagem é menos frequente e, quando ocorre, é de menor magnitude. Para o PCT também são notadas melhoras com o PLS, especialmente para $p>5$. Nesta situação, ele supera o RP na maioria das vezes, ao contrário do que ocorre no caso do PCA. O LR é menos sensível

\footnotetext{
${ }^{3}$ Quando o número de componentes é maior que 3 , considera-se $p=3$ para o cálculo de $\mathrm{N}-1$ devido a uma restrição no pacote $\mathrm{R}$ utilizado (spatgraphs) para construir a árvore geradora mínima requerida pela medida.
} 
ao método de redução empregado, posicionando-se sempre próximo ao RP, exceto para $p=9$ para o PLS e $p=2,3$ para o PCA.

A Figura 5.1(b) mostra ainda uma entrada $p *$. Ela representa o número de componentes PLS otimizado para cada problema. Ela é obtida com a utilização da estatística PRESS (do inglês Predicted Residual Error Sum of Squares), a exemplo de (Dai et al., 2006; Nguyen e Rocke, 2002) para classificação em dados de expressão gênica. Ela estima o desempenho da saída produzida por algoritmos de regressão quando aplicados a dados não vistos na indução do regressor, em um esquema de LOO. Sua definição é dada pela Equação 5.5

$$
\text { PRESS }=\sum_{i=1}^{n}\left(y_{i}-\widehat{y_{i}}\right)^{2}
$$

onde $n$ representa o número de exemplos $i$ em uma base de dados supervisionada, $y_{i}$ é a saída esperada de $i$ e $\widehat{y_{i}}$ é seu valor estimado pelo PLS.

Variando-se $\mathrm{p}=2, \ldots, 15$, a PRESS selecionou em média 7.38 componentes (com desvio padrão de 4.09) para os problemas considerados. Através da aplicação do teste de Friedman com 95\% de confiança seguido do teste de Dunn com 90\% de confiança, não se observou diferenças significantes de desempenho entre os 14 valores de $p$ quando comparados a $p *$, para os métodos de ranking $1 \mathrm{NN}$, LR e PCT. Portanto, para o restante dos experimentos deste trabalho utilizando o conjunto de medidas VALIDITY, emprega-se o PLS a priori com $p *$ selecionado pela estatística PRESS.

O conjunto STATLOG também pode beneficiar-se da aplicação de técnicas de redução de dimesionalidade. Isto ocorre devido a dificuldades numéricas e ao alto requerimento computacional de algumas medidas desse conjunto. Desde a execução dos experimentos iniciais deste trabalho (Souza et al., 2008), observou-se que as medidas MDP, COR, CAN e PRO não eram adequadas a dados de alta dimensionalidade, pois ou exigiam o cálculo de determinantes de matrizes de covariância muito grandes ou de correlações par a par entre os todos os atributos (Kalousis, 2002), fazendo com que valores nulos fossem retornados em seu cômputo. Desta forma, como no caso do conjunto VALIDITY, adotou-se a estratégia de aplicação de uma abordagem de redução antes da caracterização dos dados ${ }^{4}$.

Assim, utilizando a mesma configuração experimental empregada na Figura 5.1, analisou-se a influência de PCA e PLS na qualidade dos rankings gerados. Pela Figura 5.2, não percebe-se uma supremacia clara de nenhuma das técnicas. Com o PCA, o $1 \mathrm{NN}$ resultou discretamente inferior ao RP para

\footnotetext{
${ }^{4}$ Embora apenas MDP, COR, CAN e PRO não sejam apropriadas a dados com alta dimensionalidade, calculou-se todas as medidas do conjunto STATLOG sobre os dados reduzidos por PCA ou PLS. Em experimentos preliminares, tal abordagem resultou na construção de rankings mais acurados pelos métodos 1NN, LR e PCT.
} 


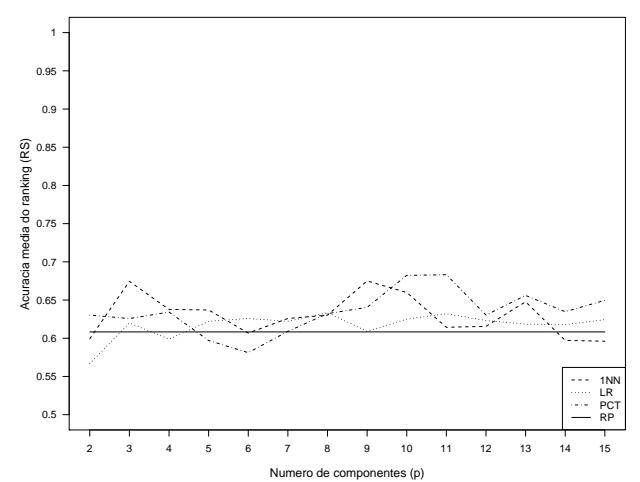

(a) Redução por PCA

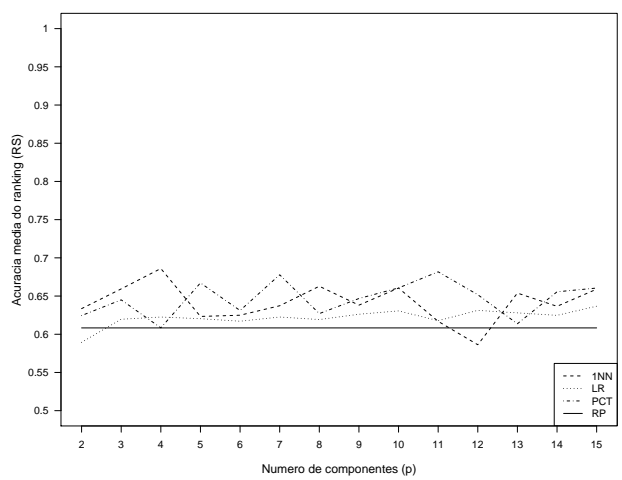

(b) Redução por PLS

Figura 5.2: Desempenho dos métodos 1NN, LR e PCT com caracterização de dados utilizando o conjunto STATLOG após redução

4 valores de $p$, enquanto que o PLS apenas para $p=12$. Para o PCT, esta situação ocorre 2 vezes para o PCA e nenhuma para o PLS. Para o LR, o desempenho foi inferior ao RP para 2 valores de $P$ com o PCA e para um com o PLS. A relativa robustez do conjunto STATLOG em relação ao tipo de redução empregado ocorre devido à maioria de suas medidas não considerarem a associação entre atributo e classe (apenas CAN e PRO o fazem). Com isso, a principal diferença entre PCA e PLS tem seu efeito minimizado. Como no caso do conjunto VALIDITY, a utilização do $p *$ na Figura 5.2(b) não ocasionou diferenças estatisticamente significantes de desempenho para nenhum dos métodos de ranking, quando comparado a $p=2, \ldots, 15$. Portanto, PLS com $p *$ também é empregado no restante dos experimentos envolvendo o conjunto STATLOG.

A fim de investigar a interação entre as diferentes medidas dos conjuntos STATLOG e VALIDITY, considera-se também neste trabalho o grupo híbrido MIXED, composto pelas 20 medidas apresentadas na Tabela 5.2. Com ele, espera-se adquirir informações sobre aspectos mais variados dos dados, e agregá-las para a construção dos rankings recomendados.

\subsection{Ranking por vizinhos mais próximos}

Nesta seção, a recomendação dos algoritmos de AM é provida ao usuário na forma de rankings gerados pelo método $k \mathrm{NN}$, descrito detalhadamente no Capítulo 4. Brevemente, ele opera selecionando os meta-exemplos do conjunto de treinamento mais similares ao meta-exemplo de teste, de acordo com suas descrições e, posteriormente, combinando os rankings ideais dos meta-exemplos recuperados para a construção da nova predição. A seguir, são reportados os resultados obtidos com essa abordagem. 


\subsection{Limites do $k N N$}

Na Seção 5.2.3, apresentou-se o RP como base de comparação para os métodos de ranking. No caso do $k \mathrm{NN}$, uma análise complementar de seu desempenho pode ser realizada considerando os limites superior e inferior do método. No arcabouço de LOO, o limite superior do $k \mathrm{NN}$ é obtido selecionando-se os $k$ vizinhos no conjunto de treinamento que produzam as maiores correlações com o ranking ideal de cada meta-exemplo de teste, independente das distâncias entre os meta-exemplos no espaço de meta-atributos de entrada, e aplicando-se sobre eles o AR para a geração das predições. Desta forma, obtém-se a máxima acurácia média do $k \mathrm{NN}$ quando empregado sobre um determinado grupo de problemas. Para calcular o limite inferior, escolhe-se, para cada valor de $k$, meta-vizinhos aleatórios no conjunto de treinamento, novamente desconsiderando as distância para o meta-exemplo de teste, e constrói-se os rankings utilizando o AR. Com isso, simula-se a situação em que o desempenho do $k \mathrm{NN}$ depende tão somente da agregação fortuita de rankings de $k$ meta-exemplos. Por meio desses dois limites, a intenção é contextualizar o desempenho do $k \mathrm{NN}$, apreciando quão bom o método é e quão melhor (teoricamente) ele ainda pode ser.

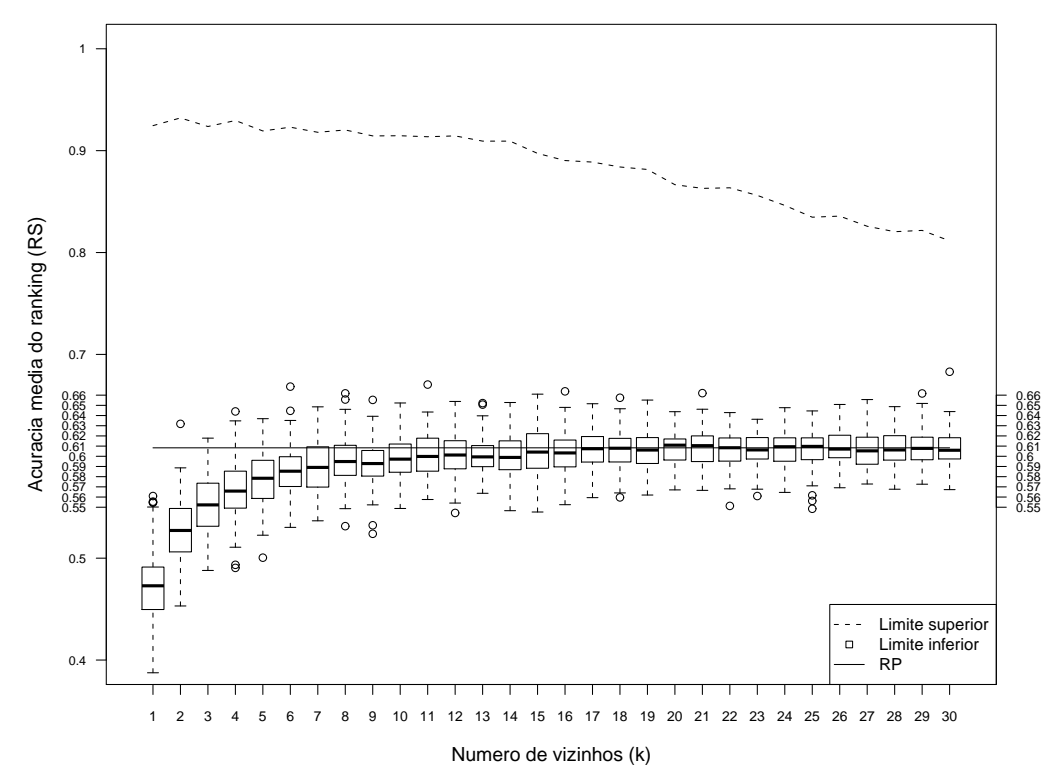

Figura 5.3: Limites superior e inferior do método $k \mathrm{NN}$.

A Figura 5.3 exibe os limites inferior e superior do $k \mathrm{NN}$ variando-se $k=$ $1, \ldots, 30$. Os valores apresentados são as médias de acurácia (utilizando o $r_{S}$ ) dos rankings obtidos no decorrer do LOO para os 49 problemas considerados. O limite superior é dado pela linha tracejada. Percebe-se que o desempenho do $k \mathrm{NN}$ inicia superior a 0.9 e vai decrescendo com o número de vizinhos. Isso é natural, dado que os vizinhos neste limite são selecionados segundo 
sua correlação com os meta-exemplos de teste. Então, à medida que o AR vai sendo empregado com valores de $k$ crescentes, espera-se uma redução de desempenho, pois meta-exemplos com rankings ideais cada vez mais heterogêneos vão sendo utilizados na construção das predições. Quando todos os 48 meta-exemplos de treinamento são aplicados ao AR, o limite superior coincide com o RP (linha completa na figura).

No caso do limite inferior (boxplots ${ }^{5}$ obtidos a partir de 100 amostragens randômicas), o emprego de poucos meta-exemplos resulta em baixa acurácia em relação ao $\mathrm{RP}$, pois os rankings considerados não apresentam uma grande correlação com os rankings dos meta-exemplos de teste. A situação pode ser explicada pela aleatoriedade da escolha dos meta-exemplos. Este comportamento é suavizado com o aumento de $k$. Assim, com a utilização de mais meta-exemplos na composição pelo AR, a probabilidade de que melhores rankings sejam utilizados cresce, o que leva, gradativamente, a acurácias próximas à obtida pelo RP. De fato, a partir de $k=17$, a mediana dos boxplots varia em torno de 0.608, a acurácia média de RP.

\subsubsection{Desempenho do kNN}

A Figura 5.4 exibe os resultados da aplicação do $k \mathrm{NN}$ para a predição de rankings nos 49 problemas em uso. As acurácias médias do LOO utilizando o $r_{S}$ são mostradas. A caracterização dos dados ocorre segundo os conjuntos de medidas STATLOG, VALIDITY e MIXED. Variando-se $k=1, \ldots, 30$, o desempenho do $k \mathrm{NN}$ STATLOG no começo aumenta com o número de vizinhos, até alcançar seu desempenho máximo de 0.698 com $k=4$. Depois disso, ele sofre uma leve diminuição e mantém uma inclinação descendente até o RP, que possui acurácia média de 0.608 (linha completa na figura). No caso do $k \mathrm{NN}$ VALIDITY, também há melhoras iniciais. Em seguida, ele sofre pequenas variações, encontrando diversos mínimos locais até alcançar seu ápice de 0.754 , com $k=12$. A partir deste ponto, seu desempenho se deteriora. Com o $k \mathrm{NN}$ MIXED, a situação se repete. Os rankings construídos são mais acurados à medida em que $k$ cresce, até atingir seu ponto máximo em $0.745, \operatorname{com} k=6$, e depois decai gradativamente.

Para todos os valores de $k$, as 3 variações do $k \mathrm{NN}$ são sobremaneira superiores ao RP. O mesmo ocorre em relação ao limite inferior da Figura 5.3. Tal fato ratifica a importância de se selecionar os vizinhos mais próximos, e não simplesmente quaisquer meta-exemplos, para a construção dos rankings preditos. A vantagem do $k$ NN VALIDITY é patente em relação ao $k$ NN STATLOG

\footnotetext{
${ }^{5}$ Os 5 traços horizontais de cada boxplot representam, respectivamente: o mínimo, o primeiro quartil, a mediana, o terceiro quartil e o máximo da amostra de observações consideradas. Os círculos indicam observações usuais da amostra, considerando ela segue uma distribuição normal.
} 


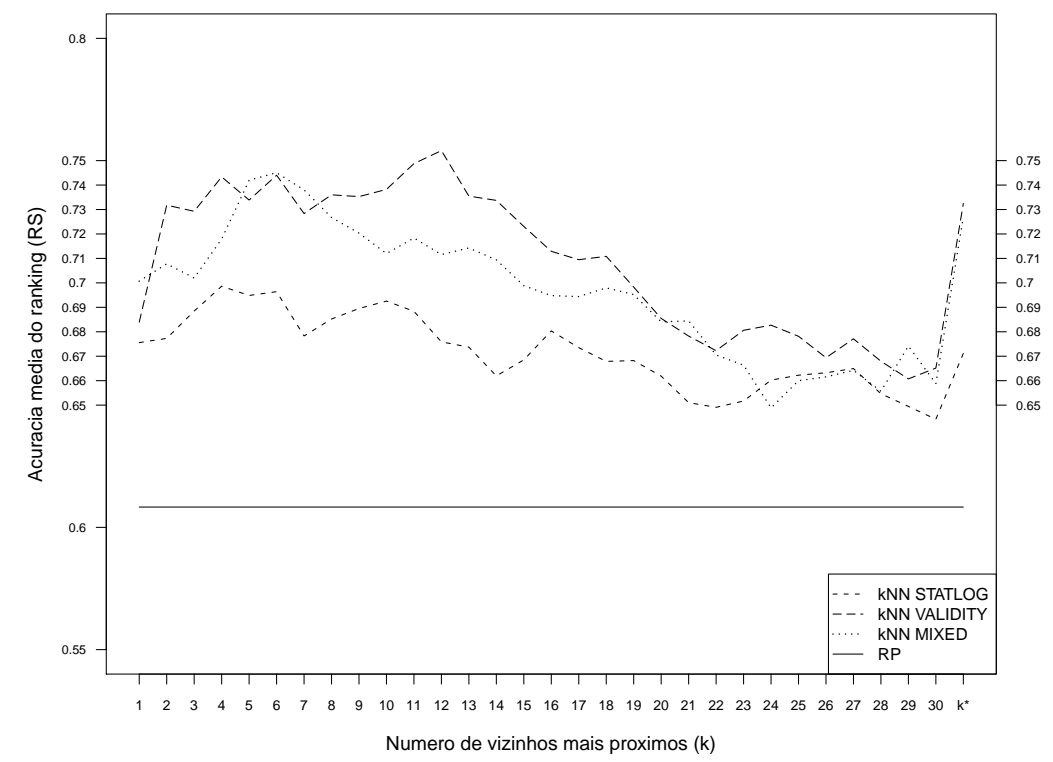

Figura 5.4: Desempenho do método $k \mathrm{NN}$ com caracterização de dados utilizando os conjuntos STATLOG, VALIDITY E MIXED

para todos os números de vizinhos, com picos de diferença de 0.078, $0.061 \mathrm{e}$ 0.071 para $k=12,13,14$. Isto é um indicativo de que o conjunto VALIDITY é mais informativo ao $k \mathrm{NN}$ para determinar o desempenho relativo dos algoritmos de AM nos experimentos considerados nesta seção.

O grupo MIXED situa-se em posição intermediária quando comparado aos outros 2 conjuntos, o que sugere uma relação de sinal e ruído advinda da composição das medidas VALIDITY e STATLOG, respectivamente. Como o $k \mathrm{NN}$ não é tão robusto à presença de atributos irrelevantes (Duda et al., 2000), este resultado é condizente. Todavia, pela Figura 5.4, observa-se que para alguns valores de $k$, o $k \mathrm{NN}$ MIXED é superior ao $k \mathrm{NN}$ VALIDITY, fornecendo indícios do potencial desse conjunto e sugerindo que a aplicação de técnicas de seleção de atributos (Liu e Motoda, 1998) poderia ser benéfica nesse caso.

A fim de lidar com a necessidade de escolha de um valor apropriado para $k$, aplicou-se um procedimento interno de LOO aos meta-exemplos de treinamento para selecionar um número de vizinhos específico para cada problema, sobre $k=1, \ldots, 15$. O $k$ de melhor desempenho foi escolhido. Tal valor é representado pela entrada $k^{*}$ na Figura 5.4. Ele resultou em acurácias médias de $0.671,0.732$ e 0.727 para o $k$ NN STATLOG, o $k$ NN VALIDITY e o $k$ NN MIXED, respectivamente, e selecionou as médias (com desvios padrão) de 5.645 (1.862), 9.916 (2.857) e 5.895 (0.721) vizinhos. Nota-se, portanto, que os $k^{*}$ para todos os casos concentram-se nas regiões onde os desempenhos do $k \mathrm{NN}$ são máximos. Isto faz com que suas acurácias sejam compatíveis com as melhores obtidas, apenas com uma discreta deterioração. Assim, devido à facilidade que a abordagem fornece ao usuário, considera-se a seleção 
automática de $k$ uma prática favorável.

Com o $k^{*}$, apesar de o $k \mathrm{NN}$ VALIDITY e o $k \mathrm{NN}$ MIXED apresentarem acurácias médias superiores a 0.05 em relação ao $k \mathrm{NN}$ STATLOG, não foram observadas diferenças significativas entre os 3 métodos de ranking, quando da aplicação do teste de Friedman seguido do teste de Dunn, com 95\% e 90\% de confiança, respectivamente. Entretanto, todos eles são estatisticamente superiores ao RP.

De maneira geral, os resultados na Figura 5.4 são diferentes daqueles apresentados por abordagens de recomendação de algoritmos no contexto de dados de fontes diversas, em que meta-aprendizagem tem sido usualmente empregada (vide (Brazdil et al., 2009) e referências ali contidas). Nesses estudos, as melhores acurácias médias são obtidas com um número muito reduzido de vizinhos, geralmente $k=1,2$, e então o $k \mathrm{NN}$ rapidamente se torna inferior ao RP. Esta discrepância entre os resultados dos 2 conjuntos de experimentos pode ser explicada pelo fato de que, sendo do mesmo domínio de aplicação, as bases de dados de expressão gênica utilizadas neste trabalho são mais homogêneas.

Assim, o comportamento do $k \mathrm{NN}$ parece ser mais coerente nos experimentos deste estudo do que nos anteriores, no seguinte sentido. Os rankings construídos com 1 ou 2 vizinhos estão sujeitas a erros, se os dados forem ruidosos. Este problema é minimizado quando a predição é baseada em uma vizinhança reduzida, pois o efeito do ruído é mitigado pelos outros vizinhos. Entretanto, à medida que a vizinhança aumenta de tamanho, as predições são afetadas por vizinhos cada vez menos similares ao meta-exemplo corrente de teste e, assim, o desempenho do $k \mathrm{NN}$ decresce. Como aqui utiliza-se dados com propriedades semelhantes, esta degradação é menos abrupta que aquela reportada em Brazdil et al. (2009).

\subsubsection{Extensão do $k N N$}

Embora os resultados obtidos anteriormente indiquem que o $k \mathrm{NN}$ é eficaz na predição de rankings no contexto deste trabalho, percebe-se pelo limite superior da Figura 5.3 que seu desempenho está aquém do teoricamente possivel e pode, portanto, ser melhorado. No Capítulo 4, introduziu-se o $w k \mathrm{NN}$ visando tal objetivo. Basicamente, ele representa uma extensão do $k \mathrm{NN}$ ordinário capaz de atribuir pesos aos meta-exemplos do conjunto de treinamento de acordo com sua proximidade ao meta-exemplo de teste. Com isso, os vizinhos mais próximos têm influência maior na construção dos rankings.

A Figura 5.5 mostra as vantagens do $w k \mathrm{NN}$ para os dados caracterizados com as medidas do conjunto STATLOG. Nela, exibem-se as acurácias 
médias segundo o $r_{s}$ calculadas no esquema de LOO para os 49 problemas considerados. São utilizadas 4 funções de kernel típicas para o método (Hechenbichler e Schliep, 2006): Retangular, Triangular, Epanechnikov e Gauss. O kernel Retangular pondera igualmente todos os vizinhos e corresponde exatamente ao método $k \mathrm{NN}$ utilizado na Figura 5.4. Com o número de vizinhos variando em $k=1, \ldots, 30$, os desempenhos de todas as versões do $w k \mathrm{NN}$ aumentam com o valor de $k$, inicialmente. À medida que a vizinhança ultrapassa um certo limiar, os desempenhos vão se deteriorando, pois vizinhos de menor relevância aos meta-exemplos de teste vão sendo considerados na construção dos rankings. Esta degradação ocorre primeiro com o $w k$ NN Retangular. A partir de $k=4$, ele exibe um desempenho errático em direção ao RP, indicando que o método é bastante sensível aos valores de $k$. Este comportamento é compartilhado, em certo grau, com o kernel Gauss, embora este resulte em acurácias médias levemente superiores no decorrer de todo o intervalo de $k$.

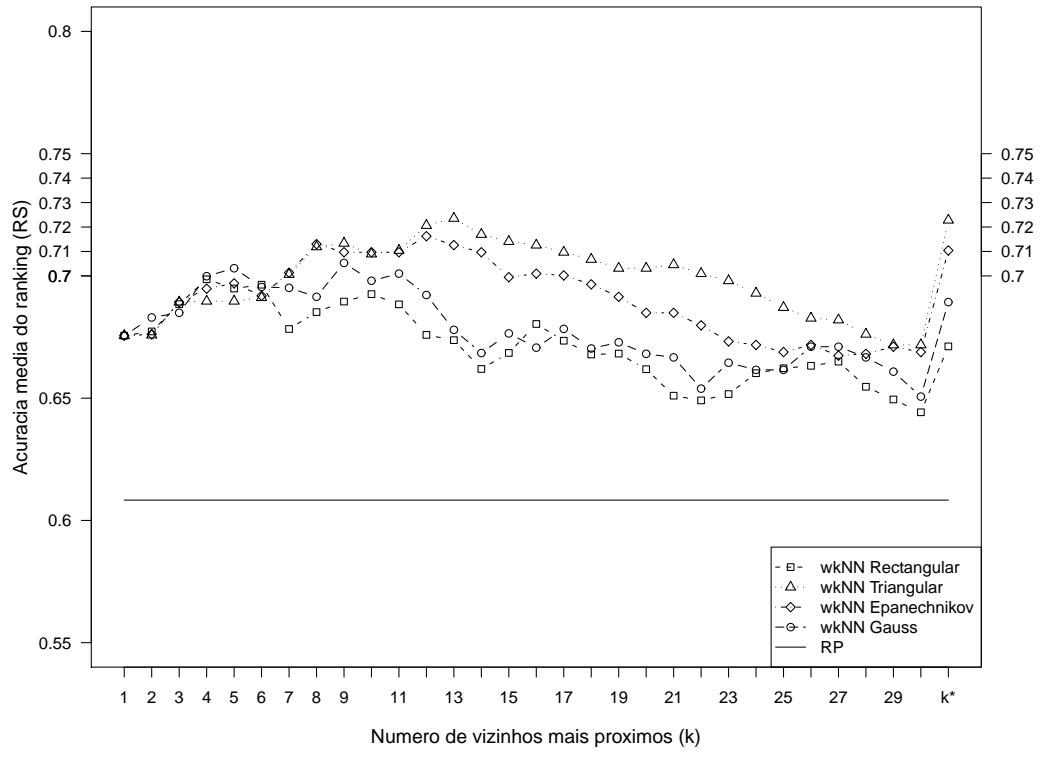

Figura 5.5: Desempenho do método $w k \mathrm{NN}$ com caracterização de dados utilizando o conjunto STATLOG e 4 funções de kernel

Os métodos $w k \mathrm{NN}$ Triangular e Epanechnikov apresentam vantagens mais notáveis em relação ao $w k \mathrm{NN}$ Retangular. Para qualquer $k>6$, ele são superiores, com primazia do primeiro kernel. Seus melhores resultados são, respectivamente: $0.723(k=13)$ e $0.716(k=12)$. Para $13<k \leq 30$, eles resultam em um suave decaimento na acurácia média. Para entender seus comportamentos, pode-se inspecionar a Figura 5.6, que ilustra a forma dessas 2 funções de acordo com as definições apresentadas pela Equação 4.19 do Capítulo 4. Elas operam transformando as distâncias normalizadas entre o meta-exemplo de teste corrente e seus vizinhos em similaridades, que são 
então utilizadas como pesos pelo $w k$ NN. Nota-se que com o kernel Triangular, o peso de vizinhos rapidamente se atenua com sua distância, fazendo com que aqueles mais distantes logo se tornem menos influentes na composição do raking. No caso do kernel Epanechnikov, o detrimento da influência dos vizinhos é menos acentuado. Para o kernel Gauss, tal declínio é ainda mais suave, dada sua forma mais próxima a do kernel Retangular.

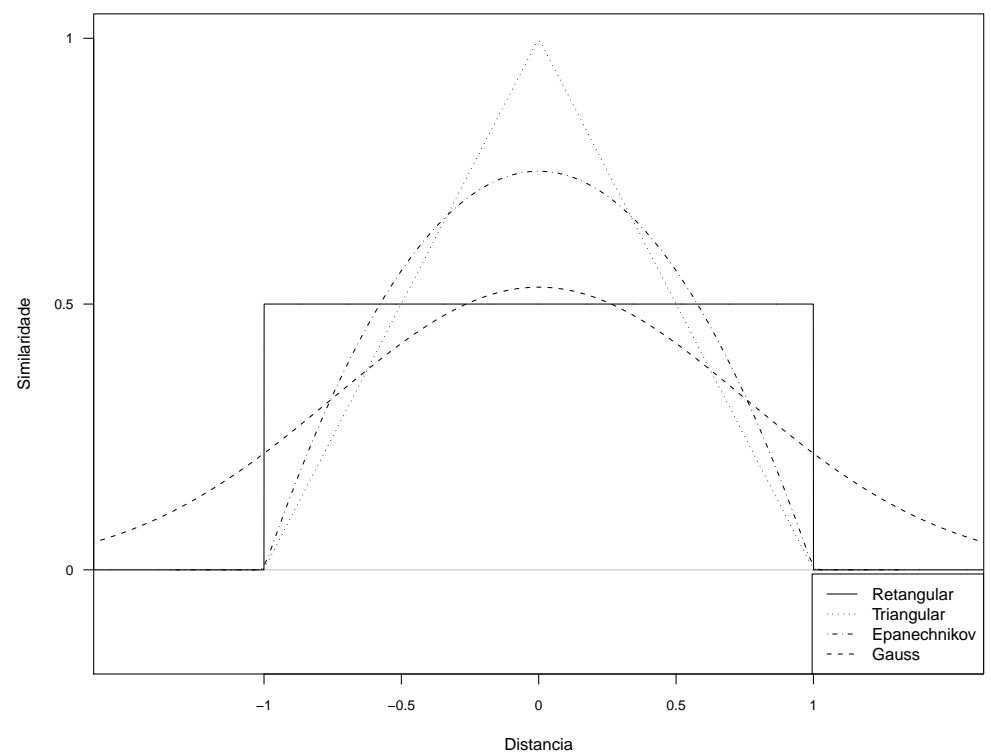

Figura 5.6: Ilustração da forma das funções de kernel Retangular, Triangular, Epanechnikov e Gauss

Pode-se perceber pela Figura 5.5 que utilizou-se o LOO interno discutido anteriormente para determinar automaticamente o número $k^{*}$ de vizinhos para cada $w k \mathrm{NN}$. A abordagem selecionou em média (com desvio padrão) 5.645 (1.862), 12.604 (1.21), 10.687 (1.925) e 8.062 (1.767) vizinhos para os $w k \mathrm{NN}$ com kernel Retangular, Triangular, Epanechnikov e Gauss, respectivamente, resultando em acurácias médias de $0.671,0.722,0.710$ e 0.689. Aplicando-se os testes de Friedman e Dunn, com 95\% e 90\% de confiança, não se observou diferenças significantes em relação aos quatro métodos. Quando comparados com o RP, todos apresentaram desempenho estatisticamente superior.

A Figura 5.7 expõe as acurácias médias do $w k \mathrm{NN}$ com os 4 kernels de antes para os dados caracterizados com as medidas do conjunto VALIDITY. A priori, a vantagem da ponderação de vizinhos não é evidente devido ao desempenho inferior do $w k \mathrm{NN}$ para $k=1$. A partir de uma vizinhança com 5 meta-exemplos, os kernels mais complexos sobrepujam o mais simples na maioria dos casos, ate $k=30$. Quando considera-se o $k^{*}$, são selecionados em média (com desvio padrão) 9.916 (2.857), 10.541 (1.529), 9.875 (2.265) e 8.854 (2.924) vizinhos para os kernels Retangular, Triangular, Epanechnikov e Gauss, respectivamente, resultando em acurácias médias de 0.732, 0.775 


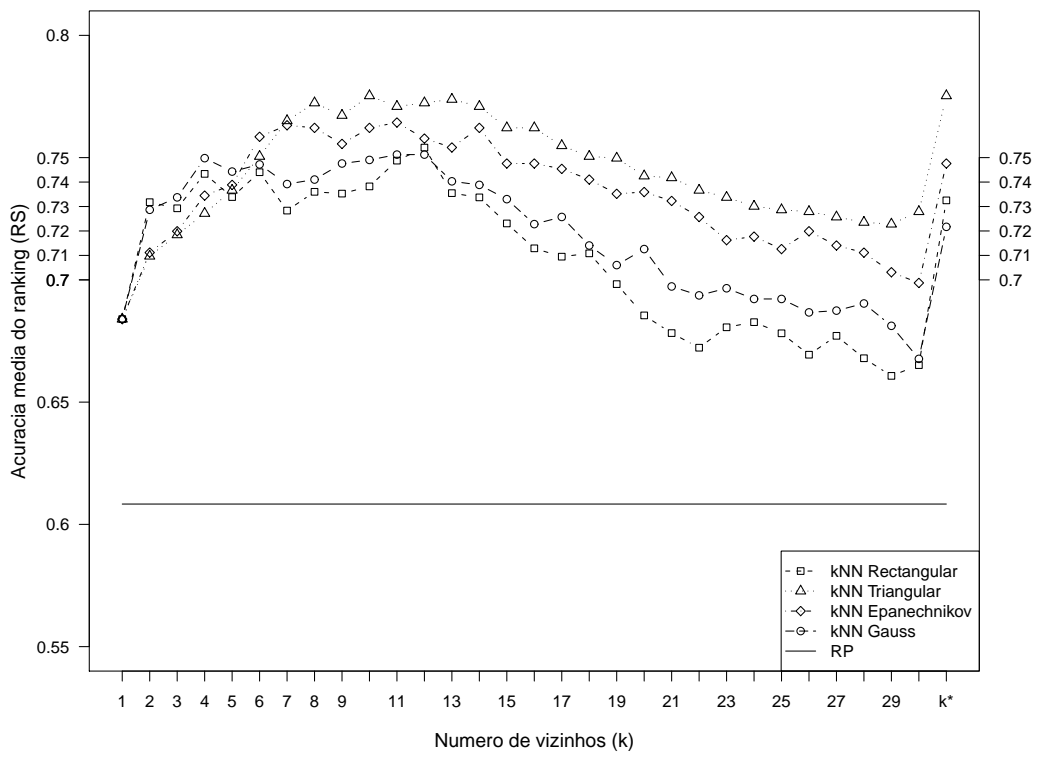

Figura 5.7: Desempenho do método $w k \mathrm{NN}$ com caracterização de dados utilizando o conjunto VALIDITY e 4 funções de kernel

0.747 e 0.721 . Com os testes estatísticos apropriados, verifica-se que o kernel Triangular resulta em desempenho significativamente superior àquele obtido com o kernel Gauss e equivalente aos outros kernels. Todas as 4 versões do $w k \mathrm{NN}$ são mais acurados que o RP.

Na Figura 5.8, observa-se os resultados dos $w k N N$ Rectangular, Triangular, Epanechnikov e Gauss com a caracterização de dados realizada pelo conjunto MIXED. O comportamento destes métodos é similar àqueles observados para as demais abordagens de construção de ranking baseadas em vizinhos mais próximos: após minimizar a influência de meta-exemplos ruidosos através da inserção de mais elementos à vizinhança, atinge-se uma região de acurácias médias máximas. Em seguida, inicia-se um processo de deterioração de desempenho no decorrer do intervalo de $k$, com intensidade inversamente proporcional às inclinações de pesos ilustradas na Figura 5.6. Quando considera-se a determinação automática de $k$, tem-se, para os 4 kernels supracitados, respectivamente, as médias (com desvios padrão) de 5.895 (0.721), 8.437 (1.911), 8.166 (1.692) e 6.250 (0.601) vizinhos. Este valores encontram-se nas regiões de melhores $k$ para cada $w k \mathrm{NN}$ e resultaram em acurácias médias de 0.727, 0.734, 0.733 e 0.739 fazendo com que os métodos, segundo os teste de Friedman e Dunn com os níveis de confiança considerados aqui, sejam todos estatisticamente equivalentes entre si e superiores ao RP.

Como um todo, os resultados apresentados nas Figuras 5.5, 5.7 e 5.8 alinham-se com aqueles da Figura 5.4 no que tange à caracterização de dados: os conjuntos STATLOG, VALIDITY e MIXED permitem ao $w k \mathrm{NN}$ produzir evidências convincentes do êxito da recomendação de algoritmos para dados 


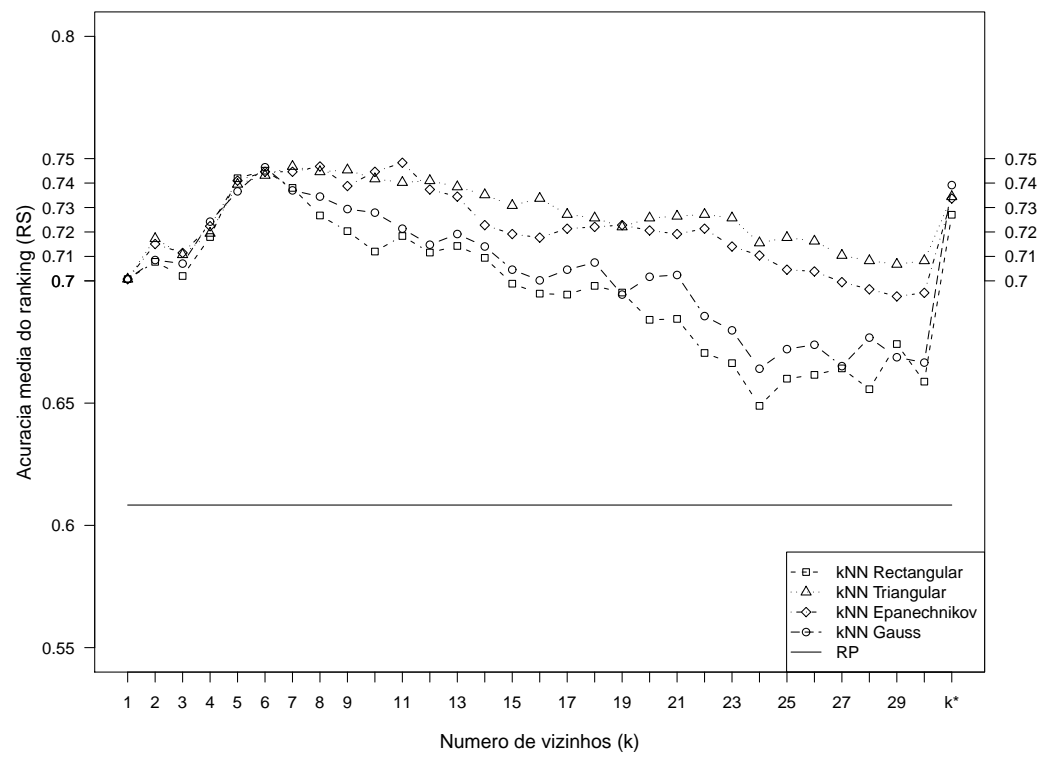

Figura 5.8: Desempenho do método $w k \mathrm{NN}$ com caracterização de dados utilizando o conjunto MIXED e 4 funções de kernel

de expressão gênica. Entretanto, o VALIDITY o faz com maior propriedade para todos os números de vizinho e funções de kernel considerados. Em especial, o desempenho do método com este conjunto utilizando o $k^{*}$ e o kernel Triangular mostra-se bastante superior às demais acurácias obtidas. Para o STATLOG, o $w k \mathrm{NN}$ Triangular com $k^{*}$ também tem seu valor, assim como o wkNN Gauss para o conjunto MIXED. Assim, estas configurações serão empregadas na Seção 5.6 para uma comparação geral entre representantes do três paradigmas de construção de ranking utilizados neste trabalho.

\subsection{Ranking por regressão}

Nesta seção, a construção da recomendação fornecida ao usuário é realizada no contexto de regressão, cuja descrição encontra-se no Capítulo 4. Em tal arcabouço, os desempenhos esperados dos algoritmos de AM são inicialmente preditos pela aplicação de meta-regressores e depois combinados para a composição final do ranking. Para esta tarefa, diversas métodos têm sido aplicados (Brazdil et al., 2009). No presente trabalho, a exemplo de Prudêncio et al. (2008), utilizam-se os algoritmos SVM, 1NN, LR e M5, que são avaliados segundo sua capacidade tanto de aproximar os desempenhos específicos dos classificadores quanto de construir rankings dos mesmos. A seguir, reportam-se os resultados obtidos com essa abordagem. 


\subsubsection{Predição de desempenho}

A fim de adequar o uso de meta-aprendizagem à predição de desempenhos, é necessário modificar os meta-exemplos para permitir a aplicação de técnicas de regressão. Isso é realizado pela alteração na forma como a sugestão é fornecida ao usuário no meta-atributo alvo. Dessa maneira, os rankings são substituídos por alguma medida de qualidade própria dos algoritmos de AM. Logo, é possível estudar diretamente a relação entre as propriedades das bases de dados e o desempenho de um classificador específico, originando tantos problemas de regressão quanto forem os classificadores disponíveis. Nos experimentos a seguir, os dados são caracterizados segundo os conjuntos STATLOG, VALIDITY e MIXED, os algoritmos de classificação considerados são o DLDA, o DQDA, o PAM, o $k$ NN, o SVM-L, o SVM-R e o RF, e a medida de desempenho de cada algoritmo é dada pelo erro estimado utilizando o método $.632+$.

A avaliação dos meta-regressores ocorre de acordo com o LOO aplicado sobre os 49 meta-exemplos aqui considerados. Assim, para cada iteração do procedimento, um modelo de regressão é induzido sobre os meta-exemplos de treinamento e o erro do classificador é predito para o meta-exemplo de teste. O processo é repetido para cada algoritmo de AM. Para mensurar a qualidade das predições realizadas, calcula-se o seu desvio em relação ao erro real ${ }^{6}$ obtido pelo classificador. A média dos desvios absolutos (MDA) é então empregada como medida de desempenho da meta-aprendizagem, de modo que valores menores de MDA indicam uma menor discrepância entre os erros predito e real e, portanto, estão associados a melhores regressores. Tal estratégia foi também aplicada em (Bensusan e Kalousis, 2001).

As SVMs para regressão aqui utilizadas (Schölkopf et al., 2000) apresentam diversos parâmetros livres cujos valores precisam ser estimados. Para a realização desta tarefa, diversas técnicas de otimização podem ser aplicadas (Chapelle et al., 2002). Aqui, com a finalidade de minimizar o custo computacional despendido na seleção de modelos, empregou-se um conjunto de heurísticas. Assim, considerando-se o kernel radial utilizado, o valor para $\gamma$ foi determinado de acordo com a variante do método de Jaakkola apresentado em (Prudêncio et al., 2008). O Custo $C$ do algoritmo foi escolhido segundo a prescrição fornecida em (Cherkassky e Ma, 2002) e o parâmetro $\nu$ da regressão foi definido como o valor assintoticamente ótimo derivado em (Chalimourda et al., 2004).

A Tabela 5.3 mostra os resultados da meta-regressão para os dados caracterizados utilizando-se o conjunto STATLOG. Os valores apresentados

\footnotetext{
${ }^{6}$ Apesar dda utilização deste termo, o erro considerado é, de fato, apenas uma estimativa do erro real realizada pelo $.632+$.
} 
correspondem à medida MDA dos métodos SVM, 1NN, LR e M5 quando utilizados para predizer o desempenho dos 7 algoritmos de AM considerados. Para fornecer uma base de comparação para os desempenhos obtidos, exibe-se também predições realizadas pelo método MEDIA, que simplesmente prediz de acordo com a média dos meta-atributos alvo dos meta-exemplos de treinamento. Logo, espera-se que 4 regressores anteriores produzam valores de MDA menores que os obtidos por MEDIA. A melhor entrada para cada classificador é destacada na tabela (e nas subsequentes contendo os MDAs dos meta-regressores).

Tabela 5.3: Desempenho de 4 meta-regressores na estimação de erro de 7 classificadores, utilizando caracterização pelo conjunto STATLOG

\begin{tabular}{cccccccc}
\hline Meta-regressor & DLDA & DQDA & PAM & $k$ NN & SVM-L & SVM-R & RF \\
\hline SVM & 0.121 & 0.126 & 0.118 & 0.112 & $\mathbf{0 . 0 7 1}$ & 0.082 & $\mathbf{0 . 0 8 4}$ \\
1NN & 0.134 & 0.153 & 0.136 & 0.150 & 0.093 & 0.109 & 0.110 \\
LR & 0.123 & 0.125 & 0.118 & 0.116 & 0.072 & 0.091 & 0.086 \\
M5 & $\mathbf{0 . 1 1 1}$ & $\mathbf{0 . 1 1 6}$ & $\mathbf{0 . 0 9 6}$ & $\mathbf{0 . 1 0 8}$ & 0.076 & $\mathbf{0 . 0 8 0}$ & 0.097 \\
MEDIA & 0.130 & 0.130 & 0.116 & 0.117 & 0.078 & 0.093 & 0.085 \\
\hline
\end{tabular}

Como pode-se notar, o M5 apresenta o melhor desempenho geral, sendo superior ao MEDIA para todos os classificadores, exceto para o RF. Em 4 casos, ele consegue ainda as menores MDAs entre os meta-regressores. Considerando sua MDA máxima de 0.116 para o DQDA, espera-se que o erro médio de sua estimação em novos meta-exemplos seja inferior a $12 \%$ para os 7 classificadores. O SVM exibe resultados bons, sendo o método de menor MDA para o SVM-L e o RF, mas com pequena desvantagem em relação ao MEDIA para o PAM. O LR é a abordagem que menos se destaca, negativa ou positivamente. Ele tende a produzir MDAs situadas entre as obtidas por SVM e MEDIA. Por fim, LR aparenta não ser suficientemente eficaz em utilizar as informações providas pelo conjunto STATLOG para predizer o desempenho dos classificadores, sendo consistentemente superado pelo MEDIA. Para o $k \mathrm{NN}$, a diferença observada é mais patente.

Conforme discutido anteriormente, os resultados apresentados na Tabela 5.3 correspondem a valores médios dos erros de estimação dos meta-regressores. Para tornar as comparações realizadas mais informativas, pode-se fazer uso de testes estatísticos complementares, como sugerido em (Kalousis, 2002). Assim, exibem-se os p-valores ${ }^{7}$ produzidos pela aplicação do teste $\mathrm{t}$ pareado utilizado para verificar a hipótese nula de igualdade entre os desempenhos de cada um dos métodos SVM, 1NN, LR e M5 e o

\footnotetext{
${ }^{7}$ Para as comparações realizadas nesta seção, considera-se p-valor a probabilidade de que as MDAs obtidas por dois métodos sejam provenientes de uma mesma população, considerando a hipótese nula como verdadeira. Valores baixos de probabilidade são indícios contra a hipotése nula e a favor da hipótese alternativa de diferença de desempenho entre os métodos.
} 
desempenho do MEDIA. Como várias comparações entre os 4 métodos e o MEDIA são realizadas, para os 7 classificadores, é necessário modificar o nível de confiança dos testes. Para isso, utiliza-se a correção de Bonferroni (Bland e Altman, 1995). Assim, considerando uma confiança geral de 90\%, tem-se o valor ajustado de $\alpha=0.00357$ para cada um dos testes.

Tabela 5.4: P-valores do teste $\mathrm{t}$ pareado utilizado para comparar os os meta-regressores SVM, 1NN, LR e M5 com o MEDIA, utilizando caracterização pelo conjunto STATLOG

\begin{tabular}{cccccccc}
\hline Meta-regressor & DLDA & DQDA & PAM & $k$ NN & SVM-L & SVM-R & RF \\
\hline SVM & 0.1183 & 0.4957 & 0.7522 & 0.4100 & 0.0657 & 0.0422 & 0.7329 \\
1NN & 0.8441 & 0.1982 & 0.2070 & 0.0495 & 0.1598 & 0.2442 & 0.0292 \\
LR & 0.4292 & 0.0685 & 0.8016 & 0.6780 & 0.1156 & 0.1433 & 0.9581 \\
M5 & 0.1268 & 0.2814 & 0.3057 & 0.7187 & 0.5395 & 0.1601 & 0.1669 \\
\hline
\end{tabular}

Percebe-se que nenhuma diferença de desempenho entre os 4 métodos e o MEDIA pode ser considerada estatisticamente significante segundo o nível de confiança requerido. Entretanto, a análise dos p-valores da Tabela 5.4 podem complementar os resultados apresentados na Tabela 5.3. Por exemplo, para o DQDA, o LR exibe p-valor menor que o do M5, indicando que o primeiro método pode ser mais vantajoso que do o segundo em relação ao MEDIA, apesar de apresentar MDA maior. Para o SVM-L e O SVM-R, o meta-regressor SVM apresenta os menores p-valores, o que sugere que ele pode ser mais adequado à tarefa de estimar o desempenho de tais classificadores, em comparação ao M5. Os pequenos p-valores do 1NN para $k \mathrm{NN}$ e o RF corroboram sua deficiência como meta-regressor para estes casos.

Tabela 5.5: Desempenho de 4 meta-regressores na estimação de erro de 7 classificadores, utilizando caracterização pelo conjunto VALIDITY

\begin{tabular}{cccccccc}
\hline Meta-regressor & DLDA & DQDA & PAM & $k$ NN & SVM-L & SVM-R & RF \\
\hline SVM & 0.109 & 0.119 & 0.103 & 0.110 & $\mathbf{0 . 0 7 2}$ & $\mathbf{0 . 0 8 6}$ & 0.082 \\
1NN & 0.124 & 0.142 & 0.118 & 0.149 & 0.098 & 0.118 & 0.097 \\
LR & 0.122 & 0.125 & 0.117 & 0.115 & 0.075 & 0.098 & 0.084 \\
M5 & $\mathbf{0 . 0 9 3}$ & $\mathbf{0 . 1 1 1}$ & $\mathbf{0 . 0 9 1}$ & 0.108 & 0.079 & 0.092 & $\mathbf{0 . 0 8 1}$ \\
MEDIA & 0.130 & 0.130 & 0.116 & 0.117 & 0.078 & 0.093 & 0.085 \\
\hline
\end{tabular}

A Tabela 5.5 mostra os resultados da estimação de desempenho dos algoritmos de AM para os dados caracterizados segundo as medidas do conjunto VALIDITY. As entradas mostradas correspondem à medida MDA dos meta-regressores SVM, 1NN, LR e M5, e do método MEDIA. Novamente, o M5 apresentou MDAs pequenas, produzindo valores mínimos para 4 classificadores e sendo inferior ao MEDIA apenas para o SVM-L. O SVM conseguiu ser superior ao MEDIA em todas as situações. Ele foi ainda o método de menor MDA para o SVM-L e o SVM-R. O LR manteve-se como meta-regressor mediano. O $1 \mathrm{NN}$ foi superior ao MEDIA somente para o caso 
do DLDA. Para os outros algoritmos, suas estimativas não se mostraram tão adequadas.

Tabela 5.6: P-valores do teste $\mathrm{t}$ pareado utilizado para comparar os os meta-regressores SVM, 1NN, LR e M5 com o MEDIA, utilizando caracterização pelo conjunto VALIDITY

\begin{tabular}{cccccccc}
\hline Meta-regressor & DLDA & DQDA & PAM & $k$ NN & SVM-L & SVM-R & RF \\
\hline SVM & 0.0017 & 0.1316 & 0.0374 & 0.2682 & 0.0754 & 0.1295 & 0.4521 \\
1NN & 0.722 & 0.4727 & 0.8989 & 0.03442 & 0.0767 & 0.08197 & 0.2659 \\
LR & 0.4736 & 0.3452 & 0.9075 & 0.8178 & 0.0993 & 0.5702 & 0.7028 \\
M5 & 0.0006 & 0.1249 & 0.0284 & 0.2495 & 0.8529 & 0.8805 & 0.5119 \\
\hline
\end{tabular}

Considerando uma confiança de 90\%, verifica-se na Tabela 5.6 que tanto o SVM quanto o M5 são estatisticamente superiores ao MEDIA na estimação de desempenho do DLDA. Ambos apresentam ainda $\mathrm{p}$-valores pequenos para o PAM. Para o SVM-L, o teste t pareado produziu p-valores abaixo de 0.10 para o SVM e o LR, sugerindo uma vantagem desses meta-regressores em relação ao MEDIA. Nenhum método aproximou-se do nível necessário para apresentar diferenças significantes ao MEDIA para o SVM-L e o RF. O 1NN, novamente, representou o método de menor capacidade.

Tabela 5.7: Desempenho de 4 meta-regressores na estimação de erro de 7 classificadores, utilizando caracterização pelo conjunto MIXED

\begin{tabular}{cccccccc}
\hline Meta-regressor & DLDA & DQDA & PAM & $k$ NN & SVM-L & SVM-R & RF \\
\hline SVM & 0.102 & 0.109 & 0.098 & $\mathbf{0 . 1 0 1}$ & $\mathbf{0 . 0 6 5}$ & $\mathbf{0 . 0 7 3}$ & $\mathbf{0 . 0 7 5}$ \\
1NN & 0.112 & 0.122 & 0.114 & 0.126 & 0.087 & 0.104 & 0.102 \\
LR & 0.121 & 0.134 & 0.118 & 0.112 & 0.071 & 0.093 & 0.082 \\
M5 & $\mathbf{0 . 0 9 8}$ & $\mathbf{0 . 1 0 8}$ & $\mathbf{0 . 0 9 3}$ & 0.115 & 0.091 & 0.077 & 0.080 \\
MEDIA & 0.130 & 0.130 & 0.116 & 0.117 & 0.078 & 0.093 & 0.085 \\
\hline
\end{tabular}

Utilizando-se o conjunto MIXED para realizar a caracterização dos dados, o SVM logrou apresentar as menores MDAs para 4 algoritmos de AM, conforme pode ser observado na Tabela 5.7, sem ser inferior ao MEDIA para caso algum. O M5 obteve MDAs mínimos para o DLDA, o DQDA e o PAM, e foi suplantado pelo MEDIA para o $k$ NN e o SVM-L. O LR apresentou desempenho discreto, sendo superado pelo MEDIA em 2 ocasiões. Por sua vez, o $1 \mathrm{NN}$ foi vantajoso pra 3 classificadores e para os demais as diferenças em relação ao MEDIA tornaram-se menos acentuadas que aquelas apresentadas nas Tabelas $5.3 \mathrm{e}$ 5.5 .

Quando o teste $\mathrm{t}$ pareado é utilizado na comparação entre os 4 meta-regressores e o MEDIA, a Tabela 5.8 exibe resultados expressivos para o SVM. Com valor o ajustado $\alpha=0.00357$, este método resulta estatisticamente superior ao MEDIA para 5 classificadores. Para o $k \mathrm{NN}$ e o $\mathrm{RF}$, o p-valor também é pequeno, embora não o suficiente para superar o nível de 
Tabela 5.8: P-valores do teste $\mathrm{t}$ pareado utilizado para comparar os os meta-regressores SVM, 1NN, LR e M5 com o MEDIA, utilizando caracterização pelo conjunto MIXED

\begin{tabular}{cccccccc}
\hline Meta-regressor & DLDA & DQDA & PAM & $k$ NN & SVM-L & SVM-R & RF \\
\hline SVM & 0.0000 & 0.0022 & 0.0026 & 0.0127 & 0.0017 & 0.0003 & 0.0181 \\
1NN & 0.2906 & 0.6577 & 0.8921 & 0.5904 & 0.4910 & 0.4987 & 0.2050 \\
LR & 0.4184 & 0.2260 & 0.8643 & 0.3917 & 0.0222 & 0.8629 & 0.5124 \\
M5 & 0.0041 & 0.1426 & 0.0204 & 0.8447 & 0.2623 & 0.0895 & 0.5255 \\
\hline
\end{tabular}

significância estipulado. Os demais métodos de regressão não apresentam diferenças significantes

Analisando-se as Tabelas 5.3, 5.5 e 5.7 em conjunto, algumas considerações podem ser tecidas. Inicialmente, nota-se que os métodos SVM e M5 são consistentemente superiores aos outros meta-regressores na tarefa de predizer o desempenho de algoritmos de AM no contexto deste trabalho. Como estas abordagens são mais complexas que o 1NN e o LR, elas apresentam maior eficácia na extração de relações explicativas entre os meta-atributos de entrada e o meta-atributos alvo. Por sua vez, o 1NN exibiu resultados pouco promissores, sendo na maioria das situações inferior ao MEDIA. O LR demonstrou alternância de desempenho conforme o classificador considerado, mas invariavelmente não apresentou grande desvio do patamar do MEDIA.

Outro aspecto importante dos resultados reportados refere-se à influência da caracterização de dados no desempenho dos meta-regressores. Considerando-se os conjuntos STATLOG e VALIDITY, percebe-se uma certa estratificação em seus domínios de competência. Através do uso das medidas do primeiro grupo, é possivel predizer melhor os desempenhos de SVM-L e SVM-R, para todos os meta-regressores. Com as medidas do segundo grupo, as predições para DLDA, DQDA, PAM e RF são mais acuradas. As predições de desempenho para o $k \mathrm{NN}$ são mais robustas quanto ao conjunto de medidas utilizado. Quando o conjunto MIXED é empregado, o SVM obtém os p-valores mais significantes globalmente, indicando sua superioridade sobre o MEDIA, e o $1 \mathrm{NN}$ logra seus melhores desempenhos. Isto indica que a agregação de medidas de diferentes conjuntos pode fornecer informações mais abrangentes sobre o comportamento dos classificadores em relação às propriedades das bases de dados. O LR e o M5 não apresentam um padrão bem definido para o conjunto MIXED, sendo seu desempenho dependente do algoritmo de AM.

A fim de obter uma maior compreensão desses resultados, analisou-se brevemente a relação entre os classificadores e as medidas de caracterização de dados. A metodologia empregada para tanto utiliza, a exemplo de (Costa et al., 2009), uma representação gráfica exibindo o desempenho dos algoritmos e os meta-atributos computados. Para determinar se os valores estão relacionados, calculou-se o coeficiente de correlação de Pearson seguido 
de um teste t apropriado Sokal e Rohlf (1995). Estas informações são exibidas nas Figuras 5.9 (conjunto STATLOG) e 5.10 (conjunto VALIDITY). Cada bloco mostra a estimativa de erro usando o .632+ (eixo das abscissas) e a medida de caracterização (eixo das ordenadas) determinadas para as 49 bases de dados. Nos cantos superiores direitos, encontram-se os valores de correlação entre os pares. Valores em negrito indicam significância estatística com $90 \%$ de confiança.

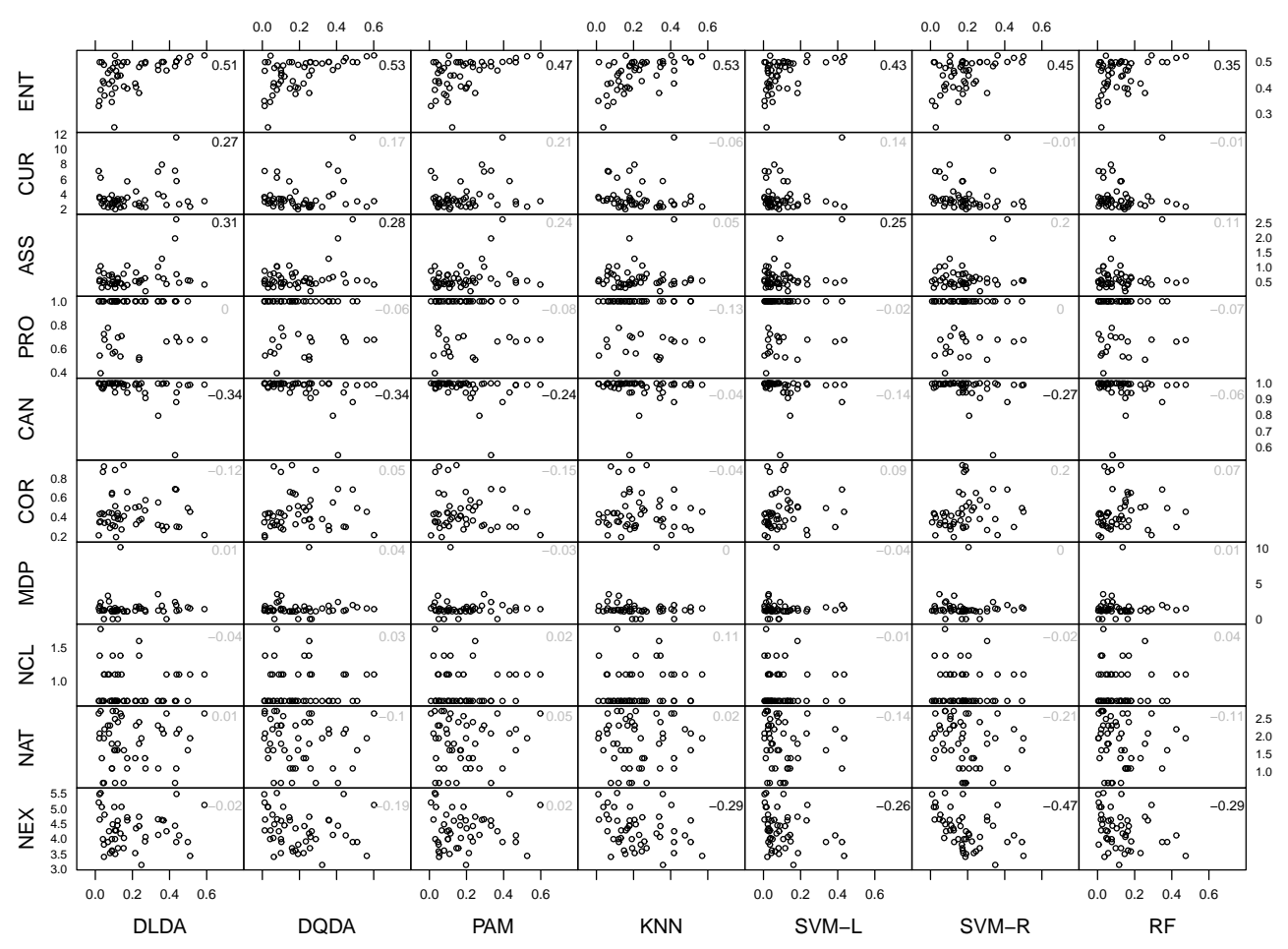

Figura 5.9: Correlação entre as medidas STATLOG e o erro dos classificadores

Como pode-se perceber na Figura 5.9, NEX apresenta correlações negativas significantes com os algoritmos $k \mathrm{NN}$, SVM-L, SVM-R e RF, indicando que estes se beneficiam de um número maior de exemplos para produzir classificadores de menor erro. NAT representa o número de componentes PLS extraídas antes da caracterização de dados e aparenta não ter correlação relevante com os desempenhos obtidos. Este também é o caso com o NCL, o número de classes, que, neste trabalho, é predominantemente 2. O MDP é uma maneira de informar quão diferentes são as matrizes de covariância dos dados para cada classe. Quanto maior seu valor, menos linear deve ser a fronteira de separação. Com a utilização do PLS, a separação entre as classes é maximizada e, portanto, a importância dessa medida é minorada. O mesmo acontece com a COR, que representa as correlações médias entre atributos, por classe.

A CAN é uma medida de associação entre atributos e classes baseada 
na análise de correlação canônica entre ambos. Ela pretende capturar a quantidade de informação útil para a classificação dos dados. Quanto maior seu valor, menor o erro do classificador, o que explica as correlações negativas observadas. o PRO é a proporção de variância explicada pelo primeiro discriminante linear encontrado no cálculo de CAN. Verifica-se que para a maioria das bases de dados consideradas, $\mathrm{PRO}=1$, reduzindo a informação dessa medida pra estimar o desempenho dos algoritmos. Para cada atributo, ASS e CUR indicam, respectivamente, a falta de simetria em sua distribuição e a altura relativa da cauda desta. Ela apresentam razoável correlação com o desempenho de alguns classificadores, em especial do DLDA, que assume atributos normalmente distribuídos. Por fim, a distribuição dos exemplos pelas classes do problema, representada por ENT, exibe correlação positiva significante para todos os classificadores.

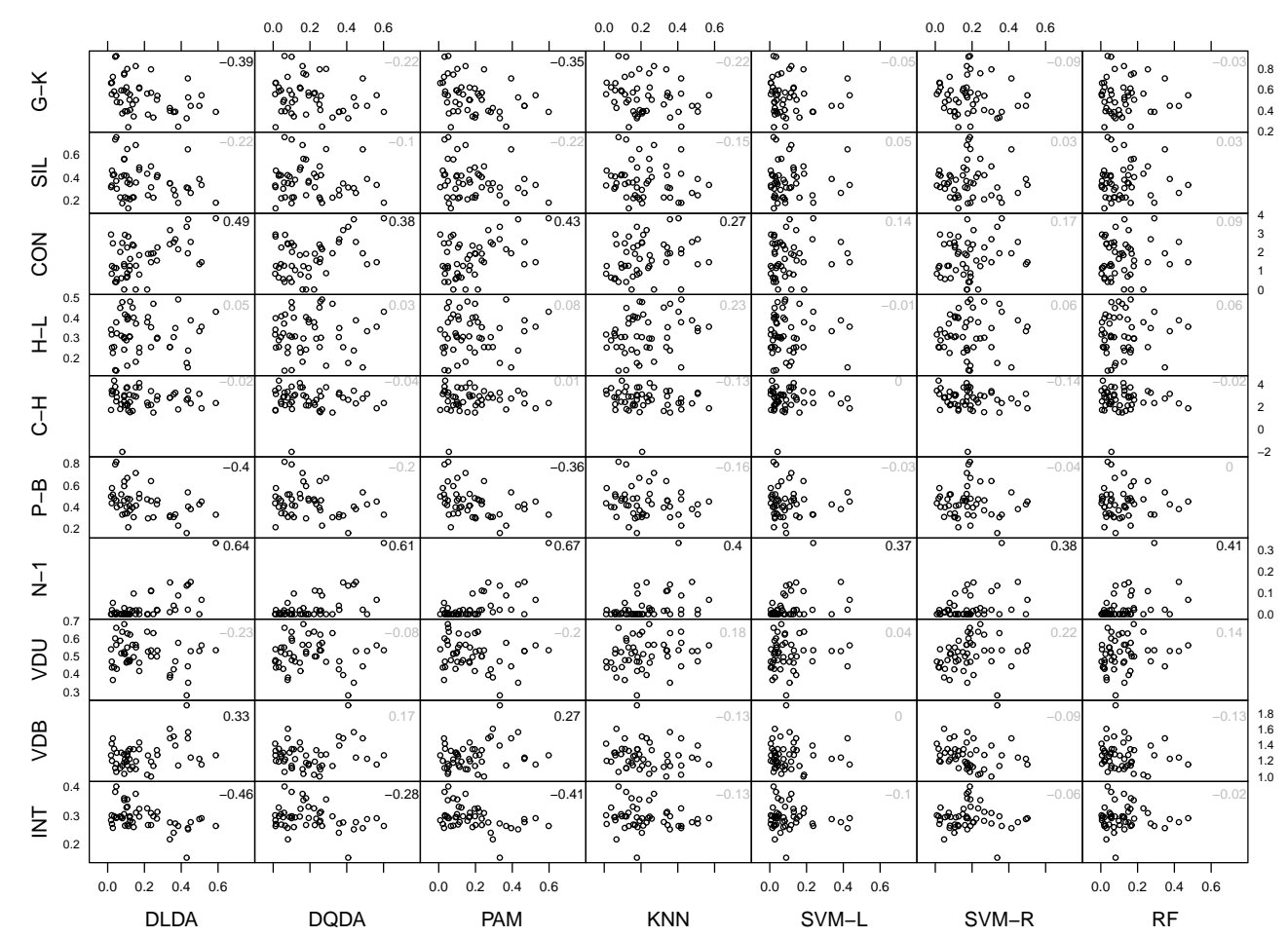

Figura 5.10: Correlação entre as medidas VALIDITY e o erro dos classificadores

A Figura 5.10 exibe os resultados da análise para o conjunto VALIDITY. VDU e VDB medem a separação e dispersão dos grupos presentes nos dados. Elas obtêm razoável correlação com o desempenho dos classificadores, principalmente para o DLDA, DQDA e PAM, com vantagem para o VDB. P-B, G-K, C-H e H-L também tencionam avaliar quão compactos e separados são os grupos mas utilizando diferentes critérios de otimização. Aparentemente, as duas primeiras medidas são mais adequadas aos propósitos deste trabalho dadas suas correlações com os desempenhos dos classificadores. 
Comparando-se os valores obtidos pelas 6 medidas anteriores com aqueles conseguidos pelo INT, percebe-se que esta tende a resultar em correlações absolutas maiores. Esta observação é coerente com a discussão realizada em (Bezdek e Pal, 1998b), segundo a qual a separação entre grupos é a componente mais importante de um índice de validação para examinar a qualidade de um agrupamento. Neste sentido, as altas correlações o N-1 para todos os classificadores também são esperadas, pois esta medida busca identificar se exemplos de classes distintas vêm da mesma distribuição. Investigando a complexidade de classificação em dados de expressão gênica, Costa et al. (2009) chegaram à conclusões similares quanto a utilização de N-1 para predizer o comportamento de classificadores. O mesmo estudo também sugeriu que métricas de complexidade baseadas em vizinhos mais próximos Ho e Basu (2002) fornecem resultados igualmente interessantes nesse contexto, o que é corroborado pelos valores apresentados pela medida CON na figura.

Considerando-se as correlações observadas nas Figuras 5.9 e 5.10, pode-se obter um maior entendimento sobre os resultados apresentados nas Tabelas 5.3 e 5.5 quanto à relação entre a caracterização de dados e a predição de desempenho para determinados classificadores. Para SVM-L e SVM-R, os valores de correlação absoluta exibidos são maiores para as medidas STATLOG que para as medidas VALIDITY. Isto explica as MDAs mais baixas conseguidas pelos meta-regressores quando o primeiro conjunto de caracterização é empregado. Para DLDA, DQDA, PAM e RF, o conjunto VALIDITY exibe melhores correlações que aquelas observadas com o conjunto STATLOG, fazendo com que os valores preditos para os meta-atributos alvo sejam mais acurados quando da utilização daquele conjunto. Percebe-se ainda que nem todas as medidas apresentam a mesma importância preditiva. Sendo assim, a aplicação de técnicas de seleção de atributos (Liu e Motoda, 1998) poderia ajudar a melhorar as predições realizadas.

\subsubsection{Construção de rankings}

Conforme discutido durante esta seção, meta-regressores podem ser eficazmente empregados na predição do comportamento de algoritmos de AM. Com isso, é possível fornecer ao usuário um valor de desempenho esperado para o classificador de interesse. Quando mais de uma abordagem de classificação está disponível, um número correspondente de problemas de regressão é considerado, permitindo a obtenção de diversas predições. Elas podem então ser ordenadas para a composição de um ranking. Como no presente trabalho esta é a forma preferencial de recomendação de algoritmos, sua construção por regressão é avaliada a seguir. 
A Tabela 5.9 exibe os resultados da utilização dos métodos SVM, 1NN, LR e M5 para a predição dos desempenhos utilizados na construção dos rankings. Suas entradas correspondem às médias de acurácia (utilizando o coeficiente de Spearman, $r_{S}$ ) dos rankings preditos no decorrer do LOO para os 49 problemas considerados. A caracterização dos dados ocorre segundo os conjuntos STATLOG, VALIDITY e MIXED. Para fornecer uma base de comparação para os valores obtidos, exibe-se também as correlações resultantes da aplicação do ranking padrão, RP.

Tabela 5.9: Acurácias médias dos rankings $\left(r_{S}\right)$ gerados utilizando 4 meta-regressores e 3 conjuntos de caracterização

\begin{tabular}{cccc}
\hline Método & STATLOG & VALIDITY & MIXED \\
\hline SVM & 0.716 & 0.731 & 0.733 \\
1NN & 0.675 & 0.683 & 0.700 \\
LR & 0.592 & 0.604 & 0.586 \\
M5 & 0.588 & 0.580 & 0.510 \\
\hline RP & 0.608 & 0.608 & 0.608 \\
\hline
\end{tabular}

Pode-se perceber uma clara divisão no desempenho dos métodos. Enquanto SVM e 1NN, são capazes de superar o RP por considerável vantagem, o L5 e o M5 não logram alcançar o patamar da abordagem de referência. As diferenças entre os métodos mais e menos eficazes acentuam-se com a alteração dos conjuntos utilizados para caracterizar os dados, na ordem: STATLOG, VALIDITY e MIXED. Através da aplicação dos testes de Friedman e de Dunn, com 95\% e 90\% de confiança, respectivamente, observou-se superioridade do SVM em relação ao LR, ao M5 e ao RP, quando o primeiro conjunto de caracterização é empregado. Nesta situação, 1NN obteve diferença significante apenas quando comparado ao LR. Considerando-se os outros conjuntos, tanto o SVM quanto 1NN superam estatisticamente os demais métodos de construção de ranking. Todos os demais desempenhos resultaram similares.

É interessante ainda confrontar os resultados dos meta-regressores mostrados na Tabela 5.9 para a construção de rankings com aqueles apresentados nas Tabelas 5.3, 5.5 e 5.7 para a predição de desempenho dos algoritmos. Pode-se perceber que não há uma correspondência direta entre a adequação dos métodos para as 2 tarefas. Assim, se anteriormente o $1 \mathrm{NN}$ apresentava MDAs grandes para a maioria dos classificadores e era frequentemente inferior ao MEDIA nas predições de desempenho, na situação atual ele é a segunda melhor abordagem para recomendação de rankings, excedendo a acurácia média do RP por diferença mínima de 0.07. Inversamente, o M5, mesmo apresentado MDAs invariavelmente bastante competitivos, resultou em rankings preditos de baixa qualidade. Isto acontece porque os diversos problemas de regressão são resolvidos de forma 
independente uns dos outros. Assim, a ordem relativa das predições nem sempre é preservada, fazendo com que rankings espúrios possam ser gerados. Neste contexto, resultados similarmente contra-intuitivos têm sido reportados (Brazdil et al., 2009; Bensusan e Kalousis, 2001; Koepf et al., 2000).

Como o SVM foi o meta-regressor de maior destaque para todos os conjuntos de caracterização de dados nos experimentos aqui conduzidos, ele será empregado na Seção 5.6 para uma comparação geral entre representantes do 3 paradigmas de construção de ranking utilizados neste trabalho.

\subsection{Ranking por árvores}

Nesta Seção, os rankings sugeridos ao usuário são construídos utilizando a abordagem de árvores, descrita no Capítulo 4. Especificamente, as PCTs (do inglês Predictive Clustering Trees) (Todorovski et al., 2002) são empregadas. Elas operam particionando recursivamente os meta-exemplos disponíveis tal que grupos homogêneos em relação aos meta-atributos alvo sejam obtidos. Quando um meta-exemplo de teste é apresentado à árvore gerada, sucessivas regras sobre seus meta-atributos de entrada decidem qual o grupo mais adequado ao novo problema. A ordenação de algoritmos de AM é então predita com base no ranking associado à folha retornada. A fim de melhorar a robustez das PCTs, faz-se uso de bagging para combinar as predições de árvores individuais. A seguir, os resultados obtidos com essas abordagens são reportados.

\subsubsection{Desempenho do PCT}

Para a realização dos experimentos desta seção, utilizou-se o software Clus $^{8}$. Basicamente, ele consiste em um sistema de AM que trabalha na geração de árvores e regras de decisão baseadas no conceito de agrupamento preditivo (Blockeel et al., 1998). Com isso, o Clus é capaz de criar hierarquias de grupos como as PCTs. Dependendo das necessidades específicas de cada aplicação, diversas opções de configuração relativas a critérios de otimização e heurísticas correspondentes estão disponíveis para seleção.

Em particular, os resultados são podem ser severamente influenciados pela escolha do parâmetro Ftest, que determina o nível de significância utilizado no critério de parada da indução da árvore. Ele varia de 0 a 1 . Valores pequenos produzem um número menor de particionamentos, o que pode provocar uma convergência prematura da etapa de treinamento. Valores próximos a 1 resultam em árvores maiores. A exemplo de (Todorovski et al.,

\footnotetext{
${ }^{8}$ Software disponível em http://dtai.cs.kuleuven.be/clus/index.html
} 
2002), utilizou-se, nos experimentos conduzidos aqui, Ftest=1, que gera árvores de tamanho máximo.

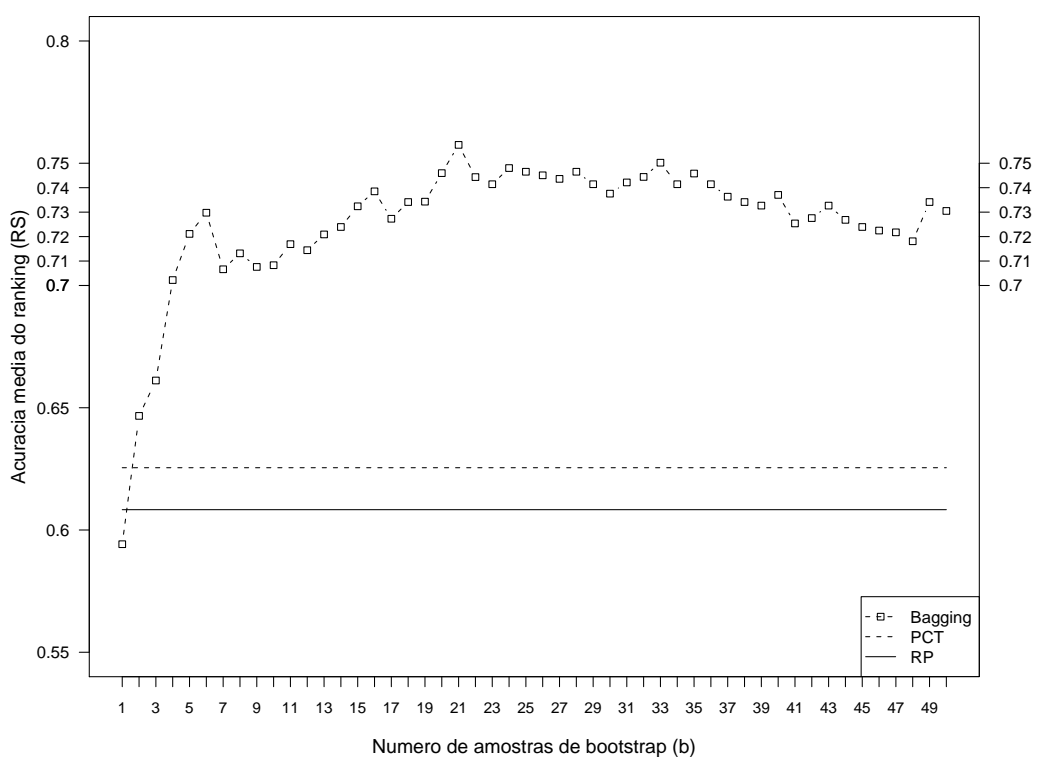

Figura 5.11: Desempenho dos métodos PCT e bagging com caracterização de dados utilizando o conjunto STATLOG

A Figura 5.11 exibe os efeitos da aplicação do PCT e do bagging para as predições envolvendo os 49 problemas em uso. As acurácias médias do LOO utilizando o $r_{S}$ são mostradas. A caracterização dos dados ocorre segundo o conjunto de medidas STATLOG. Como pode ser observado, o PCT não foi muito eficaz na construção de rankings no contexto deste trabalho, com um desempenho de 0.625, apenas discretamente superior ao 0.608 obtido pelo RP (linha completa na figura). Este resultado pode estar associado à profundidade da árvore gerada, que aparenta ajustar sobremaneira o modelo preditivo aos meta-exemplos de treinamento. Para realizar uma redução na quantidade de nós, aplicou-se a modificação experimental do método de poda do M5 (Quinlan, 1992), como implementada no Clus (parâmetro M5Multi=1). Assim, a acurácia média do PCT ampliou-se para 0.658.

Melhorias mais expressivas foram observadas com a utilização do bagging. Para ele, varia-se o número de amostras bootstrap no intervalo de $b=1, \ldots, 50$, sendo o valor máximo definido conforme recomendação em (Breiman, 1996b). Inicialmente, percebe-se que os rankings construídos não são muito acurados. Isto pode ser devido à quantidade reduzida de meta-exemplos únicos de treinamento, aproximadamente $63.2 \%$ do total disponivel. Assim, menos informação é disponibilizada ao PCT para a indução das árvores. À medida que mais amostras bootstrap vão sendo considerados, o desempenho aumenta de acordo, pois predições de diferentes árvores são combinadas. Enquanto $b \leq 21$, o bagging apresenta vários mínimos locais em seu desempenho, mas com uma 
inclinação ascendente. O ápice de 0.757 ocorre em $b=21$. Posteriormente, as acurácias apresentam menor heterogeneidade, pois, através da combinação de um número crescente de árvores, o método torna-se mais robusto à natureza aleatória do procedimento de amostragem e tende a produzir resultados mais estáveis. Com $b=50$, o desempenho é de 0.730, fazendo com que o bagging seja, segundo os testes de Friedman e de Dunn, com 95\% e 90\% de confiança, respectivamente, estatisticamente superior aos métodos PCT e RP. Estes últimos resultaram similar.

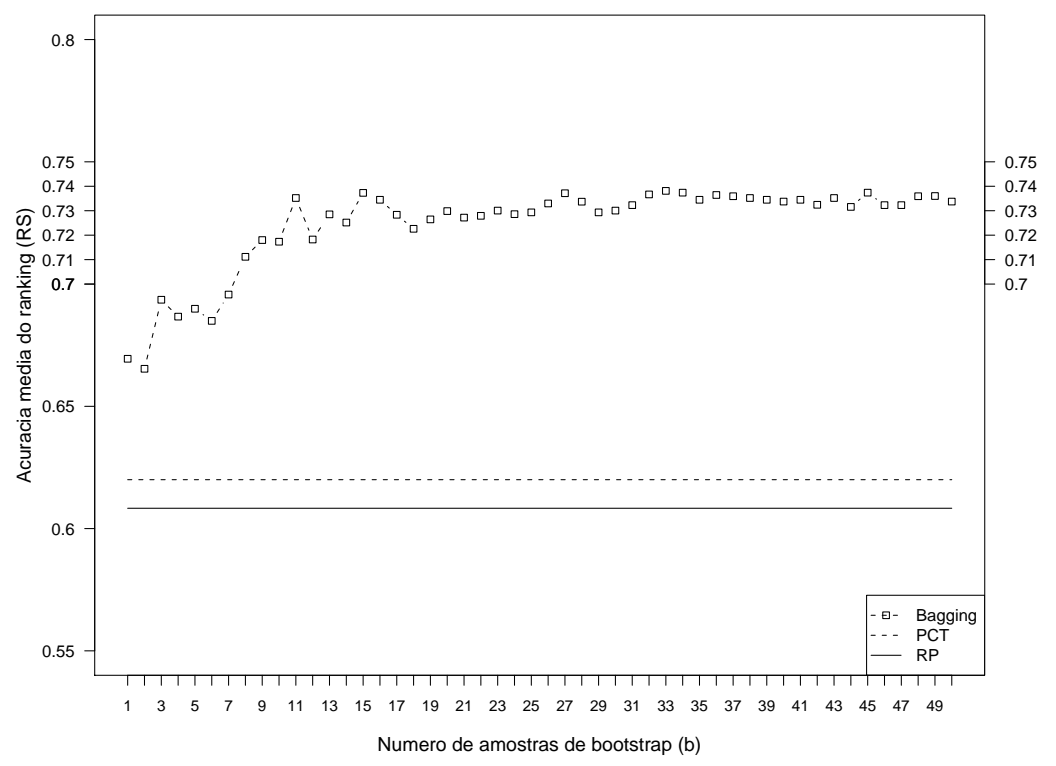

Figura 5.12: Desempenho dos métodos PCT e bagging com caracterização de dados utilizando o conjunto VALIDITY

A Figura 5.12 exibe as acurácias médias dos métodos baseados em árvores para os dados caracterizados segundo o conjunto VALIDITY. Novamente, o PCT não se sobressai em relação ao RP, logrando um desempenho de 0.619. A aplicação de poda ao modelo gerado produz uma melhoria perceptível de acurácia, 0.676 Com a utilização de bagging, o resultados são mais promissores. Para todo o intervalo $b=1, \ldots, 50$, o método é superior tanto ao RP quanto ao PCT. À medida que mais árvores são combinadas, o desempenho aumenta, atingindo seu valor máximo em 0.738 para $b=33$. Em seguida, ocorre uma estabilização nas predições. Considerando-se $b=50$, obteve-se uma acurácia de 0.733. Nesta configuração, o bagging é estatisticamente superior aos outros métodos de rankings, enquanto o PCT e o RP não apresentam diferenças significantes.

Na Figura 5.13, a caracterização dos dados é realizada segundo o conjunto MIXED. Os desempenhos exibidos correspondem às médias das acurácias obtidas no LOO, considerando o $r_{S}$. Percebe-se que o PCT apresenta um resultado moderadamente superior em relação ao RP, com um valor de 0.658. 


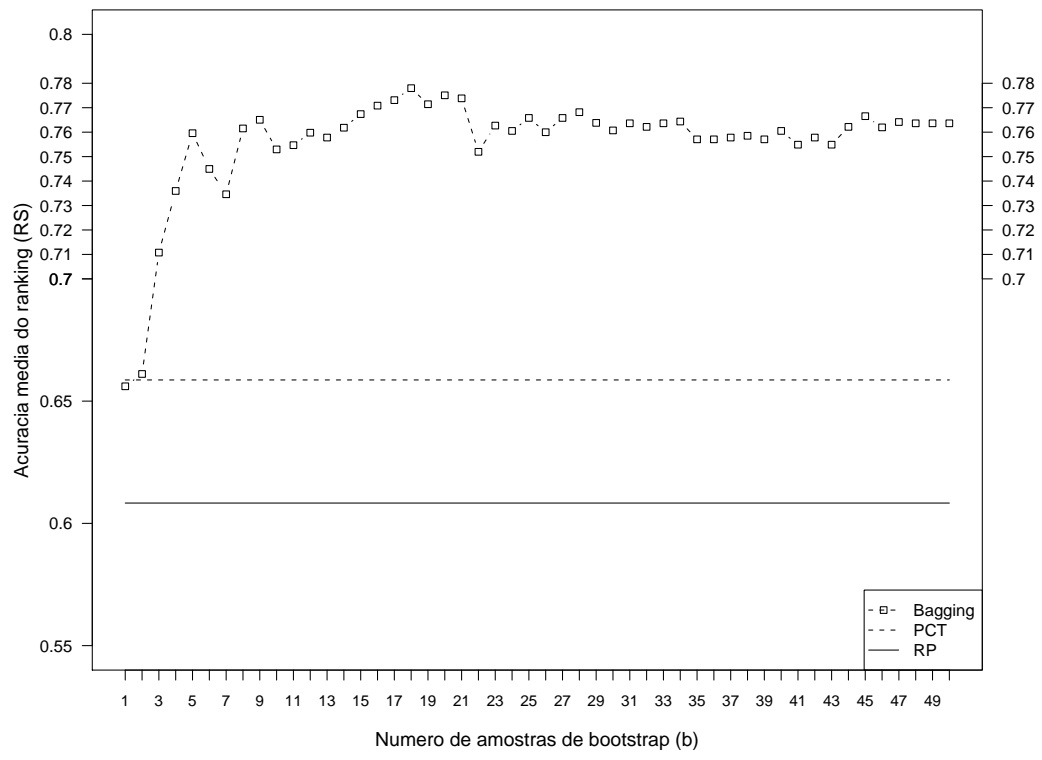

Figura 5.13: Desempenho dos métodos PCT e bagging com caracterização de dados utilizando o conjunto MIXED

A aplicação de poda à árvore gerada obteve uma acurácia de 0.625, indicando que nem sempre essa prática origina ganhos de desempenho. A utilização de bagging, por sua vez, aparenta ser consistentemente vantajosa. Após uma melhora inicial de acurácia com o aumento do número de amostras bootstrap, ele apresenta um intervalo de variação até atingir seu máximo de 0.777 para $b=18$. Na sequência, os resultados se tornam mais uniformes. Utilizando-se os testes de Friedman e de Dunn com as significâncias apropriadas, verifica-se que bagging com $b=50$ é superior aos métodos PCT e RP, enquanto que estes são similares entre si.

Comparando-se as Figuras 5.11, 5.12 e 5.13, observa-se que a diferença de resultados entre a caracterização feita pelos conjuntos STATLOG e VALIDITY não é acentuada, tanto para o PCT quanto para o bagging. Para este método, o primeiro conjunto resulta em acurácias levemente superiores para valores intermediários de $b$, enquanto o segundo é vantajoso para os valores mais extremos. No caso do conjunto MIXED, as melhorias são patentes para todo o intervalo de $b$, indicando os benefícios preditivos da associação de medidas. Pode-se destacar ainda que, independente da caracterização empregada, a estratégia de combinação de modelos é eficaz na construção de rankings no contexto de recomendação de algoritmos. Sendo assim, apenas bagging, com $b=50$, será considerado na comparação geral de paradigmas apresentada na Seção 5.6. 


\subsection{Comparação global}

No decorrer deste capítulo, avaliou-se 3 paradigmas de construção de rankings. Nesta seção, a intenção é confrontá-los a fim de se obter conclusões mais gerais sobre seu comportamento na recomendação de algoritmos. Assim, para cada um deles, selecionou-se um representante específico de acordo com as considerações apresentadas durante as análises apropriadas. Para a abordagem baseada em vizinhos mais próximos, o $w k \mathrm{NN}$ foi escolhido, pois apresentou considerável superioridade em relação ao método original, que não pondera a influência de vizinhos com base em distância. Quando as sugestões fornecidas ao usuário foram geradas a partir de problemas de regressão, o SVM se destacou e foi escolhido. Ele foi eficaz tanto em predizer satisfatoriamente o desempenho dos classificadores quanto em efetuar uma ordenação acurada dos mesmos. No contexto de meta-aprendizagem utilizando árvores, a aplicação de uma única PCT geralmente resultou em acurácias não muito adequadas, por vezes competindo com o método padrão. Entretanto, quando várias PCTs foram consideradas para realizar predições conjuntas, o desempenho apresentou sensivel melhora, fazendo com que o bagging fosse escolhido. A seguir, são reportados os resultados obtidos com essas abordagens, estratificados pelo conjunto utilizado na caracterização de dados.

\subsubsection{Conjunto STATLOG}

A comparação entre os métodos $w k \mathrm{NN}$ com kernel Triangular, SVM, bagging com $b=50$ e RP, quando a caracterização dos dados é realizado segundo o conjunto STATLOG, é fornecida na Figura 5.14. Ela exibe as acurácias (utilizando as correlações $r_{S}$ e LRA) dos rankings gerados durante o LOO sobre os 49 problemas considerados. A fim de melhorar a visibilidade dos gráficos, os meta-exemplos foram ordenados segundo o desempenho do RP.

Na Figura 5.14(a), que emprega o $r_{S}$, percebe-se que os métodos mais sofisticados são capazes de construir rankings mais correlacionados com os rankings ideais mais frequentemente que o RP. A média (e desvio padrão) das acurácias para o $w k \mathrm{NN}$, o SVM, o bagging e o RP foram, respectivamente: 0.722 (0.208), 0.716 (0.188), 0.730 (0.225) e 0.608 (0.200). Pode-se notar que os 3 melhores métodos resultaram similarmente, nesta disposição de acurácia média: bagging, wkNN e SVM. A aplicação dos testes de Friedman e de Dunn, com níveis de significância de 95\% e 90\%, confirma que eles são de fato equivalentes entre si e superiores ao RP.

Na Figura 5.14(b), o LRA é considerado como medida de desempenho. Sendo assim, as posições superiores dos rankings recebem maior importância 


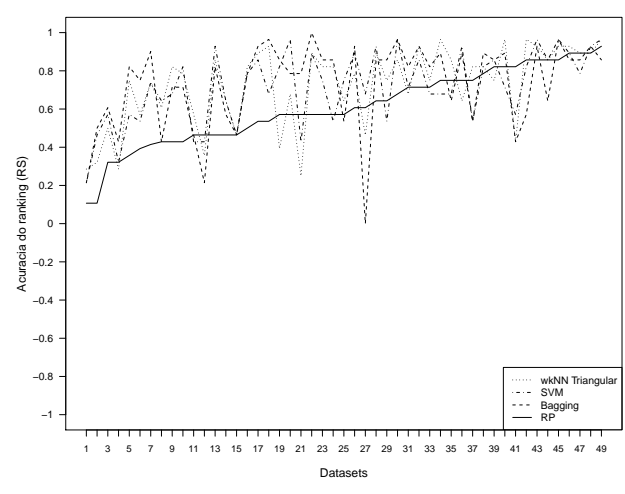

(a) Acurácia por $r_{S}$

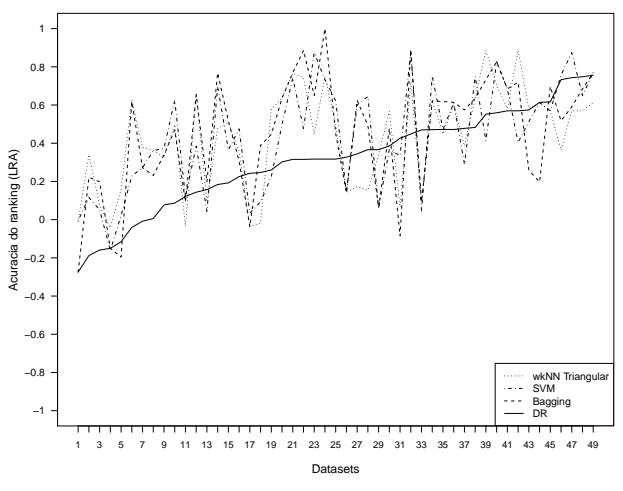

(b) Acurácia por LRA

Figura 5.14: Desempenho dos métodos $w k$ NN, SVM e bagging para os 49 problemas considerados com caracterização de dados utilizando o conjunto STATLOG

no cálculo da correlação. A média (e desvio padrão) das acurácias para o $w k \mathrm{NN}$, o SVM, o bagging e o RP foram, respectivamente: 0.428 (0.259), 0.434 (0.281), 0.446 (0.306) e 0.315 (0.259). O bagging novamente apresentou discreto aumento de desempenho. Desta vez, no entanto, o SVM mostrou-se sutilmente mais eficaz que o $w k \mathrm{NN}$. Entretanto, os teste estatísticos adequados não detectaram diferenças significantes entre os 3 métodos, embora todos sejam superiores ao RP.

\subsubsection{Conjunto VALIDITY}

A Figura 5.15 exibe os resultados da comparação dos métodos de construção de ranking aqui considerados utilizando a mesma configuração experimental empregada na Figura 5.14, com exceção da caracterização dos dados, que agora é realizada segundo o conjunto VALIDITY.

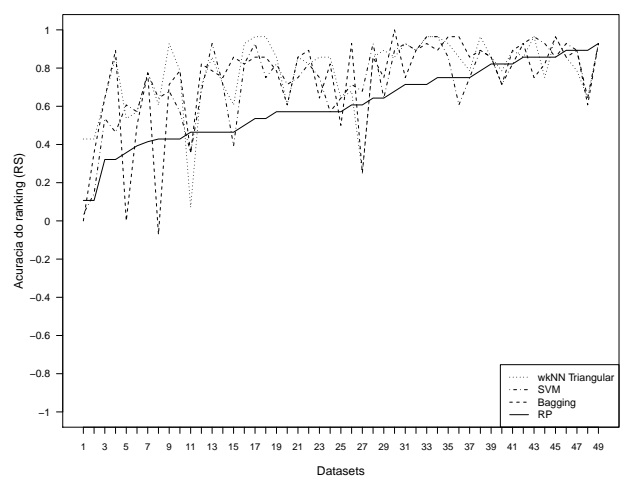

(a) Acurácia por $r_{S}$

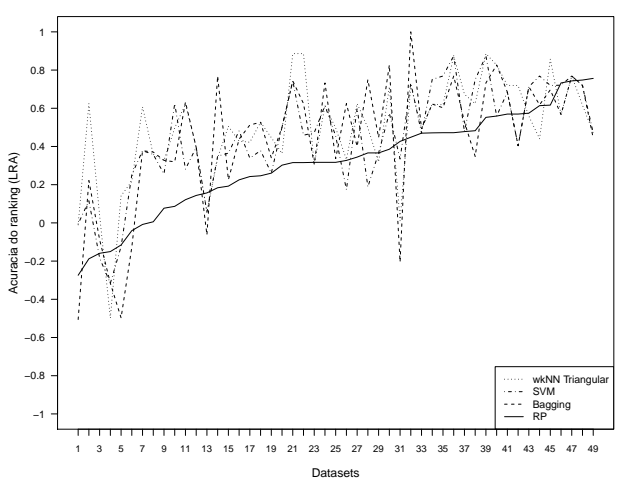

(b) Acurácia por LRA

Figura 5.15: Desempenho dos métodos $w k$ NN, SVM e bagging para os 49 problemas considerados com caracterização de dados utilizando o conjunto STATLOG

Considerando o $r_{S}$ como medida de desempenho dos rankings preditos, 
a média (e desvio padrão) das acurácias observadas na Figura 5.15(a) para o $w k \mathrm{NN}$, o SVM, o bagging e o RP foram, respectivamente: 0.775 ( 0.191), 0.731 (0.204), 0.733 (0.255) e 0.608 (0.200). Percebe-se que enquanto SVM e bagging tem desempenho semelhante, o $w k \mathrm{NN}$ se destaca positivamente, com vantagem de 0.04 sobre o segundo melhor método. Esta superioridade, no entanto, não é suportada pelos testes de Friedman e de Dunn, que resulta em equivalência estatística entre os métodos e superioridade apenas em relação ao RP.

Na Figura 5.15(b), os resultados são reportados utilizando-se o LRA. Nesta situação, o wkNN também sobressai, enquanto SVM e bagging alternam de posição. O RP permanece aquém dos demais. A média (e desvio padrão) das acurácias para esses métodos, foram, respectivamente: 0.492 ( 0.273 ), 0.448 (0.274), $0.438(0.341)$ e 0.315 (0.259). A conclusões estatísticas são as mesmas obtidas no caso do $r_{S}$.

\subsubsection{Conjunto MIXED}

Os resultados para a caracterização de dados feita como o conjunto MIXED são apresentados na Figura 5.16. Novamente, materiais e métodos semelhantes àqueles empregados na Figura 5.14 são considerados. Entretanto, com base nos experimentos realizados na Seção 5.3, o wkNN com kernel Gauss foi utilizado.

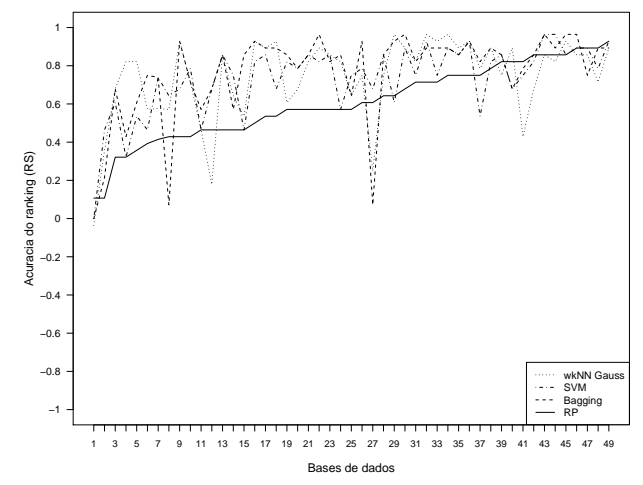

(a) Acurácia por $r_{S}$

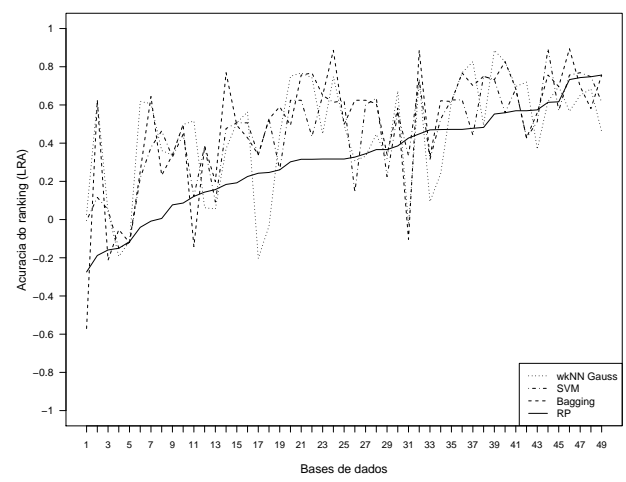

(b) Acurácia por LRA

Figura 5.16: Desempenho dos métodos $w k N N$, SVM e bagging para os 49 problemas considerados com caracterização de dados utilizando o conjunto MIXED

Quando o $r_{S}$ é utilizado para medir a qualidade dos rankings construídos pelos diversos métodos, as acurácias individuais obtidas para cada meta-exemplo podem ser observadas na Figura 5.16(a). Claramente, percebe-se a vantagem dos métodos $w k$ NN Gauss, SVM e bagging em relação ao RP. Entretanto, para alguns problemas eles mostraram-se inferiores. Isto acontece com maior intensidade para as abordagens baseadas em vizinhos 
e em árvores. Pode-se apreciar a questão numericamente através da média (e desvio padrão) das acurácias para os 4 métodos: 0.739 (0.218), 0.733 (0.185), 0.763 (0.235) e 0.608 (0.200), respectivamente. Assim, embora o bagging seja superior na maioria dos casos, ele algumas vezes apresenta as predições menos acuradas. Inversamente, o SVM apresenta a menor média, mas também o menor desvio padrão. Em termos estatísticos, os 3 métodos mais complexos resultaram superiores ao RP e equivalentes entre si, segundo os testes de Friedman e de Dunn.

Com o LRA como medida de correlação entre os rankings obtido e ideal, tem-se as acurácias apresentadas na Figura 5.16(b). Também nesta conformação, o RP é superado por wkNN Gauss, SVM e bagging. A media (e desvio padrão) das acurácias desses 3 métodos e o RP é, respectivamente: 0.449 (0.291), 0.454 (0.243), 0.494 (0.318) e 0.315 (0.259), com conclusões estatísticas iguais àquelas obtidas no caso do $r_{S}$.

\subsection{Considerações finais}

No presente capítulo, analisou-se experimentalmente as abordagens de caracterização de dados e os métodos de construção de ranking propostos nesta Tese. Estes 2 aspectos representam o fundamento operacional de qualquer sistema de recomendação de algoritmos baseado em meta-aprendizagem.

Os resultados foram estratificados de acordo com os 3 principais paradigmas utilizados para estabelecer a ordem de preferência dos classificadores. No primeiro, abordagens baseadas em vizinhos mais próximos são empregadas. A avaliação experimental realizada indicou que o $k \mathrm{NN}$ ordinário comumente empregado em meta-aprendizagem para problemas de origem heterogênea (Brazdil et al., 2009) também é adequado para a aplicação no domínio restrito de expressão gênica. Ele resultou claramente superior ao $\mathrm{RP}$ em relação à média de acurácias dos rankings preditos. Isto ocorreu para os 3 conjuntos de caracterização utilizados, com vantagem clara para o VALIDITY e moderada para MIXED. O primeiro conjunto corresponde às medidas desenvolvidas neste trabalho e o segundo é uma agregação dos conjuntos VALIDITY e STATLOG. Quando a extensão $w k \mathrm{NN}$ foi considerada, os resultados obtidos foram muito satisfatórios, logrando superioridade ímpar em relação a sua versão original. Isto indica que a ponderação de meta-exemplos por distâncias como aqui implementada é benéfica. Os kernels Triangular e Epanechnikov mostraram-se especialmente eficazes.

No segundo paradigma, a tarefa de predição de rankings de algoritmos é realizada no contexto de regressão. Desta forma, realizou-se 
extensa experimentação com SVM, 1NN, LR e M5 como meta-regressores. Inicialmente, SVM e M5 mostraram-se altamente competitivos na tarefa de predição do desempenho dos classificadores empregados. Entretanto, quando a forma básica de recomendação utilizada neste trabalho foi considerada, o SVM foi significantemente melhor, construindo rankings mais acurados que aquele obtidos pelo M5. Nesta tarefa, o 1NN também foi eficaz, e os desempenhos tanto dele quanto do SVM apresentaram melhorias progressivas de acordo com a utilização dos conjuntos STATLOG, VALIDITY e MIXED para caracterizar os dados. Assim, observou-se novamente que as medidas baseadas em índices oferecem benefícios em relação à abordagem padrão e que a combinação de medidas de ambos os conjuntos é interessante pois aspectos mais variados dos dados podem ser contemplados.

No terceiro paradigma, os rankings são construídos pela aplicação de árvores de decisão aos meta-exemplos tal que particionamento recursivos geram grupos homogêneos em relação aos meta-atributos alvo componentes. Com a utilização de PCTs únicas, os rankings resultantes não mostraram grande correlação com os rankings ideais correspondentes, para os conjunto STATLOG e VALIDITY. Entretanto quando as medidas MIXED foram empregadas, houve uma melhoria em relação ao desempenho do RP. Com a combinação de múltiplos PCTs para realizar a predição, o aumento na qualidade dos resultados foi sensivel, com vantagem novamente para a caracterização feita com o conjunto MIXED.

Além de realizar experimentos focando em cada paradigma individualmente, também considerou-se a comparação entre os melhores métodos de cada grupo. Os resultados obtidos neste cenário são sumariados na Tabela 5.10. Seus valores consistem das médias das acurácias (utilizando a correlação $r_{S}$ ) dos rankings gerados pelos métodos $w k \mathrm{NN}$, SVM, bagging e RP durante o LOO sobre as 49 bases de dados de expressão gênica consideradas, com caracterização segundo os conjuntos STATLOG, VALIDITY e MIXED.

Tabela 5.10: Acurácias médias dos rankings $\left(r_{S}\right)$ gerados utilizando 4 métodos e 3 conjuntos de caracterização

\begin{tabular}{cccc}
\hline Método & STATLOG & VALIDITY & MIXED \\
\hline wkNN & 0.722 & 0.775 & 0.739 \\
SVM & 0.716 & 0.731 & 0.733 \\
bagging & 0.730 & 0.733 & 0.763 \\
\hline RP & 0.608 & 0.608 & 0.608 \\
\hline
\end{tabular}

De forma geral, wkNN e bagging geram predições discretamente mais acuradas que aquelas realizadas pelo SVM, o que pode ser entendido pelo fato de que ambos foram especificamente desenvolvidos para a construção dessa forma de sugestão. Nota-se também que os conjuntos VALIDITY e MIXED 
são consistentemente superiores ao STATLOG e o desempenho de ambos alterna-se dependendo do método de ranking empregado. Para o $w k \mathrm{NN}$, o VALIDITY resulta superior. Para o bagging, o MIXED é mais adequado, assim como para o SVM. Estes resultados sugerem que os métodos que realizam alguma forma de seleção ou ponderação de atributos se beneficiam mais da utilização do conjunto de caracterização mais diversificado. Assim, a aplicação de técnicas explícitas de seleção de atributos (Liu e Motoda, 1998) poderia ser benéfica aos métodos de rankings, em especial ao $w k \mathrm{NN}$. 


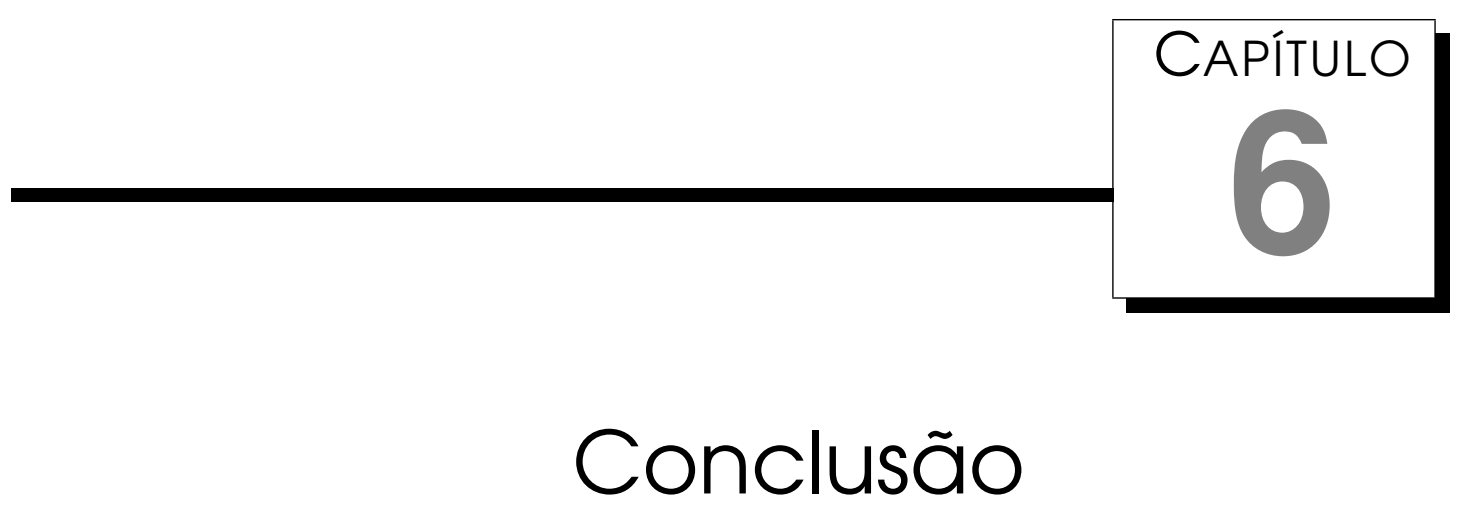

O foco da pesquisa desenvolvida durante este doutorado foi investigar a utilização de meta-aprendizagem como ferramenta de suporte à classificação de dados de expressão gênica. Tal empreendimento visou contribuir em duas áreas. Da perspectiva da aplicação, pretendeu-se desenvolver métodos que pudessem auxiliar o usuário não especialista em sistemas de classificação, tipicamente biólogos e cientistas da área médica, na tarefa de escolher as soluções mais apropriadas para seu problema. Isso facilitaria a análise dos experimentos realizados, fazendo com que a utilização de microarrays (Russell et al., 2008) no diagnóstico de doenças se torne mais acessível.

Do ponto de vista da meta-aprendizagem, a intenção foi expandir sua prática corrente em recomendação de algoritmos utilizados para classificação de dados. Conforme pode ser observado a partir da literatura especializada (vide Brazdil et al. (2009) e referências ali contidas), métodos de sugestão baseados nessa abordagem têm exibido considerável sucesso quando aplicados a problemas oriundos de âmbitos diversos, como os representados pelos conjuntos de dados disponíveis em repositórios de propósito geral (por exemplo, o da UCI (A. Asuncion, 2007)). Entretanto, sua adequação a problemas reais de natureza semelhante tem recebido menos atenção. Em situações como esta, o desempenho dos algoritmos de AM e os dados tendem a se apresentar mais homogêneos, tornando incerta a adequação dos métodos tradicionais de meta-aprendizagem ao problema de recomendação. 


\subsection{Contribuições}

A principal contribuição da pesquisa conduzida neste trabalho foi investigar empiricamente a utilização de meta-aprendizagem ao problema de recomendação de algoritmos de AM no contexto de dados de expressão gênica. A validação das propostas apresentadas foi verificada por meio de numerosos experimentos e análises, reportados no Capítulo 5. Os resultados obtidos forneceram evidências significantes do êxito das propostas e foram divulgados na forma de artigos científicos (Souza et al., 2010b,a, 2009, 2008). Além de lograr cumprir o objetivo geral desta tese, este trabalho resultou em algumas contribuições pontuais importantes durante o processo. Elas são comentadas a seguir.

Conforme visto no Capitulo 4, a caracterização dos dados tem impacto direto na qualidade da meta-aprendizagem, à medida que esta depende daquela para determinar o mapeamento adequado entre as propriedades de diferentes problemas e o desempenho dos algoritmos em consideração. Neste estudo, buscou-se contribuir com o tema por meio da introdução do conjunto VALIDITY, cujos elementos baseiam-se na noção de índices de validação de agrupamentos a fim de explorar certos aspectos da distribuição dos dados com potencial relevância preditiva. Quando os conjuntos VALIDITY e STATLOG foram confrontados no Capítulo 5, as novas medidas mostraram-se invariavelmente vantajosas. Com a aplicação conjugada de medidas de ambos os conjuntos, observou-se melhorias ainda mais patentes em alguns casos, destacando a importância de se considerar facetas mais variadas dos dados.

De acordo com Brazdil et al. (2009), o $k \mathrm{NN}$ é o método de meta-aprendizagem mais utilizado para a recomendação de sequências ordenadas de algoritmos. Isto se deve tanto a sua simplicidade de implementação quanto a sua eficiência em acurácia preditiva. No contexto de classificação, diversas variações do método básico estão disponiveis (Atkeson et al., 1997). Neste trabalho, adaptou-se uma delas para construção de rankings. Assim, o $w k \mathrm{NN}$ desenvolvido aqui pondera a influência de cada problema de treinamento na composição da predição final de acordo com sua similaridade ao problema de teste. Embora seja baseado em uma intuição elementar, esta extensão mostrou-se consistentemente superior à versão não ponderada no estudo comparativo efetuado no Capítulo 5. Os resultados desses experimentos foram divulgadas em (Souza et al., 2010a).

Embora menos usual, a construção de rankings no contexto de meta-aprendizagem também pode ser realizada por meio de regressão. Neste caso, os desempenhos dos classificadores são preditos e depois combinados para a sugestão de uma ordem de preferência dos algoritmos. Diferentes 
abordagens têm sido utilizadas como meta-regressores. Recentemente, SVMs (Steinwart e Christmann, 2008) foram consideradas em dois trabalhos distintos. Prudêncio et al. (2008) as utilizaram com sucesso para predizer o desempenho de redes neurais MLP e Souto et al. (2008) as aplicaram para fornecer rankings de algoritmos de agrupamento. Após revisão bibliográfica, não foram encontradas referências da utilização de SVMs no contexto de recomendação de algoritmos de classificação. Assim, outra contribuição original deste trabalho foi suprir tal carência. Os resultados completos obtidos com essa técnica estão detalhados no Capítulo 5 e publicados parcialmente em (Souza et al., 2009).

Outro paradigma disponível para a determinação da posição relativa de algoritmos de AM baseia-se em árvores. Especificamente, as PCTs (Todorovski et al., 2002) têm sido empregadas para tal fim. Relatórios conflitantes quanto a seu desempenho em aplicações despertaram o interesse em investigá-las neste trabalho. Enquanto Todorovski et al. (2002) reportaram a habilidade das PCTs de superar o $k \mathrm{NN}$ na acurácia de suas predições, Rebelo et al. (2008) apresentam um abrangente conjunto de experimentos que contradizem tal afirmação. Quando da utilização das versões básicas de ambas as abordagens, os experimentos realizados no Capítulo 5 tendem a advogar a favor das conclusões dos últimos autores. No entanto, com a combinação de predições de árvores individuais, foi percebido um incremento substancial na qualidade dos rankings gerados, fazendo com que bagging de PCTs figurem entre as mais promissoras abordagens consideradas neste trabalho. Sua introdução foi uma importante contribuição desta tese e os resultados de sua avaliação foram difundidos em (Souza et al., 2010a).

Embora não tenha sido o foco do trabalho, durante esta pesquisa despendeu-se considerável esforço na realização de uma comparação extensiva entre algoritmos de classificação em dados de expressão gênica. A necessidade de tal investigação surgiu da percepção de que os estudos disponíveis na literatura são deficientes em diversos aspectos em relação aos materiais e métodos empregados (vide (Boulesteix et al., 2008) e estudos ali contidos). Em especial, constatou-se que eles tendem a apresentar poucas bases de dados ou um número limitado de algoritmos de AM ou uma análise estatística deficiente. Assim, em (Souza et al., 2010b), esses aspectos foram acomodados com a intenção de prover ao possivel analista desse tipo de dados algumas diretrizes de como proceder na escolha da abordagem de classificação mais apropriada de acordo com seus objetivos de pesquisa. Nesse estudo também foi desenvolvida uma metodologia de redução de dimensionalidade baseada em seleção aleatória de genes, que pretendeu diminuir a complexidade computacional das análises realizadas sem favorecer 
algum método de classificação em específico.

\subsection{Limitações}

Embora os resultados reportados nesta tese demonstrem que os principais objetivos da pesquisa foram cumpridos, pode-se destacar algumas limitações das propostas deste trabalho, assim como nos experimentos conduzidos. Elas são comentadas a seguir.

Os rankings construídos pelos métodos empregados neste trabalho não consideraram a significância das diferenças entre os desempenhos dos classificadores. Sendo assim, algoritmos em posições diferentes na ordem de preferência sugerida ao usuário podem, de fato, ter comportamento estatisticamente semelhante e, portanto, serem utilizados de maneira indiscriminada. Este problema é largamente difundido nos estudo de recomendação utilizando meta-aprendizagem e uma solução satisfatória ainda não é consenso. No caso do domínio de expressão gênica, a questão se agrava devido à maldição da esparsidade dos dados (Somorjai et al., 2003), segundo a qual, nessa situação, os classificadores tendem a apresentar desempenho similar. Isto foi confirmado também em um dos cenários analisados em (Souza et al., 2010b).

Conforme visto no Capítulo 5, os resultados dos métodos de ranking se beneficiaram da aplicação das medidas de caracterização baseadas em índices de validação, sejam em suas versões original (conjunto VALIDITY) ou combinada (conjunto MIXED). Entretanto, não houve um esforço sistemático em selecionar um conjunto otimizado de medidas. Basicamente, os critérios de escolha utilizados foram sua aplicação prévia em estudos de agrupamento envolvendo dados microarrays ou simplesmente disponibilidade de sua implementação. Acredita-se que a utilização de outras medidas, potencialmente mais apropriadas, possa resultar em rankings mais acurados. Observou-se ainda no capítulo de experimentos que a aplicação de técnicas de seleção de atributos (Liu e Motoda, 1998) podem ser benéficas no contexto do trabalho. De fato, alguns estudos têm reportado os benefícios em realizar seleção de meta-atributos (Kalousis e Hilario, 2001; Todorovski et al., 2000). Entretanto, devido ao bias de seleção (Ambroise e McLachlan, 2002) exibido em ambos os trabalhos, a influência desse aspecto na qualidade da meta-aprendizagem ainda precisa ser experimentalmente analisada. Ainda no contexto de caracterização de dados, seria interessante realizar comparações do conjunto VALIDITY com outras abordagens, como aquelas baseadas em modelos (Bensusan et al., 2000) e em landmarking (Pfahringer et al., 2000).

Neste trabalho, mostrou-se que os métodos empregados são capazes de 
realizar predições acuradas em comparação àquelas obtidas pelo ranking padrão. Esse é um resultado muito positivo que favorece a aplicação de meta-aprendizagem para recomendação de algoritmos. Entretanto, tal comparação com a abordagem de referência representa apenas uma faceta da avaliação dos rankings. Outro aspecto a ser considerado é o desempenho de classificação que o usuário pode esperar caso ele siga a sugestão a ele provida. Assim, uma análise complementar pode ser realizada pela utilização do método Top- $N$ apresentado em (Soares, 2004), que simula a situação previamente descrita. Ele foi utilizado também, de maneira preliminar, para a avaliação de resultados em (Souza et al., 2009).

Na configuração experimental utilizada no decorrer do Capítulo 5, adotou-se a opção de executar todos os algoritmos de AM com seus parâmetros padrão. Para alguns casos, como o SVM-R, tal decisão pode ter um impacto negativo no desempenho (Keerthi e Lin, 2003). Entretanto, dado que, neste trabalho, a preocupação primária é determinar o desempenho relativo dos algoritmos e não realizar um estudo comparativo focado no desempenho absoluto em si, essa estratégia pode ser considerada razoável e de menor complexidade computacional. Com a mesma finalidade de simplificar os experimentos conduzidos, aplicou-se os classificadores diretamente às matrizes de alta dimensionalidade de expressão gênica. Embora tal prática não seja a mais usual no domínio, ela tem sido utilizada (Man et al., 2004) e pretendeu-se evitar o nível extra de complexidade conceitual necessário à utilização de alguma abordagem de seleção de atributos (Liu e Motoda, 1998). Entretanto, destaca-se que 4 dos 7 classificadores utilizados possuem mecanismos de seleção ou ponderação de atributos (PAM, SVM-L, SVM-R e $\mathrm{RF}$ ), sendo a abordagem mais influenciada pela escolha aqui realizada foi o $k \mathrm{NN}$ (Duda et al., 2000).

Nos experimentos reportados com a utilização do bagging, conseguiu-se demonstrar de maneira convincente que seu desempenho oferece vantagens em relação ao do PCT. Entretanto, é necessário conduzir uma análise mais rigorosa no que tange à aleatoriedade própria do método, pois para os resultados obtidos e exibidos no Capítulo 5, o processo foi executado apenas um vez. Assim, a fim de minimizar os efeitos da amostragem randômica, utilizou-se 50 conjuntos bootstrap para realizar as principais comparações. Tal número também precisa ser determinado de maneira mais consistente (Breiman, 1996b). Por fim, como as bases de expressão gênica são escassas, é preciso avaliar a abordagem de bagging com um número maior de meta-exemplos. 


\subsection{Trabalhos futuros}

Esse estudo representou um primeiro esforço para a aplicação de meta-aprendizagem à análise de dados de expressão gênica no contexto de classificação de dados. O enfoque foi dado para recomendação de algoritmos de AM dispostos na forma de rankings. Considerando as etapas do processo de Extração de Conhecimento como propostas por Baranauskas (2001), trabalhou-se na etapa de Mineração de Dados (MD). As etapas anterior e posterior da MD, chamadas de Pré-processamento e Pós-processamento, respectivamente, não foram aqui contempladas. Entretanto, elas também podem ser beneficiadas pelo emprego de meta-aprendizagem. Assim, algumas propostas nesse âmbito são apresentadas a seguir.

Os experimentos de expressão gênica apresentam um número excessivo de atributos potencialmente redundantes e irrelevantes, conforme visto no Capítulo 2. Para lidar com a situação, técnicas de seleção de atributos podem ser utilizadas. Pode-se explorar a aplicação de meta-aprendizagem para escolher qual abordagem de seleção empregar em determinada base de dados. A motivação é a mesma da escolha do algoritmo de AM, ou seja, utilizar conhecimento armazenado para definir, eficientemente, que abordagem utilizar em problemas de propriedades semelhantes.

O pequeno número de exemplos das bases de dados, aliado a variações biológicas e experimentais, fazem com que os experimentos de expressão gênica apresentem dificuldades potenciais à aplicação de algoritmos convencionais de AM (Peng, 2005). A combinação de classificadores, formando os ensembles, pode resultar em uma classificação mais robusta dos dados. Um vislumbre dessa possibilidade está nos resultados apresentados em (Souza et al., 2010b), em que abordagens distintas de classificação levam a resultados preditivos diferentes para alguns dos exemplos de teste, sugerindo que a combinação de suas predições pode levar a uma acurácia global superior. Dessa forma, pode-se investigar a utilização de meta-aprendizagem para determinar uma combinação adequada de classificadores.

Além de sugerir algoritmos de AM, a meta-aprendizagem tem sido utilizada para escolher configurações adequadas de parâmetros. Por exemplo, Soares e Brazdil (2006) propuseram uma metodologia para selecionar a largura do kernel Radial de SVMs no contexto de regressão. Os autores mostraram que é possível utilizar informação sobre o desempenho passado de diferentes valores de largura do kernel para predizer o desempenho relativo dos mesmos em novos problemas, de forma eficiente. Assim, pode-se explorar o potencial da meta-aprendizagem em sugerir parâmetros de algoritmos de AM em geral. 


\section{Referências Bibliográficas}

A. Asuncion, D. N. (2007). UCI machine learning repository. Citado na página 97.

Aha, D. W. (1989). Incremental, instance-based learning of independent and graded concept descriptions. Proceedings of the Sixth International Workshop on Machine Learning, p. 387-391, Ithaca,NY. Morgan Kaufmann. Citado na página 42 .

Aha, D. W. (1992). Generalizing from case studies: a case study. ML92: Proceedings of the ninth international workshop on Machine learning, p. 1-10, San Francisco, CA, USA. Morgan Kaufmann Publishers Inc. Citado na página 4.

Aha, D. W. (1997). Lazy learning. Artificial Intelligence Review, v.17, p.7-10. Citado na página 26.

Alizadeh, A. A.; Eisen, M. B.; Davis, R. E.; Ma, C.; Lossos, I. S.; Rosenwald, A.; Boldrick, J. C.; Sabet, H.; Tran, T.; Yu, X.; Powell, J. I.; Yang, L.; Marti, G. E.; Moore, T.; Hudson, J.; Lu, L.; Lewis, D. B.; Tibshirani, R.; Sherlock, G.; Chan, W. C.; Greiner, T. C.; Weisenburger, D. D.; Armitage, J. O.; Warnke, R.; Levy, R.; Wilson, W.; Grever, M. R.; Byrd, J. C.; Botstein, D.; Brown, P. O.; Staudt, L. M. (2000). Distinct types of diffuse large b-cell lymphoma identified by gene expression profiling. Nature, v.403, n.6769, p.503-511. Citado na página 19.

Alon, U.; Barkai, N.; Notterman, D. A.; Gish, K.; Ybarra, S.; Mack, D.; Levine, A. J. (1999). Broad patterns of gene expression revealed by clustering analysis of tumor and normal colon tissues probed by oligonucleotide arrays. Proc Natl Acad Sci USA, v. 96, p. 6745-6750. National Academy of Sciences. Citado na página 19.

Ambroise, C.; McLachlan, G. J. (2002). Selection bias in gene extraction 
on the basis of microarray gene-expression data. PNAS USA, v.99, n.10, p.6562-6566. Citado na página 100.

Andersson, A.; Ritz, C.; Lindgren, D.; Edén, P.; Lassen, C.; Heldrup, J.; Olofsson, T.; Rade, J.; Fontes, M.; Porwit-MacDonald, A.; Behrendtz, M.; Höglund, M.; Johansson, B.; Fioretos, T. (2007). Microarray-based classification of a consecutive series of 121 childhood acute leukemias: prediction of leukemic and genetic subtype as well as of minimal residual disease status. Leukemia, v.61, p.1198-1203. Citado na página 19.

Armstrong, S. A.; Staunton, J. E.; Silverman, L. B.; Pieters, R.; den Boer, M. L.; Minden, M. D.; Sallan, S. E.; Lander, E. S.; Golub, T. R.; Korsmeyer, S. J. (2002). Mll translocations specify a distinct gene expression profile, distinguishing a unique leukemia. Nature Genetics, v.30, p.41-47. Citado na página 19.

Asyali, M. H.; Colak, D.; Demirkaya, O.; Inan, M. S. (2006). Gene expression profile classification: A review. Current Bioinformatics, v.1, n.1, p.55-73. Citado nas páginas 3, 28, e 61 .

Atkeson, C.; Moore, A.; Schaal, S. (1997). Locally weighted learning. AI Review, v.11, p.11-73. Citado na página 98.

Bø, T. H.; Dysvik, B.; Jonassen, I. (2004). Lsimpute: accurate estimation of missing values in microarray data with least squares methods. Nucleic Acids Research, v.32, n.3, p.e34. Citado na página 61.

Baeza-Yates, R.; Ribeiro-Neto, B. (1999). Modern Information Retrieval. Addison Wesley, $1^{\mathrm{a}}$ edição. Citado na página 29.

Baker, F. B.; Hubert, L. J. (1975). Measuring the power of hierarchical clistering analysis. Journal of the American Statistical Association, v.40, n.349, p.31 - 38. Citado na página 49.

Baranauskas, J. A. (2001). Extração automática de conhecimento por múltiplos indutores. Tese, Instituto de Ciências Matemáticas e de Computação da Universidade de São Paulo, São Carlos - SP. Citado nas páginas 31 e 102.

Barbara, D. (2000). An introduction to cluster analysis for data mining. Citado na página 25.

Barrett, T.; Edgar, R. (2006). Mining microarray data at ncbi's gene expression omnibus (geo)*. Methods Mol Biol, v.338, p.175-190. Citado na página 60.

Barrett, T.; Suzek, T. O.; Troup, D. B.; Wilhite, S. E.; Ngau, W.-C.; Ledoux, P.; Rudnev, D.; Lash, A. E.; Fujibuchi, W.; Edgar, R. (2005). Ncbi geo: mining 
millions of expression profiles-database and tools. Nucleic Acids Research, v.33, n.Database Issue, p.D562-D566. Citado na página 19.

Barzily, Z.; Volkovich, Z.; Akteke-Öztürk, B.; Weber, G.-W. (2009). On a minimal spanning tree approach in the cluster validation problem. Informatica, v.20, n.2, p.187-202. Citado na página 49.

Batista, G. E. A. P. A. (2003). Pré-processamento de dados em aprendizado de máquina supervisionado. Tese de doutorado, Instituto de Ciências Matemáticas e de Computação da Universidade de São Paulo, São Carlos, SP. Citado na página 26.

Ben-Dor, A.; Friedman, N.; Yakhini, Z. (2001). Class discovery in gene expression data. RECOMB '01: Proceedings of the fifth annual international conference on Computational biology, p. 31-38, New York, NY, USA. ACM. Citado na página 51.

Bensusan, H. (1998). God doesn't always shave with occam's razor - learning when and how to prune. Proceedigs of the 10th European Conference on Machine Learning, p. 119-124. Springer. Citado na página 45.

Bensusan, H.; Giraud-Carrier, C. (2000a). Casa batlo is in passeig de gracia or landmarking the expertise space. Proceedings of the ECML'2000 workshop on Meta-Learning: Building Automatic Advice Strategies for Model Selection and Method Combination, p. 29-47. ECML'2000. Citado na página 44.

Bensusan, H.; Giraud-Carrier, C. (2000b). Discovering task neighbourhoods through landmark learning performances. Zighed, D.; Komorowski, J.; Zytkow, J., editores, Proceedings of the 4th European Conference on Principles and Practice of Knowledge Discovery in Databases, p. 325-331. Springer. Citado na página 53.

Bensusan, H.; Giraud-Carrier, C.; Kennedy, C. (2000). A higher-order approach to meta-learning. Proceedings of the ECML'2000 workshop on Meta-Learning: Building Automatic Advice Strategies for Model Selection and Method Combination, p. 109-117. ECML'2000. Citado nas páginas 45 e 100.

Bensusan, H.; Kalousis, A. (2001). Estimating the predictive accuracy of a classifier. EMCL '01: Proceedings of the 12th European Conference on Machine Learning, p. 25-36, London, UK. Springer-Verlag. Citado nas páginas 53,78 , e 87 .

Berrar, D.; Bradbury, I.; Dubitzky, W. (2006). Avoiding model selection bias in small-sample genomic datasets. Bioinformatics, v.22, n.10, p.1245-1250. Citado nas páginas 31 e 36. 
Bezdek, J. C.; Pal, N. R. (1998a). Some new indexes of cluster validity. IEEE Transactions on Systems, Man, and Cybernetics, Part B, v.28, n.3, p.301-315. Citado na página 47.

Bezdek, J. C.; Pal, N. R. (1998b). Some new indexes of cluster validity. IEEE Transactions on Systems, Man, and Cybernetics, Part B, v.28, n.3, p.301-315. Citado nas páginas 48 e 85.

Bhattacharjee, A.; Richards, W. G.; Staunton, J.; Li, C.; Monti, S.; Vasa, P.; Ladd, C.; Beheshti, J.; Bueno, R.; Gillette, M.; Loda, M.; Weber, G.; Mark, E. J.; Lander, E. S.; Wong, W.; Johnson, B. E.; Golub, T. R.; Sugarbaker, D. J.; Meyerson, M. (2001). Classification of human lung carcinomas by mrna expression profiling reveals distinct adenocarcinoma subclasses. Proc Natl Acad Sci U S A, v.98, n.24, p.13790-5. Citado na página 19.

Bild, A. H.; Yao, G.; Chang, J. T.; Wang, Q.; Potti, A.; Chasse, D.; Joshi, M.-B.; Harpole, D.; Lancaster, J. M.; Berchuck, A.; Olson, J. A.; Marks, J. R.; Dressman, H. K.; West, M.; Nevins, J. R. (2005). Oncogenic pathway signatures in human cancers as a guide to targeted therapies. Nature, v.439. Citado na página 19.

Bishop, C. M. (2006). Pattern Recognition and Machine Learning (Information Science and Statistics). Springer-Verlag New York, Inc., Secaucus, NJ, USA. Citado nas páginas $2,23,28$, e 61 .

Bland, J. M.; Altman, D. G. (1995). Multiple significance tests: the bonferroni method. BMJ, v.310, n.6973. Citado nas páginas 65 e 80.

Blockeel, H.; De Raedt, L.; Ramon, J. (1998). Top-down induction of clustering trees. Proceedings of the 15th International Conference on Machine Learning, p. 55-63. Morgan Kaufmann. URL: http://www.cs.kuleuven.ac.be/cgi-bin-dtai/publ_info.pl?id=20419. Citado na página 87.

Bolshakova, N.; Azuaje, F. (2003). Cluster validation techniques for genome expression data. Signal Process., v.83, n.4, p.825-833. Citado nas páginas 46 e 47.

Booman, M.; Douwes, J.; Glas, A. M.; Riemersma, S. A.; Jordanova, E. S.; Kok, K.; Rosenwald, A.; de Jong, D.; Schuuring, E.; Kluin, P. M. (2006). Mechanisms and effects of loss of human leukocyte antigen class ii expression in immune-privileged site-associated b-cell lymphoma. Clinical Cancer Research, v.12, p.2698-2705. Citado na página 19. 
Bouckaert, R. R. (2004). Estimating replicability of classifier learning experiments. ICML '04: Proceedings of the twenty-first international conference on Machine learning, p. 15, New York, NY, USA. ACM. Citado na página 36.

Boulesteix, A.-L.; Strimmer, K. (2007). Partial least squares: A versatile tool for the analysis of high-dimensional genomic data. Briefings in Bioinformatics, v.8, n.1, p.32-44. Citado nas páginas 28 e 52.

Boulesteix, A.-L.; Strobl, C.; Augustin, T.; Daumer, M. (2008). Evaluating microarray-based classifiers: An overview. Cancer Informatics, v.4, p.77-97. Citado nas páginas 3, 29, 31, 36, 61, e 99.

Braga-Neto, U. M.; Dougherty, E. R. (2004). Is cross-validation valid for small-sample microarray classification? Bioinformatics, v.20, n.3, p.374-380. Citado nas páginas 33 e 61.

Bramer, M. (2007). Principles of Data Mining. Springer. Citado na página 56.

Brazdil, P.; Giraud-Carrier, C.; Soares, C.; Vilalta, R. (2009). Metalearning: Applications to Data Mining. Cognitive Technologies. Springer. Citado nas páginas xi, 4, 39, 41, 53, 54, 55, 56, 59, 63, 66, 73, 77, 87, 94, 97, e 98.

Brazdil, P. B.; Soares, C.; Da Costa, J. P. (2003). Ranking learning algorithms: Using ibl and meta-learning on accuracy and time results. Mach. Learn., v.50, n.3, p.251-277. Citado na página 64 .

Breiman, L. (1996a). Bagging predictors. Mach. Learn., v.24, n.2, p.123-140. Citado nas páginas 5 e 57.

Breiman, L. (1996b). Bagging predictors. Machine Learning, v.24, n.2, p.123-140. Citado nas páginas 88 e 101.

Breiman, L. (2001). Random forests. Machine Learning, v.45, n.1, p.5-32. Citado nas páginas 28 e 61 .

Brock, G. N.; Shaffer, J. R.; Blakesley, R. E.; Lotz, M. J.; Tseng, G. C. (2008). Which missing value imputation method to use in expression profiles: a comparative study and two selection schemes. BMC Bioinformatics, v.9, n.12. Citado na página 61 .

Brodley, C. E. (1995). Recursive automatic bias selection for classifier construction. Mach. Learn., v.20, n.1-2, p.63-94. Citado nas páginas 3 e 40 . 
Brown, M. P. S.; Grundy, W. N.; Lin, D.; Cristianini, N.; Sugnet, C.; Jr., M. A.; Haussler, D. (2000). Support vector machine classification of microarray gene expression data. Proc Natl Acad Sci USA, v. 97, p. 262-267. National Academy of Sciences. Citado na página 20.

Brown, P. O.; Botstein, D. (1999). Exploring the new world of the genome with dna microarrays. Nature Genetics, v.21, p.33-37. Citado na página 7.

Calinski, T.; Harabasz, J. (1974). A dendrite method for cluster analysis. Communications in Statistics - Theory and Methods, v.3, n.1, p.1-27. Citado na página 50 .

Calza, S.; Raffelsberger, W.; Ploner, A.; Sahel, J.; Leveillard, T.; Pawitan, Y. (2007). Filtering genes to improve sensitivity in oligonucleotide microarray data analysis. Nucleic Acids Research, v.35, n.16, p.1-10. Citado na página 18.

Caruana, R.; Niculescu-Mizil, A. (2006). An empirical comparison of supervised learning algorithms. ICML '06: Proceedings of the 23rd international conference on Machine learning, p. 161-168, New York, NY, USA. ACM Press. Citado na página 52.

Casley, D. (1992). Primer on molecular genetics. Technical Report, U.S. Departmente of Energy, Office of Energy Research, Office of Health and Environmental Research. Citado nas páginas xi, 10, 11, e 12.

Catherino, W. H.; Leppert, P. C.; Segars, J. H. (2006). The promise and perils of microarray analysis. American Journal of Obstetrics and Gynecology, v. 195, p.389-93. Citado na página 20.

Chalimourda, A.; Schölkopf, B.; Smola, A. J. (2004). Experimentally optimal \&\#x03bd; in support vector regression for different noise models and parameter settings. Neural Networks, v.17, n.1, p.127-141. Citado na página 78.

Chapelle, O.; Schölkopf, B.; Zien, A., editores (2006). Semi-Supervised Learning. MIT Press, Cambridge, MA. Citado na página 24.

Chapelle, O.; Vapnik, V.; Bousquet, O.; Mukherjee, S. (2002). Choosing multiple parameters for support vector machines. Mach. Learn., v.46, n.1-3, p.131-159. Citado na página 78.

Chen, X.; Cheung, S. T.; So, S.; Fan, S. T.; Barry, C.; Higgins, J.; Lai, K.-M.; Ji, J.; Dudoit, S.; Ng, I. O.; van de Rijn, M.; Botstein, D.; Brown, P. O. (2002). Gene expression patterns in human liver cancers. Mol Biol Cell, v.13, n.6, p.1929-39. Citado na página 19. 
Cherkassky, V.; Ma, Y. (2002). Selection of meta-parameters for support vector regression. ICANN '02: Proceedings of the International Conference on Artificial Neural Networks, p. 687-693, London, UK. Springer-Verlag. Citado na página 78.

Choi, S. (2004). DNA Chips and Microarray Analysis: An Overview, chapter Handbook of fungal biotechnology, p. 173 - 179. Marcel Dekker, Inc., New York, second edition edição. Citado nas páginas 16 e 17.

Chowdary, D.; Lathrop, J.; Skelton, J.; Curtin, K.; Briggs, T.; Zhang, Y.; Yu, J.; Wang, Y.; Mazumder, A. (2006). Prognostic gene expression signatures can be measured in tissues collected in rnalater preservative. J Mol Diagn., v.8, n.1, p.31-39. Citado na página 19.

Clark, P.; Niblett, T. (1989). The cn2 induction algorithm. Machine Learning, v.3, n.4, p.261-283. Citado na página 27.

Collins, F. S.; Green, E. D.; Guttmacher, A. E.; Guyer, M. S. (2003). A vision for the future of genomics research. Nature, v.422, p.835 - 847. Citado na página 1 .

Consortium, I. H. G. S. (2004). Finishing the euchromatic sequence of the human genome. Nature, v.431, n.7011, p.931-945. Citado na página 1.

Costa, I. G.; Lorena, A. C.; y Peres, L. R. M. P.; de Souto, M. C. P. (2009). Using supervised complexity measures in the analysis of cancer gene expression data sets. Guimarães, K. S.; Panchenko, A.; Przytycka, T. M., editores, Brazilian Symposium on Bioinformatics, v. 5676 de Lecture Notes in Computer Science, p. 48-59. Springer. Citado nas páginas 49, 82, e 85.

Dai, J. J.; Lieu, L.; Rocke, D. (2006). Dimension reduction for classification with gene expression microarray data. Statistical Applications in Genetics and Molecular Biology, v.5, n.1. Citado nas páginas 51, 52, e 68.

Dave, S. S.; Fu, K.; Wright, G. W.; Lam, L. T.; Kluin, P.; Boerma, E.-J.; Greiner, T. C.; Weisenburger, D. D.; Rosenwald, A.; Ott, G.; Müller-Hermelink, H.-K.; Gascoyne, R. D.; Delabie, J.; Rimsza, L. M.; Braziel, R. M.; Grogan, T. M.; Campo, E.; Jaffe, E. S.; Dave, B. J.; Sanger, W.; Bast, M.; Vose, J. M.; Armitage, J. O.; Connors, J. M.; Smeland, E. B.; Kvaloy, S.; Holte, H.; Fisher, R. I.; Miller, T. P.; Montserrat, E.; Wilson, W. H.; Bahl, M.; Zhao, H.; Yang, L.; Powell, J.; Simon, R.; Chan, W. C.; Staudt, L. M. (2006). Molecular diagnosis of burkitt's lymphoma. $N$ Engl $J$ Med., v.354, n.23, p.2431-42. Citado na página 19. 
Davies, D. L.; Bouldin, D. W. (1979). A cluster separation measure. IEEE Trans. Pattern Anal. Mach. Intell., v.1, n.2, p.224-227. Citado na página 47.

de Pádua Braga, A.; de Leon Ferreira de Carvalho, A. C. P.; Ludermir, T. B. (2003). Sistemas Inteligentes - Fundamentos e Aplicações, chapter Redes Neurais Artificiais, p. 141-168. Editora Manole, Barueri, SP. Citado na página 28.

Demeter, J.; Beauheim, C.; Gollub, J.; Hernandez-Boussard, T.; Jin, H.; Maier, D.; Matese, J. C.; Nitzberg, M.; Wymore, F.; Zachariah, Z. K.; Brown, P. O.; Sherlock, G.; Ball, C. A. (2007). The stanford microarray database: implementation of new analysis tools and open source release of software. Nucleic Acids Research, v.35, n.Database-Issue, p.766-770. Citado na página 60.

D'haeseleer, P. (2005). How does gene expression clustering work? Nature Biotechnology, v.23, n.12, p.1499-1501. Citado nas páginas 51 e 67.

Dietterich, T. G. (1998). Approximate statistical tests for comparing supervised classification learning algorithms. Neural Computation, v.10, n.7, p.1895-1924. Citado nas páginas 34 e 35.

Dietterich, T. G. (2000). Ensemble methods in machine learning. MCS '00: Proceedings of the First International Workshop on Multiple Classifier Systems, p. 1-15, London, UK. Springer-Verlag. Citado nas páginas 31 e 57.

Ding, Y.; Wilkins, D. (2004). The effect of normalization on microarray data analysis. DNA and Cell Biology, v.23, n.10, p.635-642. Citado na página 17.

Duda, R. O.; Hart, P. E.; Stork, D. G. (2000). Pattern Classification. Wiley-Interscience, 2 edição. Citado nas páginas 27, 42, 48, 54, 72, e 101.

Dudoit, S.; Fridlyand, J.; Speed, T. P. (2002). Comparison of discrimination methods for the classification of tumors using gene expression data. Journal of the American Statistical Association, v.97, n.457, p.77-87. Citado nas páginas 3,28 , e 61 .

Duggan, D. J.; Bittner, M.; Chen, Y.; Meltzer, P.; Trent, J. (1999). Expression profiling using cdna microarrays. Nature, v.21, p.10 - 14. Citado na página 13.

Dunn, J. (1973). A fuzzy relative of the isodata process and its use in detecting compact well-separated clusters. J. Cybernet., v.3, n.3, p.32-57. Citado na página 46. 
Dyrskjot, L.; Thykjaer, T.; Kruhoffer, M.; Jensen, J. L.; Marcussen, N.; Hamilton-Dutoit, S.; Wolf, H.; Orntoft, T. F. (2002). Identifying distinct classes of bladder carcinoma using microarrays. Nature Genetics, v.33, n.1, p.90-96. Citado na página 19.

Efron, B. (1983). Estimating the error rate of a prediction rule: Improvement on cross-validation. Journal of the American Statistical Association, v.78, n.382, p.316-331. Citado na página 32.

Efron, B.; Tibshirani, R. (1997). Improvements on cross-validation: The .632+ bootstrap method. Journal of the American Statistical Association, v.92, p.548-560. Citado nas páginas 33 e 62.

Efron, B.; Tibshirani, R. J. (1993). An Introduction to the Bootstrap. Chapman \& Hall, New York. Citado na página 33.

Eisen, M. B.; Spellman, P. T.; Brown, P. O.; Botstein, D. (1998). Cluster analysis and display of genome-wide expression patterns. Proc Natl Acad Sci USA, v. 95, p. 14863-14868. National Academy of Sciences. Citado na página 15.

Fan, X.; Shi, L.; Fang, H.; Cheng, Y.; Perkins, R.; Tong, W. (2010). Dna microarrays are predictive of cancer prognosis: a re-evaluation. Clinical cancer research : an official journal of the American Association for Cancer Research, v.16, n.2, p.629-636. Citado na página 2.

Farmer, P.; Bonnefoi, H.; Becette, V.; Tubiana-Hulin, M.; Fumoleau, P.; Larsimont, D.; MacGrogan, G.; Bergh, J.; Cameron, D.; Goldstein, D.; Duss, S.; Nicoulaz, A.-L.; Brisken, C.; Fiche, M.; Delorenzi, M.; Iggo, R. (2005). Identification of molecular apocrine breast tumours by microarray analysis. Oncogene, v.24, n.29, p.4660-71. Citado na página 19.

Fawcett, T. (2003). Roc graphs: Notes and practical considerations for data mining researchers. Relatório técnico. Citado na página 30.

Fawcett, T. (2006). An introduction to roc analysis. Pattern Recogn. Lett., v.27, n.8, p.861-874. Citado nas páginas 29 e 30.

Ferri, C.; Hernández-Orallo, J.; Modroiu, R. (2009). An experimental comparison of performance measures for classification. Pattern Recognition Letters, v.30, n.1, p.27-38. Citado na página 29.

Filho, I. G. C. (2003). Comparative analysis of clustering methods for gene expression data. Dissertação de mestrado, Centro de Informática, Universidade Federal de Pernambuco, Recife. Citado nas páginas xi e 10. 
Freije, W. A.; Castro-Vargas, F. E.; Fang, Z.; Horvath, S.; Cloughesy, T.; Liau, L. M.; Mischel, P. S.; Nelson, S. F. (2004). Gene expression profiling of gliomas strongly predicts survival. Cancer Research, v.64, n.18, p.6503-10. Citado na página 19.

Friedman, J. H.; Rafsky, L. C. (1979). Multivariate generalizations of the wald-wolfowitz and smirnov two-sample tests. Annals of Statistics, v.7, n.4, p.697-717. Citado na página 48.

Fürnkranz, J. (1999). Separate-and-conquer rule learning. Artif. Intell. Rev., v.13, n.1, p.3-54. Citado na página 26.

Fu, W. J.; Carroll, R. J.; Wang, S. (2005). Estimating misclassification error with small samples via bootstrap cross-validation. Bioinformatics, v.21, n.9, p.1979-1986. Citado na página 33.

Galperina, M. Y.; Koonin, E. V. (2010). From complete genome sequence to complete understanding? Trends in Biotechnology, v.28, n.8, p.398-406. Citado na página 1 .

Garvey, C. (2010). A decade and genome of change. Genome Biology, v.11, n.5, p.120. Citado na página 7 .

Gibson, G.; Muse, S. V. (2004). A Primer of Genome Science, chapter Gene Expression and the Transcriptome, p. 123 - 181. Sinauer Associates, Inc., Sunderland, second edition edição. Citado nas páginas 16 e 17.

Gilks, C. B.; Vanderhyden, B. C.; Zhu, S.; van de Rijn, M.; Longacre, T. A. (2005). Distinction between serous tumors of low malignant potential and serous carcinomas based on global mrna expression profiling. Gynecol Oncol., v.96, n.3, p.684-94. Citado na página 19.

Giraud-Carrier, C.; Vilalta, R.; Brazdil, P. (2004). Introduction to the special issue on meta-learning. Mach. Learn., v.54, n.3, p.187-193. Citado na página 4.

Golub, T. R.; Slonim, D. K.; Tamayo, P.; Huard, C.; Gaasenbeek, M.; Mesirov, J. P.; Coller, H.; Loh, M. L.; Downing, J. R.; Caligiuri, M. A.; Bloomfield, C. D.; Lander, E. S. (1999). Molecular classification of cancer: Class discovery and class prediction by gene expression monitoring. Science, v.286, p.531-537. Citado nas páginas 2, 19, e 20.

Gordon, G. J.; Jensen, R. V.; Hsiao, L.-L.; Gullans, S. R.; Blumenstock, J. E.; Ramaswamy, S.; Richards, W. G.; Sugarbaker, D. J.; Bueno, R. (2002). Translation of microarray data into clinically relevant cancer diagnostic tests 
using gene expression ratios in lung cancer and mesothelioma. Clinical Investigations, v.62, n.17, p.4963-7. Citado na página 19.

Gruvberger, S.; Ringnér, M.; Chen, Y.; Panavally, S.; Saal, L. H.; Borg, A.; Ferno, M.; Peterson, C.; Meltzer, P. S. (2001). Estrogen receptor status in breast cancer is associated with remarkably distinct gene expression patterns. Cancer Research, v.61, n.16, p.5979-84. Citado na página 19.

Halkidi, M.; Batistakis, Y.; Vazirgiannis, M. (2001). On clustering validation techniques. J. Intell. Inf. Syst., v.17, n.2-3, p.107-145. Citado nas páginas 46 e 66.

Hand, D. J.; Till, R. J. (2001). A simple generalisation of the area under the roc curve for multiple class classification problems. Mach. Learn., v.45, p.171-186. Citado na página 30.

Handl, J.; Knowles, J.; Kell, D. B. (2005a). Computational cluster validation in post-genomic data analysis. Bioinformatics, v.21, n.15, p.3201-3212. Citado na página 46.

Handl, J.; Knowles, J.; Kell, D. B. (2005b). Computational cluster validation in post-genomic data analysis. Bioinformatics, v.21, n.15, p.3201-3212. Citado na página 48 .

Harrington, C. A.; Rosenow, C.; Retief, J. (2000). Monitoring gene expression using dna microarrays. Curr. Opin. Microbiol., v.3, p.285-291. Citado nas páginas xi, 14, 16, e 17.

Haslinger, C.; Schweifer, N.; Stilgenbauer, S.; Döhner, H.; Lichter, P.; Kraut, N.; Stratowa, C.; Abseher, R. (2004). Microarray gene expression profiling of b-cell chronic lymphocytic leukemia subgroups defined by genomic aberrations and vh mutation status. Journal of Clinical Oncology, v.22, n.19, p.3937-3949. Citado na página 19.

Haykin, S. (1998). Neural Networks: A Comprehensive Foundation. Prentice Hall PTR, Upper Saddle River, NJ, USA. Citado nas páginas 24, 27, e 42.

Hechenbichler, K.; Schliep, K. (2006). Weighted k-nearest-neighbor techniques and ordinal classification. Discussion Paper 399, SFB 386. Citado nas páginas 54 e 74 .

Hippo, Y.; Taniguchi, H.; Tsutsumi, S.; Machida, N.; Chong, J.-M.; Fukayama, M.; Kodama, T.; Aburatani, H. (2002). Global gene expression analysis of gastric cancer by oligonucleotide microarrays. Cancer Research, v.62, p.233-240. Citado na página 19. 
Ho, T. K.; Basu, M. (2002). Complexity measures of supervised classification problems. IEEE Transactions on Pattern Analysis and Machine Intelligence, v.24, n.3, p.289 - 300. Citado nas páginas 31, 49, e 85.

Hoheisel, J. D. (2006). Microarray technology: beyond transcript profiling and genotype analysis. Nature Reviews Genetics, v.7, n.3, p.200-210. Citado nas páginas 2 e 18.

Holmstrom, L.; Koistinen, P.; Laaksonen, J.; Oja, E. (1997). Neural and statistical classifiers-taxonomy and two case studies. IEEE Transactions on Neural Networks, v.8, n.1, p.5-17. Citado na página 26.

Hu, M.; Polyak, K. (2006). Serial analysis of gene expression. Nature Protocols, v.1, p.1743-1760. Citado na página 8.

Huang, X.; Pan, W.; Grindle, S.; et al (2005). A comparative study of discriminating human heart failure etiology using gene expression profiles. BMC Bioinformatics, v.6, p.205. Citado na página 3.

Hubert, L. J.; Levin, J. R. (1976). A general statistical framework for assessing categorical clustering in free recall. Psychological Bulletin, v.83, n.6, p.1072-1080. Citado na página 50.

Hucka, M.; Szallasi, Z. (2003). Introduction to computational approaches in systems biology. Online. Citado na página 16.

Hunter, L. (1993). Molecular biology for computer scientists. Hunter, L., editor, Artificial Intelligence and Molecular Biology, p. 1-46, Menlo Park, CA. AAAI Press. Citado nas páginas 9 e 10.

Isaksson, A.; Wallman, M.; Göransson, H.; Gustafsson, M. G. (2008). Cross-validation and bootstrapping are unreliable in small sample classification. Pattern Recogn. Lett., v.29, n.14, p.1960-1965. Citado na página 34 .

Ishikawa, M.; Yoshida, K.; Yamashita, Y.; Ota, J.; Takada, S.; Kisanuki, H.; Koinuma, K.; Lim, C. Y.; Kaneda, R.; Iwao, T.; Tamada, K.; Sugano, K.; Mano, H. (2005). Experimental trial for diagnosis of pancreatic ductal carcinoma based on gene expression profiles of pancreatic ductal cells. Cancer Science, v.96, n.7, p.387-393. Citado na página 19.

Jaeger, J.; Sengupta, R.; Ruzzo, W. L. (2003). Improved gene selection for classification of microarrays. Proceedings of the Pac Symp Biocomput. 2003, p. 53-64. Citado na página 18. 
Jain, A.; Dubes, R. (1988). Algorithms for Clustering Data. Prentice Hall, Englewood Cliffs, N.J. Citado na página 25.

Jain, A. K.; Duin, R. P. W.; Mao, J. (2000). Statistical pattern recognition: A review. IEEE Transactions on Pattern Analysis and Machine Intelligence, v.22, n.1, p.4-37. Citado na página 26.

Jajuga, K.; Walesiak, M.; Bak, A. (2003). Exploratory Data Analysis in Empirical Research, chapter On the general distance measure, p. 104-109. Springer. Citado na página 46.

Jazaeri, A. A.; Yee, C. J.; C, C. S.; KR, B.; J, B.; ET, L. (2002). Gene expression profiles of brca1-linked, brca2-linked, and sporadic ovarian cancers. J Natl Cancer Inst., v.94, n.13, p.990-1000. Citado na página 19.

Jiang, W.; Simon, R. (2007). A comparison of bootstrap methods and an adjusted bootstrap approach for estimating the prediction error in microarray classification. STATISTICS IN MEDICINE, v.26, p.5320-5334. Citado nas páginas 33 e 34.

Jolliffe, I. T. (2002). Principal Component Analysis. Springer, segunda edição edição. Citado nas páginas 52 e 67.

Kalousis, A. (2002). Algorithm Selection via Meta-Learning. Tese de doutorado, Centre Universiteire d'Informatique, Université de Genève, Geneva, Suíça. Citado nas páginas 39, 43, 53, 66, 68, e 79.

Kalousis, A.; Hilario, M. (2001). Feature selection for meta-learning. PAKDD '01: Proceedings of the 5th Pacific-Asia Conference on Knowledge Discovery and Data Mining, p. 222-233, London, UK. Springer-Verlag. Citado na página 100.

Kalousis, A.; Hilario, M. (2003). Representational issues in meta-learning. Fawcett, T.; Mishra, N., editores, ICML, p. 313-320. AAAI Press. Citado na página 3.

Keerthi, S. S.; Lin, C. J. (2003). Asymptotic behaviors of support vector machines with gaussian kernel. Neural Computation, v.15, n.7, p.1667-1689. Citado na página 101.

Kemmer, D.; Faxén, M.; Hodges, E.; Lim, J.; Herzog, E.; Ljungström, E.; Lundmark, A.; Olsen, M. K.; Podowski, R.; Sonnhammer, E. L. L.; Nilsson, P.; Reimers, M.; Lenhard, B.; Roberds, S. L.; Wahlestedt, C.; Höög, C.; Agarwal, P.; Wasserman, W. W. (2004). Exploring the foundation of genomics: a northern blot reference set for the comparative analysis of 
transcript profiling technologies: Research papers. Comp. Funct. Genomics, v.5, n.8, p.584-595. Citado na página 7.

Khan, J.; et al (2001). Classification and diagnostic prediction of cancers using gene expression profiling and artificial neural networks. Nat Med, v.7, n.6, p.673-9. Citado na página 19.

Kim, R. D.; Park, P. J. (2004). Improving identification of differentially expressed genes in microarray studies using information from public databases. Genome Biol., v.5, n.9, p.R70. Citado na página 18.

Koepf, C.; Taylor, C. C.; Keller, J. (2000). Meta-analysis: From data characterisation for meta-learning to meta-regression. Brazdil, P.; Jorge, A., editores, Proceedings of the PKDD-OO Workshop on Data Mining, Decision Support,Meta-Learning and ILP: Forum for Practical Problem Presentation and Prospective Solutions, Lyon, France. Citado nas páginas 53 e 87.

Kohavi, R. (1995). A study of cross-validation and bootstrap for accuracy estimation and model selection. IJCAI'95: Proceedings of the 14th international joint conference on Artificial intelligence, p. 1137-1143, San Francisco, CA, USA. Morgan Kaufmann Publishers Inc. Citado na página 32 .

Kuncheva, L. I. (2004). Combining Pattern Classifiers: Methods and Algorithms. Wiley-Interscience. Citado nas páginas 26 e 31.

Kyrpides, N. C. (2009). Fifteen years of microbial genomics: meeting the challenges and fulfilling the dream. Nature Biotechnology, v.27, n.7, p.627-632. Citado na página 1.

Laiho, P.; Kokko, A.; Vanharanta, S.; Salovaara, R.; Sammalkorpi, H.; Järvinen, H.; Mecklin, J.-P.; Karttunen, T. J.; Tuppurainen, K.; Davalos, V.; Jr, S. S.; Arango, D.; Mäkinen, M. J.; Aaltonen, L. A. (2007). Serrated carcinomas form a subclass of colorectal cancer with distinct molecular basis. Oncogene, v.26, n.2, p.312-20. Citado na página 19.

Langley, P.; Sage, S. (1994). Induction of selective bayesian classifiers. Proceedings of the 10th Conference on Uncertainty in Artificial Intelligence, p. 399-406, Seattle, WA. Morgan Kaufmann, San Mateo, CA. Citado na página 42 .

Larranaga, P.; Calvo, B.; Santana, R.; et al (2006). Machine learning in bioinformatics. Briefings in Bioinformatics, v.7, n.1, p.86-112. Citado nas páginas 2,3 , e 61 . 
Lee, J. W.; Lee, J. B.; Park, M.; Song, S. H. (2005). An extensive comparison of recent classification tools applied to microarray data. Computational Statistics \& Data Analysis, v.48, n.4, p.869-885. Citado nas páginas 3 e 28.

Li, G. Z.; Bu, H. L.; Yang, M. Q.; Zeng, X. Q.; Yang, J. Y. (2008). Selecting subsets of newly extracted features from pca and pls in microarray data analysis. BMC genomics, v.9, n.2. Citado na página 52.

Li, Q.; Racine, J. S. (2006). Nonparametric Econometrics: Theory and Practice. Princeton University Press. Citado na página 54.

Li, Y.; Campbell, C.; Tipping, M. (2002). Bayesian automatic relevance determination algorithms for classifying gene expression data. Bioinformatics, v.18, n.10, p.1332-9. Citado na página 19.

Liang, P. (2002). A decade of differential display. Biotechniques, v.33, n.2, p.338-44, 346. Citado na página 7.

Lindner, G.; Studer, R. (1999). Ast: Support for algorithm selection with a cbr approach. PKDD '99: Proceedings of the Third European Conference on Principles of Data Mining and Knowledge Discovery, p. 418-423, London, UK. Springer-Verlag. Citado na página 43.

Liolios, K.; Chen, I.-M. A.; Mavromatis, K.; Tavernarakis, N.; Hugenholtz, P.; Markowitz, V. M.; Kyrpides1, N. C. (2009). The genomes on line database (gold) in 2009: status of genomic and metagenomic projects and their associated metadata. Nucleic Acids Research, v.38, p.346-354. Citado na página 1 .

Lipmann, R. P. (1991). A critical overview of neural network pattern classifiers. Proceedings of the 1991 IEEE Workshop Neural Networks for Signal Processing, p. 266-275, Princeton, NJ. IEEE Press. Citado na página 26.

Lipshutz, R. J.; Fodor, S. P.; Gingeras, T. R.; Lockhart, D. J. (1999). High density synthetic oligonucleotide arrays. Nature Genetics, v.21, p.20-24. Citado nas páginas 13 e 16.

Liu, H.; Motoda, H. (1998). Feature selection for knowledge discovery data mining. Citado nas páginas 51, 72, 85, 96, 100, e 101.

Lodish, H.; Berk, A.; Kaiser, C. A.; Krieger, M.; Scott, M. P.; Bretscher, A.; Ploegh, H.; Matsudaira, P. (2007). Molecular Cell Biology (Lodish, Molecular Cell Biology). W. H. Freeman, New York, 6th edição. Citado nas páginas xi, xiii, $1,8,9,10,12,14$, e 16 . 
Man, M. Z.; Dyson, G.; Johnson, K.; Liao, B. (2004). Evaluating methods for classifying expression data. J Biopharm Stat., v.14, n.4, p.1065-84. Citado nas páginas 3,28 , e 101 .

McLachlan, G. J. (1992). Discriminant Analysis and Statistical Pattern Recognition. John Wiley and Sons, Inc, New York. Citado na página 32.

Mendel, G. (1865). Versuche über pflanzen-hybriden. Verhandlungen des Naturforschenden Vereines in Bruenn, v.IV, p.3-47. Tradução para o inglês feita por C.T. Druery and William Bateson disponivel em http://www. mendelweb. org/Mendel.html. Citado na página 9.

Menke, J.; Martinez, T. R. (2004). Using permutations instead of student's $\mathrm{t}$ distribution for $\mathrm{p}$-values in paired-difference algorithm comparisons. 2004 IEEE International Joint Conference on Neural Networks (IEEE Cat. No.04CH37541), p. 1331-1335. IEEE Press. Citado na página 36.

Michalski, R. S. (1986). Understanding the nature of learning: Issues and research directions. Michalski, R. S.; Carbonell, J. G.; Mitchell, T. M., editores, Machine Learning: An Artificial Intelligence Approach: Volume II, p. 3-25. Kaufmann, Los Altos, CA. Citado na página 23.

Michie, D.; Spiegelhalter, D. J.; Taylor, C. C.; Campbell, J., editores (1994). Machine learning, neural and statistical classification. Ellis Horwood, Upper Saddle River, NJ, USA. Citado nas páginas 4 e 42.

Milligan, G. W.; Cooper, M. C. (1985). An examination of procedures for determining the number of clusters in a data set. Psychometrika, v.1. Citado na página 50.

Mitchell, T. (1997). Machine Learning. McGraw-Hill Science/Engineering/Math. Citado nas páginas 4, 23, 25, 26, 29, 32 , e 39.

Molinaro, A. M.; Simon, R.; Pfeiffer, R. M. (2005). Prediction error estimation: a comparison of resampling methods. Bioinformatics, v.21, n.15, p.3301-3307. Citado nas páginas 33 e 34 .

Monard, M. C.; Baranauskas, J. A. (2003). Sistemas Inteligentes Fundamentos e Aplicações, chapter Conceitos sobre Aprendizado de Máquina, p. 89-114. Editora Manole, Barueri, SP. Citado nas páginas 24,26 , e 29.

Monti, S.; Tamayo, P.; Mesirov, J.; Golub, T. (2003). Consensus clustering: A resampling-based method for class discovery and visualization of gene 
expression microarray data. Mach. Learn., v.52, n.1-2, p.91-118. Citado na página 19.

Murthy, S. K. (1998). Automatic construction of decision trees from data: A multi-disciplinary survey. Data Min. Knowl. Discov., v.2, n.4, p.345-389. Citado na página 26.

Nakhaeizadeh, G.; Schnabl, A. (1997). Development of multi-criteria metrics for evaluation of data mining algorithms. KDD, p. 37-42. Citado na página 53.

Neave, H.; Worthington, P. (1992). Distribution-free Tests. Routledge, Londres, $1^{\mathrm{a}}$ ed. edição. Citado nas páginas 62 e 64.

Nguyen, D. V.; Rocke, D. M. (2002). Multi-class cancer clasification via partial least squares with gene expression profiles. Bioinformatics, v.18, n.9, p.1216-1226. Citado na página 68.

Nutt, C. L.; Mani, D. R.; Betensky, R. A.; Tamayo, P. (2003). Gene expression-based classification of malignant gliomas correlates better with survival than histological classification. Cancer Res., v.63, n.7, p.1602-7. Citado na página 19.

Okun, O.; Priisalu, H. (2007). Dataset complexity and gene expression based cancer classification. WILF '07: Proceedings of the 7th international workshop on Fuzzy Logic and Applications, p. 484-490, Berlin, Heidelberg. Springer-Verlag. Citado na página 31.

Okura, V. K. (2002). Bioinformática de projetos genoma de bactérias. Dissertação, UNICAMP, Campinas, SP. Citado nas páginas 8, 10, e 11.

Pass, H. I.; Liu, Z.; Bueno, A. W. R. (2004). Gene expression profiles predict survival and progression of pleural mesothelioma. Clinical Cancer Research, v.10, p.849-859. Citado na página 20.

Peng, Y. (2005). Robust ensemble learning for cancer diagnosis based on microarray data classification. Li, X.; Wang, S.; Dong, Z. Y., editores, ADMA, v. 3584 de Lecture Notes in Computer Science, p. 564-574. Springer. Citado na página 102.

Peng, Y.; Flach, P. A.; Soares, C.; Brazdil, P. (2002). Improved dataset characterisation for meta-learning. DS '02: Proceedings of the 5th International Conference on Discovery Science, p. 141-152, London, UK. Springer-Verlag. Citado nas páginas 45 e 53. 
Perou, C. M.; Sorlie, T.; Eisen, M. B.; van de Rijn, M.; Jeffrey, S. S.; Rees, C. A.; Pollack, J. R.; Ross, D. T.; Johnsen, H.; Akslen, L. A.; Fluge, O.; Pergamenschikov, A.; Williams, C.; Zhu, S. X.; Lonning, P. E.; Dale, A. L. B.; Brown, P. O.; Botstein, D. (2000). Molecular portraits of human breast tumours. Nature, v.406, n.6797, p.747-52. Citado na página 19.

Pevsner, J. (2009). Bioinformatics and Functional Genomics. Wiley-Blackwell, 2 edição. Citado na página 18.

Pfahringer, B.; Bensusan, H.; Giraud-Carrier, C. (2000). Meta-learning by landmarking various learning algorithms. Proceedings of the Seventeenth International Conference on Machine Learning, ICML'2000, p. 743-750. Morgan Kaufmann. Citado nas páginas 44 e 100.

Phillips, H. S.; Kharbanda, S.; Chen, R.; Forrest, W. F.; Soriano, R. H.; Wu, T. D.; Misra, A.; Nigro, J. M.; Colman, H.; Soroceanu, L.; Williams, P. M.; Modrusan, Z.; Feuerstein, B. G.; Aldape, K. (2006). Molecular subclasses of high-grade glioma predict prognosis, delineate a pattern of disease progression, and resemble stages in neurogenesis. Cancer Cell, v.9, n.3, p.157-173. Citado na página 19.

Pomeroy, S. L.; Tamayo, P.; Gaasenbeek, M.; Sturla, L. M.; Angelo, M.; McLaughlin, M. E.; Kim, J. Y. H.; Goumnerova, L. C.; Black, P. M.; Lau, C.; Allen, J. C.; Zagzag, D.; Olson, J. M.; Curran, T.; Wetmore, C.; Biegel, J. A.; Poggio, T.; Mukherjee, S.; Rifkin, R.; Califano, A.; Stolovitzky, G.; Louis, D. N.; Mesirov, J. P.; Lander, E. S.; ; Golub, T. R. (2002). Prediction of central nervous system embryonal tumour outcome based on gene expression. Nature, v.415, n.6870, p.436-42. Citado na página 19.

Prasad, T.; Ahson, S. (2009). Bioinformatics: Applications in Life and Environmental Sciences, chapter Data Mining for Bioinformatics Microarray Data, p. 77-144. Springer Netherlands. Citado na página 2.

Prudêncio, R. B. C.; Guerra, S. B.; Ludermir, T. B. (2008). Using support vector machines to predict the performance of mlp neural networks. SBRN, p. 201-206. Citado nas páginas 56, 77, 78, e 99.

Pyeon, D.; Newton, M. A.; Lambert, P. F.; den Boon, J. A.; Sengupta, S.; Marsit, C. J.; Woodworth, C. D.; Connor, J. P.; Haugen, T. H.; Smith, E. M.; Kelsey, K. T.; Turek, L. P.; Ahlquist, P. (2007). Fundamental differences in cell cycle deregulation in human papillomavirus-positive and human papillomavirus-negative head/neck and cervical cancers. Cancer Research, v.67, p.4605-19. Citado na página 19. 
Quackenbush, J. (2001). Computational analysis of microarray data. Nat Rev Genet, v.2, n.6, p.418-27. Citado nas páginas 13 e 15.

Quinlan, J. R. (1993). C4.5: programs for machine learning. Morgan Kaufmann Publishers Inc., San Francisco, CA, USA. Citado na página 27.

Quinlan, R. J. (1992). Learning with continuous classes. 5th Australian Joint Conference on Artificial Intelligence, p. 343-348, Singapore. World Scientific. Citado na página 88.

R Development Core Team (2009). R: A Language and Environment for Statistical Computing. R Foundation for Statistical Computing, Vienna, Austria. ISBN 3-900051-07-0. Citado na página 61.

Rebelo, C.; Soares, C.; Costa, J. P. (2008). Empirical evaluation of ranking trees on some metalearning problems. Chomicki, J.; Conitzer, V.; Junker, U.; Perny, P., editores, Proceedings of the 4th Multidisciplinary Workshop on Advances in Preference Handling (MPREF 08), held in conjunction with the 23rd National Conference on Artificial Intelligence (AAAI 08), Chicago, Illinois, USA. Citado nas páginas 57, 63, e 99.

Rice, J. R. (1976). The algorithm selection problem. Advances in Computers, v.15, p.65-118. Citado nas páginas 4 e 40 .

Richardson, A. L.; Wang, Z. C.; Nicolo, A. D.; Lu, X.; Brown, M.; Miron, A.; Liao, X.; Iglehart, J. D.; Livingston, D. M.; Ganesan, S. (2006). X chromosomal abnormalities in basal-like human breast cancer. Cancer Cell, v.9, n.2, p.121-32. Citado na página 19.

Rickman, D. S.; Bobek, M. P.; Misek, D. E.; Kuick, R.; Blaivas, M.; Kurnit, D. M.; Taylor, J.; Hanash, S. M. (2001). Distinctive molecular profiles of high-grade and low-grade gliomas based on oligonucleotide microarray analysis. Cancer Research, v.61, n.18, p.6885-91. Citado na página 19.

Romualdi, C.; Campanaro, S.; Campagna, D.; Celegato, B.; Cannata, N.; Toppo, S.; Valle, G.; Lanfranchi, G. (2003). Pattern recognition in gene expression profiling using dna array: a comparative study of different statistical methods applied to cancer classification. Hum. Mol. Genet., v.12, n.8, p.823-836. Citado nas páginas 3 e 28.

Rosenwald, A.; Wright, G.; Chan, W. C.; Connors, J. M.; Campo, E.; Fisher, R. I.; Gascoyne, R. D.; Muller-Hermelink, H. K.; Smeland, E. B.; Giltnane, J. M.; Hurt, E. M.; Zhao, H.; Averett, L.; Yang, L.; Wilson, W. H.; Jaffe, E. S.; Simon, R.; Klausner, R. D.; Powell, J.; Duffey, P. L.; Longo, D. L.; Greiner, T. C.; Weisenburger, D. D.; Sanger, W. G.; Dave, B. J.; Lynch, J. C.; Vose, J.; 
Armitage, J. O.; Montserrat, E.; López-Guillermo, A.; Grogan, T. M.; Miller, T. P.; LeBlanc, M.; Ott, G.; Kvaloy, S.; Delabie, J.; Holte, H.; Krajci, P.; Stokke, T.; Staudt, L. M. (2002). The use of molecular profiling to predict survival after chemotherapy for diffuse large-b-cell lymphoma. Engl $J$ Med., v.346, n.25, p.1937-47. Citado na página 19.

Rousseeuw, P. (1987). Silhouettes: a graphical aid to the interpretation and validation of cluster analysis. J. Comput. Appl. Math., v.20, n.1, p.53-65. Citado na página 49.

Russel, S.; Norvig, P. (1995). Artificial Intelligence: A Modern Approach. Prentice Hall. Citado na página 25.

Russell, S.; Meadows, L.; Russell, R. (2008). Microarray Technology in Practice. Academic Press, Sanc Diego, $1^{\text {a }}$ edition edição. Citado nas páginas 1, 7, 13, 61 , e 97.

Sahiner, B.; Chan, H.-P.; Hadjiiski, L. (2008). Classifier performance estimation under the constraint of a finite sample size: Resampling schemes applied to neural network classifiers. Neural Networks, v.21, n.2, p.476-483. Citado na página 33.

Sanchez-Carbayo, M.; Socci, N. D.; Lozano, J.; Saint, F.; Cordon-Cardo, C. (2006). Defining molecular profiles of poor outcome in patients with invasive bladder cancer using oligonucleotide microarrays. Journal of Clinical Oncology, v.24, n.5, p.778-789. Citado na página 19.

Schaffer, C. (1994). A conservation law for generalization performance. ICML, p. 259-265. Citado na página 3.

Schena, M. (1999). DNA Microarrays: A Practical Approach. Practical Approach Series. Oxford University Press, Oxford, Inglaterra, $1^{\text {a }}$ edição. Citado na página 13.

Schölkopf, B.; Smola, A. J.; Williamson, R. C.; Bartlett, P. L. (2000). New support vector algorithms. Neural Comput., v.12, n.5, p.1207-1245. Citado na página 78.

Schwartz, D. R.; Kardia, S. L. R.; Shedden, K. A.; Kuick, R.; Michailidis, G.; Taylor, J. M. G.; Misek, D. E.; Wu, R.; Zhai, Y.; Darrah, D. M.; Reed, H.; Ellenson, L. H.; Giordano, T. J.; Fearon, E. R.; Hanash, S. M.; Cho, K. R. (2002). Gene expression in ovarian cancer reflects both morphology and biological behavior, distinguishing clear cell from other poor-prognosis ovarian carcinomas. Cancer Research, v.62, n.16, p.4722-9. Citado na página 19. 
Sebastiani, P.; Gussoni, E.; Kohane, I. S.; Ramoni, M. F. (2003). Statistical challenges in functional genomics. Statistical Science, v.18, n.1, p.33-70. Citado na página 17.

Shamir, R.; Torok, D.; Shtainhart, A. (2002a). Analysis of gene expression data, dna chips and gene networks lecture notes. Citado nas páginas 10 e 11 .

Shamir, R.; Torok, D.; Shtainhart, A. (2002b). Analysis of gene expression data, dna chips and gene networks lecture notes (lecture 1). Citado nas páginas 11 e 17 .

Shipp, M. A.; Ross, K. N.; Tamayo, P.; Weng, A. P.; Kutok, J. L.; Aguiar, R. C.; Gaasenbeek, M.; Angelo, M.; Reich, M.; Pinkus, G. S.; Ray, T. S.; Koval, M. A.; Last, K. W.; Norton, A.; Lister, T. A.; Mesirov, J.; Neuberg, D. S.; Lander, E. S.; Aster, J. C.; Golub, T. R. (2002). Diffuse large b-cell lymphoma outcome prediction by gene-expression profiling and supervised machine learning. Nat Med., v.8, n.1, p.68-74. Citado na página 19.

Silva, F. H. (2001). Módulo: Biologia molecular. I Escola Brasileira de Inteligência Artificial e Bioinformática InBio São Carlos, São Carlos. Citado nas páginas 9,10 , e 11 .

Singh, D.; Febbo, P. G.; Ross, K.; Jackson, D. G.; Manola, J.; Ladd, C.; Tamayo, P.; Renshaw, A. A.; D’Amico, A. V.; Richie, J. P.; Lander, E. S.; Loda, M.; Kantoff, P. W.; Golub, T. R.; Sellers, W. R. (2002). Gene expression correlates of clinical prostate cancer behavior. Cancer Cell, v.1, n.2, p.203-209. Citado na página 19.

Slonim, D. K.; Tamayo, P.; Mesirov, J. P.; Golub, T. R.; Lander, E. S. (2000). Class prediction and discovery using gene expression data. RECOMB, p. 263-272. Citado na página 2.

Smalheiser, N. R. (2002). Informatics and hypothesis-driven research. EMBO Rep, v.3, n.8, p.702. Citado na página 7.

Soares, C. (2004). Learning Rankings of Learning Algorithms: Recommendation of Algorithms with Meta-Learning. Tese de doutorado, Departamento de Ciência da Computação, Faculdade de Ciências da Universidade do Porto, Porto, Portugal. Citado nas páginas 5, 40, 43, 63, 64, e 101.

Soares, C.; Brazdil, P. (2000). Zoomed ranking: Selection of classification algorithms based on relevant performance information. PKDD 'OO: Proceedings of the 4th European Conference on Principles of Data Mining and 
Knowledge Discovery, p. 126-135, London, UK. Springer-Verlag. Citado na página 52.

Soares, C.; Brazdil, P. B. (2006). Selecting parameters of svm using meta-learning and kernel matrix-based meta-features. SAC '06: Proceedings of the 2006 ACM symposium on Applied computing, p. 564-568, New York, NY, USA. ACM Press. Citado na página 102.

Soares, C.; Brazdil, P. B.; Kuba, P. (2004). A meta-learning method to select the kernel width in support vector regression. Machine Learning, v.54, n.3, p.195-209. Citado na página 42.

Sohn, S. Y. (1999). Meta analysis of classification algorithms for pattern recognition. IEEE Trans. Pattern Anal. Mach. Intell., v.21, n.11, p.1137-1144. Citado na página 43.

Sokal, R. R.; Rohlf, F. J. (1995). Biometry. W. H. Freeman and Co.: New York. Citado na página 83.

Somorjai, R.; Dolenko, B.; Baumgartner, R. (2003). Class prediction and discovery using gene microarray and proteomics mass spectroscopy data: curses, caveats, cautions. Bioinformatics, v.19, n.12, p.1484-91. Citado nas páginas 4 e 100.

Sotiriou, C.; Wirapati, P.; Loi, S.; Harris, A.; Fox, S.; Smeds, J.; Nordgren, H.; Farmer, P.; Praz, V.; Haibe-Kains, B.; Desmedt, C.; Larsimont, D.; Cardoso, F.; Peterse, H.; Nuyten, D.; Buyse, M.; de Vijver, M. J. V.; Bergh, J.; Piccart, M.; Delorenzi, M. (2006). Gene expression profiling in breast cancer: understanding the molecular basis of histologic grade to improve prognosis. J Natl Cancer Inst., v.98, n.4, p.262-72. Citado na página 19.

Souto, M. C. P.; Prudencio, R. B. C.; Soares, R. G. F.; Araujo, D. A. S.; Costa, I. G.; Ludermir, T. B.; ; Schliep, A. (2008). Ranking and selecting clustering algorithms using a meta-learning approach. IEEE International Joint Conference on Neural Networks (IJCNN), p. 3729-3735, Hong Kong. IEEE. Citado nas páginas 56, 63, e 99.

Souza, B. F.; de Carvalho, A.; Soares, C. (2008). Metalearning for gene expression data classification. HIS '08: Proceedings of the 2008 Eighth International Conference on Hybrid Intelligent Systems, p. 441-446, Washington, DC, USA. IEEE Computer Society. Citado nas páginas 68 e 98.

Souza, B. F.; de Carvalho, A.; Soares, C. (2010a). Empirical evaluation of ranking prediction methods for gene expression data classification (aceito). 
be defined, T., editor, IBERAMIA, Lecture Notes in Computer Science, p. 1-8. Springer. Citado nas páginas 98 e 99.

Souza, B. F.; de Carvalho, A. C.; Soares, C. (2010b). A comprehensive comparison of $\mathrm{ml}$ algorithms for gene expression data classification. Proceedings of The 2010 International Joint Conference on Neural Networks (IJCNN), p. 1-8. IEEE Press. Citado nas páginas 31, 33, 36, 98, 99, 100, e 102 .

Souza, B. F.; Soares, C.; de Carvalho, A. (2009). Meta-learning approach to gene expression data classification. International Journal of Intelligent Computing and Cybernetics, v.2, n.2, p.285-303. Citado nas páginas 56, 98, 99, e 101.

Statnikov, A.; Aliferis, C. F.; Tsamardinos, I.; Hardin, D.; Levy, S. (2005). A comprehensive evaluation of multicategory classification methods for microarray gene expression cancer diagnosis. Bioinformatics, v.21, n.5, p.631-643. Citado nas páginas 3 e 28.

Statnikov, A.; Wang, L.; Aliferis, C. F. (2008). A comprehensive comparison of random forests and support vector machines for microarray-based cancer classification. BMC Bioinformatics, v.9, p.319-329. Citado nas páginas 30, 31, e 36.

Steinwart, I.; Christmann, A. (2008). Support Vector Machines. Information Science and Statistics Series. Springer. Citado nas páginas 5, 28, 56, 61, e 99.

Swagell, C.; Henly, D.; Morris, C. (2005). Expression analysis of a human hepatic cell line in response to palmitate. Biochem Biophys Res Commun., v.328, n.2, p.432-41. Citado na página 20 .

Talantov, D.; Mazumder, A.; Yu, J. X.; Briggs, T.; Jiang, Y.; Backus, J.; Atkins, D.; Wang, Y. (2005). Novel genes associated with malignant melanoma but not benign melanocytic lesions. Clinical Cancer Research, v.11, n.20, p.7234-42. Citado na página 19.

Tarca, A.; Romero, R.; Draghici, S. (2006). Analysis of microarray experiments of gene expression profiling. Am J Obstet Gynecol., v.195, n.2, p.373-88. Citado nas páginas 2, 19, e 20.

Tibshirani, R.; Hastie, T.; Narasimhan, B.; Chu, G. (2002). Diagnosis of multiple cancer types by shrunken centroids of gene expression. PNAS, v.99, n.10, p.6567-6572. Citado nas páginas 28 e 61. 
Tjaden, B.; Cohen, J. (2006). A survey of computational methods used in microarray data interpretation. Applied Mycology and Biotechnology, v.Volume 6: Bioinformatics, p.1-18. Citado na página 2.

Todorovski, L.; Blockeel, H.; Dzeroski, S. (2002). Ranking with predictive clustering trees. ECML '02: Proceedings of the 13th European Conference on Machine Learning, p. 444-455, London, UK. Springer-Verlag. Citado nas páginas 56, 57, 87, e 99.

Todorovski, L.; Brazdil, P.; Soares, C. (2000). Report on the experiments with feature selection in meta-level learning. Proceedings of the PKDD'OO Workshop on Data Mining, Decision Support, Meta-learning and ILP, p. 27-39, Lyon, France. Citado na página 100.

Tomlins, S. A.; Mehra, R.; Rhodes, D. R.; Cao, X.; Wang, L.; Dhanasekaran, S. M.; Kalyana-Sundaram, S.; Wei, J. T.; Rubin, M. A.; Pienta, K. J.; Shah, R. B.; Chinnaiyan, A. M. (2007). Integrative molecular concept modeling of prostate cancer progression. Nat Genet., v.39, n.1, p.41-51. Citado na página 19.

True, L.; Coleman, I.; Hawley, S.; Huang, C.-Y.; Gifford, D.; Coleman, R.; Beer, T. M.; Gelmann, E.; Datta, M.; Mostaghel, E.; Knudsen, B.; Lange, P.; Vessella, R.; Lin, D.; Hood, L.; Nelson, P. S. (2006). A molecular correlate to the gleason grading system for prostate adenocarcinoma. Proc Natl Acad Sci US A, v.103, n.29, p.10991-6. Citado na página 19.

Tu, Y.; Stolovitzky, G.; Klein, U. (2002). Quantitative noise analysis for gene expression microarray experiments. Proc Natl Acad Sci U S A., v.99, n.22, p.14031-6. Citado na página 18.

Utgoff, P. E. (1986). Shift of bias for inductive concept learning. Michalski, R. S.; Carbonell, J. G.; Mitchell, T. M., editores, Machine Learning: An Artificial Intelligence Approach: Volume II, p. 107-148. Kaufmann, Los Altos, CA. Citado na página 24.

VanGuilder, H. D.; Vrana, K. E.; Freeman, W. M. (2008). Twenty-five years of quantitative pcr for gene expression analysis. Biotechniques, v.44, n.5, p.619-626. Citado nas páginas 7 e 14.

Vapnik, V. N. (1995). The nature of statistical learning theory. Springer-Verlag New York, Inc. Citado na página 42.

Varmus, H. (2010). Ten years on the human genome and medicine. The New England journal of medicine, v.362, n.21, p.2028-2029. Citado nas páginas 7 e 60. 
Vilalta, R. (2006). Identifying and characterizing class clusters to explain learning performance. Shapiro, D.; Göker, M. H., editores, What Went Wrong and Why: Lessons from AI Research and Applications: Papers from the 2006 Spring Symposium, Technical Report SS-06-08, p. 19-26, Menlo Park, California. American Association for Artificial Intelligence. Citado na página 45.

Vilalta, R.; Drissi, Y. (2002). A perspective view and survey of meta-learning. Artif. Intell. Rev., v.18, n.2, p.77-95. Citado na página 39.

Vilalta, R.; Giraud-Carrier, C.; ; Brazdil, P. (2005). Data Mining and Knowledge. Discovery Handbook: A Complete Guide for Practitioners and Researchers, chapter Meta-Learning: Concepts and Techniques, p. 1-17. Kluwer Academic Publishers. Citado nas páginas 4, 39, 42, e 45.

Watanabe, T.; Kobunai, T.; Toda, E.; Yamamoto, Y.; Kanazawa, T.; Kazama, Y.; Tanaka, J.; Tanaka, T.; Konishi, T.; Okayama, Y.; Sugimoto, Y.; Oka, T.; Sasaki, S.; Muto, T.; Nagawa, H. (2006). Distal colorectal cancers with microsatellite instability (msi) display distinct gene expression profiles that are different from proximal msi cancers. Cancer Research, v.66, p.9804-9808. Citado na página 19.

West, M.; Blanchette, C.; Dressman, H.; Huang, E. (2001). Predicting the clinical status of human breast cancer by using gene expression profiles. Proc Natl Acad Sci U S A, v.98, n.20, p.11462-7. Citado na página 19.

Wold, S.; Sjostrom, M.; Eriksson, L. (2001). Pls-regression: a basic tool of chemometrics. Chemometrics and intelligent laboratory systems, v.58, p.109-130. Citado nas páginas 52 e 67.

Wolfsberg, T. G.; Landsman, D. (2001). Bioinformatics: A Practical Guide to the Analysis of Genes and Proteins, chapter Expressed Sequence Tags (ESTs), p. 283 - 299. Wiley Interscience, New York, second edition edição. Citado na página 13.

Wolpert, D. H. (1996). The lack of a priori distinctions between learning algorithms. Neural Comput., v.8, n.7, p.1341-1390. Citado nas páginas 3 e 34 .

Wolters, M.; Georgila, K.; Moore, J. D.; MacPherson, S. E. (2009). Being old doesn't mean acting old: How older users interact with spoken dialog systems. ACM Trans. Access. Comput., v.2, n.1, p.1-39. Citado na página 46. 
Wong, Y. F.; Selvanayagam, Z. E.; Wei, N.; Porter, J.; Vittal, R.; Hu, R.; Lin, Y.; Liao, J.; Shih, J. W.; Cheung, T. H.; Lo, K. W. K.; Yim, S. F.; Yip, S. K.; Ngong, D. T.; Siu, N.; Chan, L. K. Y.; Chan, C. S.; Kong, T.; Kutlina, E.; McKinnon, R. D.; Denhardt, D. T.; Chin, K.-V.; Chung, T. K. H. (2003). Expression genomics of cervical cancer: molecular classification and prediction of radiotherapy response by dna microarray. Clinical Cancer Research, v.9, n.15, p.5486-92. Citado na página 19.

Yang, I. V.; Burch, L. H.; Steele, M. P.; Savov, J. D.; Hollingsworth, J. W.; McElvania-Tekippe, E.; Berman, K. G.; Speer, M. C.; Sporn, T. A.; Brown, K. K.; Schwarz, M. I.; Schwartz, D. A. (2007). Gene expression profiling of familial and sporadic interstitial pneumonia. Am J Respir Crit Care Med, v.175, n.1, p.45-54. Citado na página 19.

Yang, X. J.; Tan, M.-H.; Kim, H. L.; et al (2005a). A molecular classification of papillary renal cell carcinoma. Cancer Research, v.65, n.13, p.5628-37. Citado na página 19.

Yang, Y.; Webb, G. I.; Wu, X. (2005b). Discretization methods. Maimon, O.; Rokach, L., editores, The Data Mining and Knowledge Discovery Handbook, p. 113-130. Springer. Citado na página 25.

Yeoh, E. .; Ross, M. .; Shurtleff, S. .; Williams, W. .; Patel, D. .; Mahfouz, R. .; Behm, F. .; Raimondi, S. .; Relling, M. .; Patel, A. . (2002). Classification, subtype discovery, and prediction of outcome in pediatric acute lymphoblastic leukemia by gene expression profiling. Cancer Cell, v.1, n.2, p.133-43. Citado na página 19.

Yoon, S. S.; Segal, N. H.; Park, P. J.; Detwiller, K. Y.; Fernando, N. T.; Ryeom, S. W.; Brennan, M. F.; Singer, S. (2006). Angiogenic profile of soft tissue sarcomas based on analysis of circulating factors and microarray gene expression. J Surg Res., v.135, n.2, p.282-90. Citado na página 19.

Yousef, W. A.; Wagner, R. F.; Loew, M. H. (2005). Estimating the uncertainty in the estimated mean area under the roc curve of a classifier. Pattern Recogn. Lett., v.26, n.16, p.2600-2610. Citado na página 33.

Zhou, D.; Rao, M. S.; Walker, R.; Khrebtukova, I.; Haudenschild, C. D.; Miura, T.; Decola, S.; Vermaas, E.; Moon, K.; Vasicek, T. J. (2006). Human Embryonic Stem Cell Protocols, capítulo Massively Parallel Signature Sequencing, p. 285-311. Methods in Molecular Biology. Humana Press. Citado na página 8. 